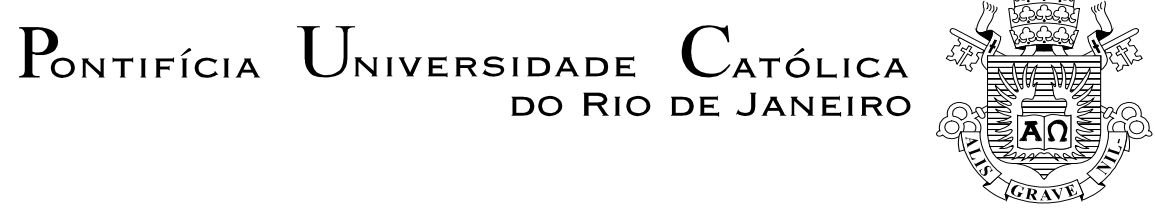

Juliana Bento Viol

\title{
Estudo da esfoliação de nanofolhas de ferrititanatos de estrutura lepidocrocítica com dimetildioctadecilamônio e sua aplicação em nanocompósitos de matriz \\ polimérica
}

Dissertação de Mestrado

Dissertação apresentada como requisito parcial para obtenção do grau de Mestre pelo Programa de Pós-graduação em Engenharia de Materiais e de Processos Químicos e Metalúrgicos do Departamento de Engenharia Química e de Materiais da PUC-Rio.

Orientador: Prof. Bojan Marinkovic

Rio de Janeiro Setembro de 2015 


$$
\text { Pontifícia } \text { Universidade }_{\text {do Rio de Janeiro }}
$$

JULIANA BENTO VIOL

\begin{abstract}
Estudo da esfoliação de nanofolhas de ferrititanatos de estrutura lepidocrocítica com dimetildioctadecilamônio e sua aplicação em nanocompósitos de matriz

polimérica
\end{abstract}

\begin{abstract}
Dissertação apresentada como requisito parcial para obtenção do grau de Mestre pelo Programa de PósGraduação em Engenharia de Materiais e de Processos Químicos e Metalúrgicos do Departamento de Engenharia Química e de Materiais do Centro Técnico Científico da PUC-Rio. Aprovada pela Comissão Examinadora abaixo assinada.
\end{abstract}

Prof. Borjan Marinkovic

Orientador e Presidente Departamento de Engenharia Química e de Materiais - PUC Rio

Prof. Roberto Ribeiro de Avillez Departamento de Engenharia Química e de Materiais - PUC Rio

Profa. Paula Mendes Jardim Universidade Federal do Rio de Janeiro - UFRJ

Prof. José Eugenio Leal Coordenador Setorial de Pós-Graduação do Centro Técnico Científico da PUC-Rio

Rio de Janeiro, 04 de setembro de 2015. 
Todos os direitos reservados. É proibida a reprodução total ou parcial do trabalho sem autorização da universidade, da autora e do orientador.

\section{Juliana Bento Viol}

Química com Atribuições Tecnológicas formada no Instituto de Química - Universidade Federal do Rio de Janeiro (UFRJ), Rio de Janeiro-Brasil, 2009.

Ficha Catalográfica

Viol, Juliana Bento

Estudo da esfoliação de nanofolhas de ferrititanatos de estrutura lepidocrocítica com dimetildioctadecilamônio e sua aplicação em nanocompósitos de matriz polimérica / Juliana Bento Viol ; orientador: Bojan Marinkovic. - 2015.

94 f. ; $30 \mathrm{~cm}$

Dissertação (mestrado) - Pontifícia Universidade Católica do Rio de Janeiro, Departamento de Engenharia Química e de Materiais, 2015.

Inclui bibliografia

1. Engenharia Química e de Materiais - Teses. 2. Nanofolhas de titanato. 3. Ferrititanato. 4. Nanocompósitos. 5. Dimetildioctadecilamonio. 6. Polietileno de alta densidade I. Marinkovic, Bojan. II. Pontifícia Universidade Católica do Rio de Janeiro. Departamento de Engenharia Química e de Materiais. III. Título.

CDD: 620.11 
Em memória do meu querido pai, à minha mãe Tereza e irmã Renata, e ao grande amor da minha vida Mateus. 


\section{Agradecimentos}

Primeiramente, à Deus por sempre iluminar o meu caminho e me amparar nos momentos difíceis.

Ao meu orientador Professor Bojan Marinkovic pela motivação, orientação, ensinamentos e confiança em mim depositada durante todo o mestrado.

À minha amiga Patrícia Pontón por seus conselhos, ensinamentos, paciência e grande contribuição na interpretação dos resultados.

À Doutora Lidija Mancic pela orientação no trabalho experimental e acompanhamento na interpretação dos resultados.

A minha colega Sônia Letichevsky, pela colaboração nas caracterizações de DRX e SAXS e interpretação dos difratogramas.

Aos meus colegas Edisson Morgado e Marco Antônio de Abreu do CENPES/Petrobrás pela e colaboração com a realização das análises de fotometria de chama e BET.

Ao meu colega Antônio Costa, pela colaboração nas análises de MET e MEV.

Ao professor José Roberto d’Almeida pelo apoio nos teste de tração dos nanocompósitos.

Aos meus amigos do laboratório de Fotocatálise: Margarita Habran, Juliana Resende, Luciana Prisco, Anja Dosen, Rafaela Carvalho, Gustavo pelos momentos compartilhados, afeto e palavras de incentivo.

À aluna de IC Gabriela Faro pela contribuição nos trabalhos experimentais.

Às minhas amigas Aline, Lívia, Rose, Malu e Suyane, por sua preocupação e apoio.

À minha querida e inspiradora mãe Tereza e minha irmã Renata pelo carinho, amor, por sempre acreditarem em mim e pelo tempo dedicado. À memória do meu pai João Viol, pelo amor que sempre me foi dado, apoio, aos ensinamentos e me ensinou a ter fé na vida.

Ao grande amor de minha vida, Mateus Castilhos, por ter sido meu grande equilíbrio, por sua paciência, carinho, apoio, compreensão, por acreditar em mim e por estar sempre ao meu lado. 


\section{Resumo}

Viol, Juliana Bento; Marinkovic, Bojan (Orientador). Estudo da esfoliação de nanofolhas de ferrititanatos de estrutura lepidocrocítica com dimetildioctadecilamônio e sua aplicação em nanocompósitos de matriz polimérica. Rio de Janeiro, 2015. 94p. Dissertação de Mestrado - Departamento de Engenharia Química e de Materiais, Pontifícia Universidade Católica do Rio de Janeiro.

Nanofolhas de ferrititanato com estrutura tipo lepidocrocita foram sintetizadas a partir de um precursor de baixo custo (areia ilmenítica), via rota hidrotérmica alcalina. Dois tipos de nanofolhas com alto e baixo teor de sódio foram obtidos: a) nanofolhas sódicas (NaLTs) e b) nanofolhas protonizadas (pLTs), obtidas mediante uma reação rápida de troca-ácida à temperatura ambiente. As capacidades de troca catiônica de ambos os tipos de nanofolhas foram determinadas seguindo-se a norma C 837 da ASTM. Após a síntese desses dois nanomateriais com diferentes teores de sódio foi estudado o processo de esfoliação em camadas de espessura sub-nanométrica, sob agitação intensa à temperatura de $60^{\circ} \mathrm{C}$, utilizando-se como o agente de esfoliação pela primeira vez numa estrutura lepidocrocítica o sal cloreto de dimetildioctadecilamônio (2C18), visando a posterior aplicação das nanofolhas esfoliadas como reforço em nanocompósitos de matriz polimérica. $\mathrm{O}$ intuito de aplicar estes reforços em uma matriz polimérica foi buscar uma dispersão mais homogênea das folhas esfoliadas, além do aumento da compatibilidade das nanocargas com a matriz polimérica pela presença dos grupos orgânicos do sal quimicamente ligados às nanofolhas e, consequentemente, o incremento das propriedades térmicas e mecânicas do material polimérico. Dependendo do teor de sódio, foram obtidas nanofolhas esfoliadas e/ou intercaladas que foram posteriormente caracterizadas por fotometria de chama, espetroscopia de infravermelho, área superficial específica por adsorção de $\mathrm{N}_{2}$, termogravimetria, difração de raios-X de alto ângulo, espalhamento de raios- $\mathrm{X}$ a baixo ângulo, microscopia de força atômica e microscopia eletrônica de transmissão. Para a fabricação dos nanocompósitos foram utilizadas duas matrizes: a) uma de PEAD puro e b) a outra de PEAD com adição de uma porcentagem baixa, e constante, de polietileno funcionalizado com anidrido maleico (PE-g-MA), sendo reforçadas com as nanocargas protonizadas virgens (pLTs) e esfoliadas (pLTs-o-2C18) nas concentrações de 1,0; 2,0 e 4,0 \%p. Finalmente, foram avaliadas as propriedades mecânicas e térmicas dos nanocompósitos por meio de ensaios de tração, termogravimetria, calorimetria diferencial de varredura e dilatometria. Os nanocompósitos preparados com pLTs virgem e os fabricados com a adição de agente de acoplamento de PE-g-MA apresentaram um aumento no módulo de Young de 12,8\% e $5,1 \%$ para cargas de $4 \%$ e $2 \%$ em peso de pLTs virgem, respectivamente. Os nanocompósitos, que apresentam o maior aumento no limite de escoamento foram os reforçados com 4\%p de nanofolhas esfoliada (pLTs-o-2C18). No entanto, estes materiais apresentam uma diminuição no módulo de Young de $~ 12 \%$. Os nanocompósitos com o maior aumento no módulo de Young foram os preparados com 4\% p pLTs ( 12,8\%), enquanto sua tensão no escoamento também foi melhorada (um aumento de $\sim 4 \%$ ). A incorporação de nanofolhas não afetou significativamente as propriedades de estabilidade térmica da matriz e uma diminuição no coeficiente de expansão térmica de 4 a 5,5\% foi apenas observada para nanocompósitos preparados com pLTs virgens. O grau de cristalinidade diminuiu para todos os nanocompósitos fabricados, no qual variou de 2,17 até $26 \%$.

\section{Palavras-chave}

Nanofolhas de titanato; ferrititanato; esfoliação; nanocompósitos; dimetildioctadecilamonio; polietileno de alta densidade. 


\section{Abstract}

Viol, Juliana Bento; Marinkovic, Bojan (Advisor). Study of the exfoliation of lepidocrocite-like ferritiatanate nanosheets with a dimethyldioctadecylammonium salt and their application in the polymerbased nanocomposites. Rio de Janeiro, 2015. 94p. MSc Dissertation Departamento de Engenharia Química e de Materiais, Pontifícia Universidade Católica do Rio de Janeiro.

Ferrititanate nanosheets with lepidocrocite-like structure were synthesized from a low cost precursor (ilmenite sand) through alkaline hydrothermal route. Two types of nanosheets with high and low-sodium content were obtained: a) sodium rich nanosheets (NaLTs) and b) protonated nanosheets (pLTs), obtained by a rapid acid-exchange reaction at room temperature. The cation exchange capacities of both types of nanosheets were determinated according ASTM C 837. After the synthesis of these two nanomaterials with different sodium levels, it was studied the exfoliation process to obtain monolayers of nanometric lateral dimensions under intensive stirring at $60{ }^{\circ} \mathrm{C}$, using dimethyldioctadecylammonium cloride (2C18) as the exfoliating agent of the lepidocrocite-like ferrititanate nanosheets for the first time, aiming the further application of the exfoliated nanosheets as reinforcement in polymer matrix nanocomposites. The purpose of the addition of these nanofillers within a polymer matrix is to obtain a more homogeneous dispersion of exfoliated nanosheets, as well as the improvement of the compatibility between nanofillers and the polymer matrix, due to the presence of the organic groups from 2C18, chemically attached to nanosheets and hence, to promote the an increase on mechanical and thermal properties of the polymeric matrix. Depending on the sodium content, it was obtained exfoliated and/or intercalated nanosheets that were further characterized by flame photometry, infrared spectroscopy, specific surface area by N2 adsorption, thermogravimetry, X-ray powder diffraction (XRPD) and of small angle $\mathrm{X}$-ray scattering (SAXS), atomic force microscopy (AFM) and transmission electron microscopy (TEM). For the manufacturing of nanocomposites two types of matrices were used: a) neat high density polyethylene (HDPE) and b) HDPE with the addition of a low percentage of polyethylene-graft-maleic anhydride (PE-g-MA). Pristine nanosheets (pLTs) and exfoliated nanosheets (pLTs-O-2C18) were used as nanofillers at loadings of 1.0; 2.0 and $4.0 \mathrm{wt} \%$. Finally, we assessed the mechanical and thermal properties of the as-prepared nanocomposites through tensile tests, thermogravimetry analysis (TGA), differential scanning calorimetry (DSC) and dilatometry. Nanocomposites prepared with pristine pLTs and those manufactured with the addition of PE-g-MA coupling agent showed an increase on the Young modulus of 12,8\% and 5,1 \% for loadings of $4 \mathrm{wt} \%$ and 2 wt $\%$ of pristine pLTs, respectively. The nanocomposites that present the highest increase on yield stress were reinforced with $4 \mathrm{wt} \%$ of exfoliated nanosheets (pLTs-o2C18). However, these materials presents a decrease in the Young modulus of $\sim 12 \%$. The nanocomposites with the highest increase on Young Modulus were those prepared with 4 wt $\%$ of pristine ( $12,8 \%$ ), and the yield stress was also improved (increase of $\sim 4 \%$ ). The incorporation of nanosheets did not affect significantly the thermal stability properties of the matrix and a decrease on the coefficient of thermal expansion was solely observed for nanocomposites prepared with pristine pLTs. The degree of crystallinity decreased for all the manufactured nanocomposites, in the range of $\sim 2,17 \mathrm{t}-26 \%$ for nanocomposites prepared with pristine pLTs and those fabricated with the addition of PE-g-MA, respectively. up to $\sim$ pLTs with the addition of PE-g-MA.

\section{Keywords}

Titanate nanosheets; ferrititanate; exfoliation; nanocomposites; dimethyldioctadecylammonium; High-density polyethylene. 


\section{Sumário}

1 Introdução 14

2 Revisão Bibliográfica 16

2.1. Nanocompósitos poliméricos $\quad 16$

2.2. Principais métodos de preparação de nanocompósitos poliméricos 17

2.3. Nanofolhas de ferrititanato 19

2.3.1. Síntese hidrotérmica alcalina 19

2.3.2. Influência do teor de sódio nas propriedades das nanofolhas 24

2.3.3. Semelhança entre titanatos lepidocrocíticos e as argilas montmorilonitas 26

2.4. Fundamentos da organofilização baseados nas argilas 28

2.4.1. Esfoliação de nanofolhas de titanato 30

2.5. Classe de nanocompósitos com estruturas lamelares 33

2.6. Polietileno 34

2.6.1. Polietileno de alta densidade $\quad 35$

2.7. Geomembranas de PEAD 36

2.7.1. PEAD funcionalizado com anidrido maleico 38

2.8. Nanocompósitos poliméricos reforçados com nanofolhas de titanatos lepidocrocíticos

3 Objetivos $\quad 42$

3.1. Objetivo geral 42

3.2. Objetivos específicos 42

4 Materiais e Métodos 43

4.1. Síntese das nanofolhas de ferrititanato de partida 43

4.2. Capacidade de Troca Catiônica (CTC) 45

4.3. Organofilização das nanofolhas 47

4.4. Caracterização das nanofolhas virgens e organofilizadas 49

4.4.1. Fotometria de chama $\quad 49$

4.4.2. Difração de raios X (DRX) 49

4.4.3. Espalhamento de raios-X a baixo ângulo (SAXS) 49

4.4.4. Microscopia eletrônica de transmissão (MET) 50

4.4.5. Espectroscopia no infravermelho por transformada de Fourier (FTIR) 50

4.4.6. Medições de área superficial específica $\quad 50$

4.4.7. Análise termogravimétrica (TGA) 51

4.4.8. Microscopia de Força Atômica (AFM) 51

4.5. Fabricação dos nanocompósitos 51

4.5.1. Condições de processamento $\quad 52$

4.6. Caracterização dos nanocompósitos

4.6.1. Ensaio de tração

4.6.2. Análise térmica simultânea (TGA/DSC) 54

4.6.3. Dilatometria $\quad 54$

5 Resultados e Discussão 55

5.1. Caracterização das nanofolhas virgens e organofilizadas 55

5.1.1. Fotometria de chama 
5.1.2. Difração de raios- $X(D R X)$

5.1.3. Espalhamento de raios-X a baixo ângulo (SAXS) 60

5.1.4. Espectroscopia de FTIR 62

5.1.5. Medições de área superficial específica (BET) 63

5.1.6. Análise termogravimétrica (TGA) 64

5.1.7. Calorimetria diferencial de varredura (DSC) 67

5.1.8. Microscopia de força atômica (AFM) 69

5.1.9. Microscopia eletrônica de transmissão (MET) 69

5.2. Caracterização dos nanocompósitos 71

5.2.1. Ensaio de tração 71

5.2.2. Dilatometria 78

5.2.3. Análise térmica simultânea $\quad 80$

6 Conclusões

7 Sugestões para trabalhos futuros $\quad 85$

8 Referências Bibliográficas $\quad 86$ 


\section{Lista de figuras}

Figura 2.1 - Alguns formatos de nanocargas [13]........................................ 16

Figura 2.2 - Microextrusora de dupla rosca da marca Xplore DSM [19]............. 19

Figura 2.3 - Camadas alternadas de Fe e Ti na ordem Ti-Fe-V-Fe-Ti da areia

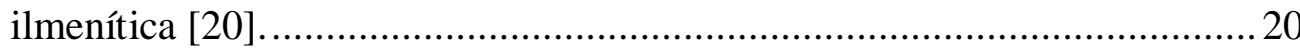

Figura 2.4 - Modelo de estrutura cristalina tipo lepidocrocita cujo sistema cristalino é ortorrômbico [20]. 21

Figura 2.5- Estrutura em camadas de forma esquemática ilustrando a região (galerias) onde se situam os cátions de compensação e as moléculas de água. 22

Figura 2.6 - Estrutura de tipo lepidocrocita de nanofolhas de ferrititano [23] .....22

Figura 2.7 - Imagem de MET das nanofolhas de titanatos [18] ......................... 23

Figura 2.8 - Estrutura molecular do hidróxido de tetrabutil amônio (TBA) [23].. 25

Figura 2.9 - Procedimento de troca iônica de nanofolhas de titanatos [35].......... 26

Figura 2.10 Estutura dos filossilicatos de estrutura TOT com cátions de compensação entre as lamelas [18]. 27

Figura 2.11- Diferença do grau de hidratação da montmorilonita sódica e

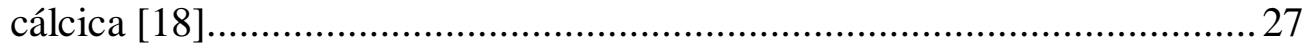

Figura 2.12- Modificação orgânica das nanofolhas [38]. ................................... 29

Figura 2.13- (a) Fórmula molecular e (b) esquema da estrutura do 2C18 [18]..... 30

Figura 2.14- Tipos de configurações das moléculas dos sais quaternários de amônio nas galerias das argilas [45] ....................................................... 30

Figura 2.15- Etapas do processo de esfoliação em folhas individuais [27]. ......... 31

Figura 2.16 - Esquema que organiza os mecanismos de inchamento, intercalação e esfoliação em titatantos lepidocrocíticos protonizados em relação a diferentes razões $\mathrm{TBA}^{+} / \mathrm{H}^{+}[46]$.

Figura 2.17- Distribuição do reforço nas distintas estruturas argila/polímero [48]

Figura 2.18- a) molécula do monômero etileno; b) unidade estrutural repetida

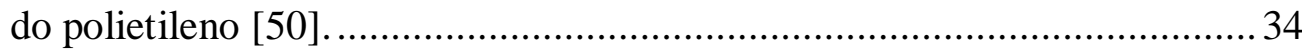

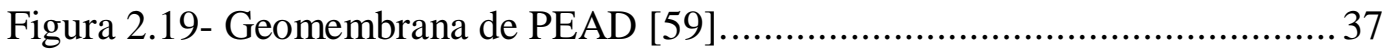

Figura 2.20- PE grafitizado com anidrido maleico........................................... 38 
Figura 2.21- Ensaio de tração dos nanocompósitos (a) Módulo de elasticidade

e (b) Tensão de escoamento [18]. ................................................................40

Figura 2.22 - Coeficiente de expansão térmica dos nanocompósitos [18]........... 40

Figura 4.1- Autoclave de alta pressão BR-500 ............................................. 43

Figura 4.2 - Esquema experimental utilizado para síntese das nanofolhas .......... 45

Figura 4.3 - Estrutura do cátion do corante azul de metileno ............................ 46

Figura 4.4 - Procedimento de titulação com azul de metileno, (b) modelo de aparecimento da coloração azul claro ao redor da gota [65] ..................... 46

Figura 4.5- Processo de esfoliação das nanofolhas, Ultra-Turrax Ika, modelo T25. 48

Figura 4.6- Esquema procedimento de esfoliação das nanofolhas. ..................... 48

Figura 5.1- Difratograma das amostras pLTs e NaLTs..................................... 56

Figura 5.2- Esquema ilustrativo das dimensões das nanofolhas protonizadas ao longo do eixo $b$

Figura 5.3- DRX das nanofolhas virgens (pLTs e NaLTs), esfoliadas

(pLTs-o-2C18) e intercaladas (NaLTs-o-2C18). 58

Figura 5.4 - Difratograma da amostra pLTs-o-2C18 lavada com água à temperatura de $60^{\circ} \mathrm{C}$. 59

Figura 5.5- Padrão de espalhamento de SAXS das amostras pLTs-o-2C18 e

NaLTs-o-2C18.

Figura 5.6- Representação da configuração da intercalação dos cátions 2C18 como estrutura bicamada para distâncias interlamelares de 4,5 nm. 61

Figura 5.7- Espectros de FTIR das nanofolhas virgem, esfoliada e intercalada. .62

Figura 5.8- Curva de TGA da amostra pLTs e pLTs-o-2C18. 64

Figura 5.9- Esquema ilustrativo das interações do cátion $2 \mathrm{C}^{+} 8^{+}$na amostra esfoliada [23]. 65

Figura 5.10 -Curva de TGA das amostras sódica e intercalada...........................66

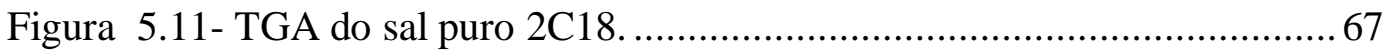

Figura 5.12 - Curvas de DSC das amostras (a) pLTs e (b) pLTs-o-2C18. ..........68

Figura 5.13- Imagens de AFM da amostra esfoliada (a) 2D e 3D e (b) perfil da seção transversal ao longo da linha branca desenhada em (a). 69

Figura 5.14- a) Imagen de MET da amostra NaLTs; imagens de MET e EDS das amostras (b) NaLTS e (c) pLTs. 
Figura 5.15- Imagem de MET da amostra pLTs-0-2C18 e seu respectivo espectro de EDS.

Figura 5.16 - Tensão no escoamento dos nanocompósitos fabricados em função da porcentagem em massa das nanocargas.

Figura 5.17- Deformação no escoamento em função da porcentagem em massa do reforço. 74

Figura 5.18- Módulo de Young dos nanocompósitos em função da porcentagem em massa do reforço. 75

Figura 5.19- Ductilidade dos nanocompósitos em função da porcentagem em massa do reforço. 76

Figura 5.20 - Tensão de ruptura dos nanocompósitos em função da porcentagem em massa do reforço. 77

Figura 5.21 - CET dos nanocompósitos .79 


\section{Lista de tabelas}

Tabela 2.1- Principais propriedades físicas do PEAD [53]................................. 36

Tabela 5.1 - Teores de $\mathrm{Na}^{+}$das amostras sintetizadas via rota hidrotérmica alcalina com diferentes tratamentos de lavagem, comparados com o teor no precursor mineral (areia ilmenítica). ....................................................55

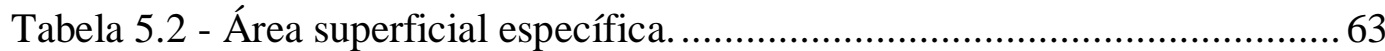

Tabela 5.3 - Resultados obtidos no ensaio de tração........................................ 71

Tabela 5.4 - Variações nas propriedades mecânicas de nanocompósitos produzidos com nanofolhas com diferentes teores de sódio, tanto virgens quanto organofilizadas com 2C18 em relação ao PEAD puro. .................... 78

Tabela 5.5 - CET do PEAD puro e dos nanocompósitos produzidos.................... 78

Tabela 5.6 - Resultados obtidos da Td máx e $\mathrm{T}_{\text {onset }}$ para o PEAD puro e os

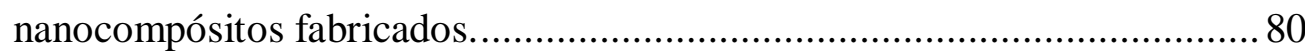

Tabela 5.7 - Parâmetros $\mathrm{T}_{10}$ e $\mathrm{T}_{50}$ para o PEAD puro e os nanocompósitos fabricados.

Tabela 5.8 - Temperatura de fusão, entalpia de fusão e grau de cristalinidade do PEAD puro e dos nanocompósitos produzidos. 


\section{1 \\ Introdução}

O emprego de nanocompósitos de matrizes poliméricas com reforço de argilas tem sido relatado na literatura como uma alternativa para o incremento das propriedades mecânicas do polímero puro. Pesquisadores da Toyota [1] relataram pela primeira vez, no início da década de 90, o incremento das propriedades mecânicas do polímero Nylon-6 com a fabricação de nanocompósitos Nylon-6argila [2], para aplicação comercial na indústria automobilística. Recentemente, os nanocompósitos polipropileno-argila foram usados no Honda Acura para fabricação de encostos para bancos automotivos [1].

O polietileno de alta densidade (PEAD) é um dos polímeros mais comercializados atualmente, devido as seguintes características tais como facilidade de processamento, baixo custo, não toxidade, boas propriedades mecânicas e sua versatilidade de aplicações. Porém, seu alto coeficiente de expansão térmica (CET) na faixa de $10^{-4}{ }^{\circ} \mathrm{C}^{-1}$ compromete a estabilidade dimensional de peças submetidas a variação de temperaturas. Portanto, a incorporação de um reforço nanohíbrido, orgânico-inorgânico, como as nanoargilas organofílicas à matriz de PEAD, é uma alternativa para incrementar as propriedades mecânicas e térmicas do polímero, especialmente para reduzir o seu CET [3] [4]. É importante salientar que geralmente as argilas organofílicas são intercaladas com sais quaternários de amônio, permitindo que a esfoliação/intercalação das camadas das argilas com as cadeias poliméricas ocorra durante a fabricação do nanocompósito.

Neste contexto, as nanofolhas de ferrititanato [5] [6], que apresentam uma estrutura lamelar similar a das argilas, tornam-se promissoras como cargas de nanocompósitos de PEAD ou de outros polímeros termoplásticos, já que durante o processo de organofilização poderiam ser intercaladas ou esfoliadas com sais quaternários de amônio. Especificamente, a incorporação de nanofolhas completamente esfoliadas (delaminadas) em camadas sub-nanométricas (monofolhas) em matrizes poliméricas poderia promover ainda mais a dispersão das mesmas dentro da matriz polimérica. Devido à natureza hidrofílica das nanofolhas, a organofilização auxilia também para melhorar a molhabilidade das 
nanofolhas ou monofolhas esfoliadas pela matriz polimérica hidrofóbica [7]. De fato, as nanofolhas organofilizadas, esfoliadas em monofolhas de espessura subnanométrica, podem ser consideradas como nanohíbridos orgânico-inorgânico e a estabilidade térmica deste composto é fundamental para garantir a presença do sal na superfície das folhas durante o processamento dos nanocompósitos de matriz polimérica, e assim a compatibilidade entre ambos os componentes. Uma forma mais convencional para a fabricação dos nanocompósitos é o processamento por microextrusão-microinjeção. Neste método, mistura-se o polímero fundido com uma baixa quantidade de nanocarga, geralmente $\leq 5 \%$, neste caso na forma de nanofolhas ou monofolhas esfoliadas, levando à formação de nanocompósitos com uma microestrutura intercalada e/ou esfoliada [8]. Porém, os nanocompósitos verdadeiros somente são sintetizados quando se atinge uma dispersão de nanocargas homogênea na escala nanométrica na matriz polimérica, além de uma interface de baixa energia e por meio de ligações fortes entre dois componentes. Assim sendo, um dos meios para melhorar tanto a dispersão das nanocargas quanto aumentar a compatibilidade entre a matriz hidrofóbica e o reforço hidrofílico é a utilização de um agente de acoplamento como o polietileno grafitizado com anidrido maleico (PE-g-MA) [9].

Desta forma, o presente trabalho visa, inicialmente, a) sintetização de nanofolhas de ferrititanato com alto e baixo teor de sódio; b) seguida pelo desenvolvimento de uma rota química para esfoliação destas nanofolhas em monofolhas sub-nanométricas utilizando-se um determinado sal quaternário de amônio, o cloreto de dimetildioctadecilamônio, resultando em c) obtenção de nanohíbridos (ferrititanato-cátion quartenário de amônio) com alta estabilidade térmica. Além disso, este trabalho pretende fabricar dois tipos de nanocompósitos de matriz PEAD e PEAD com adição de polietileno funcionalizado com anidrido maleico (PE-g-MA) reforçados com nanofolhas virgens e nanohíbridos esfoliados, assim como avaliar as propriedades mecânicas e térmicas dos nanocompósitos fabricados. 


\section{2 \\ Revisão Bibliográfica}

\section{1. \\ Nanocompósitos poliméricos}

Um compósito é um material formado por duas ou mais fases com diferentes propriedades químicas e físicas em sua composição: a fase contínua é denominada matriz e a fase descontínua é chamada de reforço. Um compósito apresenta propriedades melhoradas quando comparado com os componentes individualmente.

Por outro lado, os nanocompósitos poliméricos são formados quando cargas que apresentam dimensões nanométricas $(<100 \mathrm{~nm})$ são incorporadas dentro da matriz. Na Figura 2.1, são apresentadas cargas nanométricas com distintos formatos, onde é mostrada uma estrutura de nanofolha, referente às nanoestruturas lamelares (argilas). A utilização de nanocargas inorgânicas adicionadas, sempre, em frações em peso baixas $(\leq 0,05)$ [10] deveria levar a uma melhoria mais acentuada das propriedades da matriz polimérica quando comparada com cargas na escala micrométrica, sem prejudicar as vantagens intrínsecas de um polímero como baixo peso ou transparência ótica. De fato, as cargas de uma forma geral, são convencionalmente utilizadas em frações em peso bastante mais altas (0,1$0,5)$ para se obter um incremento substancial das propriedades da matriz dos compósitos [11] [12].

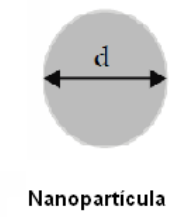

$1<\mathrm{d}<100 \mathrm{~nm}$

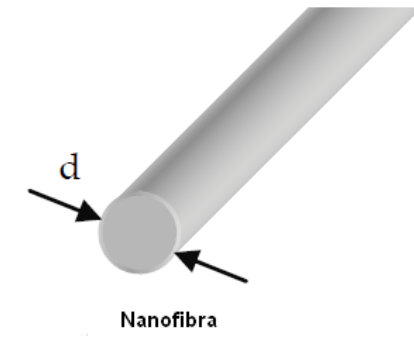

$1<\mathrm{d}<100 \mathrm{~nm}$

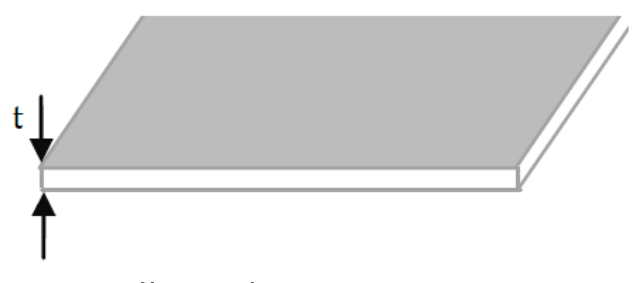

Nanocamada

$1<\mathrm{t}<100 \mathrm{~nm}$

Figura 2.1 - Alguns formatos de nanocargas [13].

Uma vantagem das nanocargas é que apresentam uma grande área superficial, com isso a possibilidade de se obter uma maior interface de contato 
entre o polímero e o reforço, resultando em uma melhoria nas propriedades do material como na resistência mecânica acrescentada, estabilidade térmica ou alta resistência química.

Alguns fatores são importantes para definir as propriedades do nanocompósito, como: o tamanho das partículas do reforço, sua dispersão e distribuição na matriz, a molhabilidade do reforço no polímero (tipo de interfaces) e o método de processamento [6].

$\mathrm{Na}$ área de nanocompósitos poliméricos aqueles reforçados com nanotubos de carbono, materiais lamelares como argilas montmorilonitas e nanopartículas $\left(\mathrm{Al}_{2} \mathrm{O}_{3}, \mathrm{SiO}_{2}, \mathrm{TiO}_{2}\right.$, etc) têm sido largamente estudados [14]. Assim sendo, na utilização das argilas como reforço de matrizes poliméricas, os nanocompósitos são obtidos quando apresentam uma microestrutura intercalada e/ou esfoliada, referindo-se à interação entre as cadeias poliméricas com as camadas das argilas. Neste caso, para obter um compósito com a microestrutura esfoliada e/ou intercalada (nanocompósito) é importante a dispersão uniforme das nanofolhas e/ou monofolhas na matriz, visto que no caso da aglomeração do reforço obtém-se um material com microestrutura de fases separadas, denominada microcompósito. Desta forma, o material final (microcompósito) apresenta propriedades inferiores às que poderiam ser apresentadas pelos nanocompósitos verdadeiros [15]. Com isso, para se desenvolver um nanocompósito com a microestrutura desejada e devido a morfologia lamelar das argilas, a metodologia atual requer a inserção de cátions de tamanhos grandes provenientes de sais orgânicos nas suas galerias (quaternários de amônio) para aumentar a distância interlamelar, facilitando a posterior esfoliação das camadas por forças cisalhantes exercidas durante a fabricação dos nanocompósitos.

\section{2. Principais métodos de preparação de nanocompósitos poliméricos}

Muita pesquisa em torno da preparação de nanocompósitos poliméricos tem sido realizada para se compreender a obtenção de nanocompósitos com microestrutura intercalada e/ou esfoliada utilizando argilas organofilizadas, um material em camadas mais tradicional, tendo como a matéria prima argilas, mineradas em abundância. A etapa de intercalação e esfoliação tem uma grande 
influência nas características finais do nanocompósito, devido à necessidade da alta dispersão do reforço na matriz polimérica para desenvolver um nanocompósito com melhores propriedades térmicas e mecânicas. Devido à natureza hidrofóbica dos polímeros, muitos estudos têm sido realizados para melhorar a dispersão das nanocargas inorgâncas hidrofílicas como por exemplo, argilas, silica, alumina, etc em matrizes poliméricas para a preparação de nanocompósitos. [14].

Em geral, distinguem-se três métodos para a preparação dos nanocompósitos poliméricos sendo estes: esfoliação/intercalação por polimerização in situ, mescla em solução e intercalação por fusão [16].

O método por esfoliação/intercalação por polimerização in situ envolve a polimerização de um monômero na presença de uma argila dispersa. Desta forma, ocorre a formação do polímero entre as camadas da argila. A polimerização é iniciada por calor ou radiação. O crescimento das cadeias poliméricas dentro das galerias das argilas pode levar a geração de um material esfoliado ou intercalado [16] [13]. Uma vantagem da polimerização in situ é a melhor dispersão das nanocargas no polímero [17].

No método mescla em solução, o polímero é dissolvido em solventes orgânicos [17] e a argila é dispersa no mesmo solvente. O polímero dissolvido é adicionado à argila previamente dispersa no mesmo solvente e as cadeias de polímeros podem intercalar entre suas camadas. O nanocompósito é obtido através da evaporação do solvente ou precipitação [13] [16].

A intercalação por fusão é um método no qual o polímero em estado fundido é misturado com a argila, geralmente, organofilizada [8]. Através da mistura direta pelo método de extrusão, pode-se obter o nanocompósito. Aplicando-se uma força cisalhante no polímero em estado fundido durante seu processamento com temperaturas e velocidade controladas, a intercalação/esfoliação pode ser promovida [18]. Uma forma de se produzir os nanocompósitos, em escala laboratorial, é através da utilização de microextrusoras (com dupla rosca co-rotante) para a fusão do polímero e a mistura da nanocarga, como pode observar na Figura 2.2. Após essa etapa a mistura é levada para microinjeção para obter um corpo de prova com o molde desejado. 


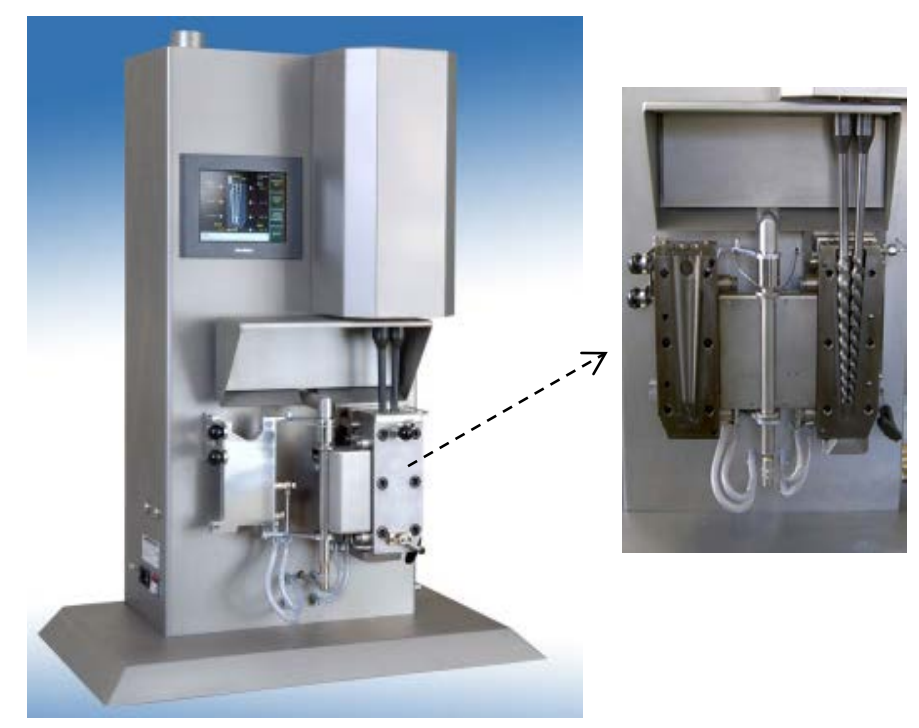

Figura 2.2 - Microextrusora de dupla rosca da marca Xplore DSM [19].

\section{3.}

\section{Nanofolhas de ferrititanato}

\subsection{1.}

\section{Síntese hidrotérmica alcalina}

Ilmenita é um mineral, que apresenta fórmula química $\mathrm{FeTiO}_{3}$ e é a principal fonte de extração de dióxido de titânio (fases cristalinas mais conhecidas anatásio, rutilo e brookita) sendo o principal componente mineral em minério denominado areia ilmenítica. Suas principais jazidas no Brasil encontram-se no Rio de Janeiro, Paraíba e toda extensão litorânea do Espírito Santo [20]. A estrutura cristalina desse mineral é descrita como uma rede hexagonal (HC) compacta de íons de oxigênio com dois terços de seus sítios octaédricos ocupados pelos metais Fe e Ti. Cada octaedro compartilha três arestas com outro octaedro dentro da camada, uma face com um octaedro do segundo tipo de cátion na camada adjacente e a face oposta com uma vacância (V) no sítio octaédrico como se pode observar na Figura 2.3 [21]. 


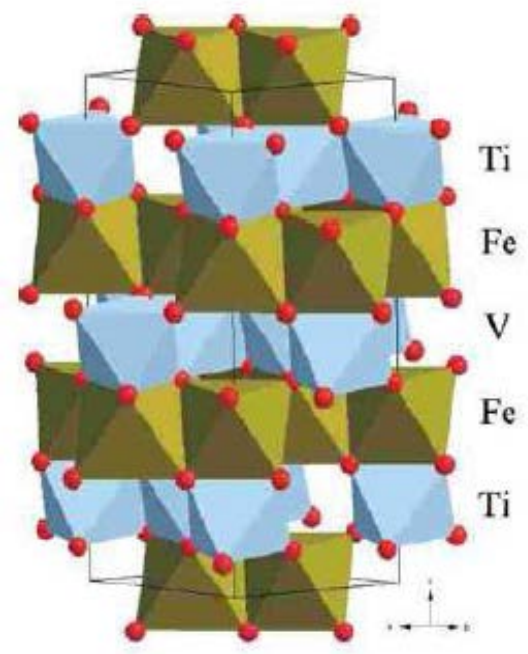

Figura 2.3 - Camadas alternadas de Fe e Ti na ordem Ti-Fe-V-Fe-Ti da areia ilmenítica [20].

Jardim et al. [5] relataram, pela primeira vez, a síntese das nanofolhas de ferrititanato via rota hidrotérmica alcalina partindo do precursor de baixo custo, areia ilmenítica, usando solução de $\mathrm{NaOH} 10 \mathrm{M}$ a $130^{\circ} \mathrm{C}$ por $72 \mathrm{~h}$. Esse tratamento térmico consiste na dissolução do principal mineral do precursor, a ilmenita, e posterior precipitação do produto, nanofolhas de ferrititanatos. Esse processo é fortemente influenciado pela temperatura da reação, matéria-prima utilizada, concentração da solução de $\mathrm{NaOH}$ e a lavagem do material.

Dissolução pode ser descrita por meio da seguinte reação:

$$
\mathrm{FeTiO}_{3}+\mathrm{NaOH} \rightarrow \mathrm{Fe}^{2+}+\mathrm{TiO}_{3}{ }^{2-}+\mathrm{Na}^{+}+\mathrm{OH}^{-}
$$

Enquanto a cristalização é descrita da seguinte forma:

$$
x \mathrm{Na}^{+}+\mathrm{x} \mathrm{Fe}{ }^{3+}+(2-\mathrm{x}) \mathrm{TiO}_{3}^{2-}+\mathrm{z} \mathrm{OH}^{-} \rightarrow \mathrm{Na}_{\mathrm{x}} \mathrm{Ti}_{2-\mathrm{x}} \mathrm{Fe}_{\mathrm{x}} \mathrm{O}_{4}+\mathrm{w} \mathrm{H} \mathrm{H}_{2} \mathrm{O}
$$

As lamelas de titanatos assim cristalizados (de estrutura lepidocrocítica; ver adiante) são carregados negativamente devido a uma deficiência de carga positiva dentro delas devido à presença de vacâncias ou substituição de $\mathrm{Ti}^{4+}$ pelos cátions de menor valência, ocasionando um potencial negativo na sua superfície. Com o tratamento hidrotérmico alcalino, os cátions de $\mathrm{Na}^{+}$e $\mathrm{H}^{+}$proveniente da 
solução aquosa de $\mathrm{NaOH}$ são adsorvidos nas galerias (espaço interlamelar das nanofolhas) tendo a função de cátion de compensação. As nanofolhas adotam a estrutura cristalina tipo lepidocrocita, com fórmula geral $\mathrm{A}_{\mathrm{x}} \mathrm{Ti}_{2-\mathrm{y}} \mathrm{M}_{\mathrm{y}} \mathrm{O}_{4}$, relatada pela primeira vez por Reid et al. [22], no qual os octaedros de $\mathrm{TiO}_{6}$ compartilham arestas, formando camadas contínuas e densas, como ilustrado na Figura 2.4.

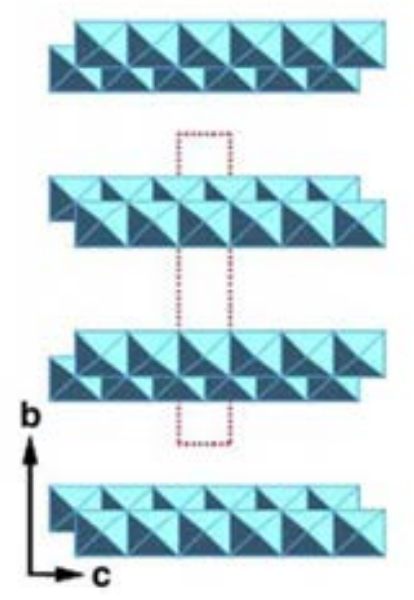

Figura 2.4 - Modelo de estrutura cristalina tipo lepidocrocita cujo sistema cristalino é ortorrômbico [20].

Como em outras estruturas em camadas (vide Figura 2.5), a distância interlamelar depende, além do tipo do cátion de compensação, da quantidade de moléculas de água presentes entre as camadas das nanofolhas. Assim, as moléculas de água podem inchar as galerias, permitindo o aumento do espaço entre as camadas, enquanto as reações de troca iônica possibilitam a substituição completa do cátion proveniente da reação de síntese hidrotérmica alcalina $\left(\mathrm{Na}^{+}\right)$ por um outro íon $\left(\mathrm{H}^{+}\right)$. 


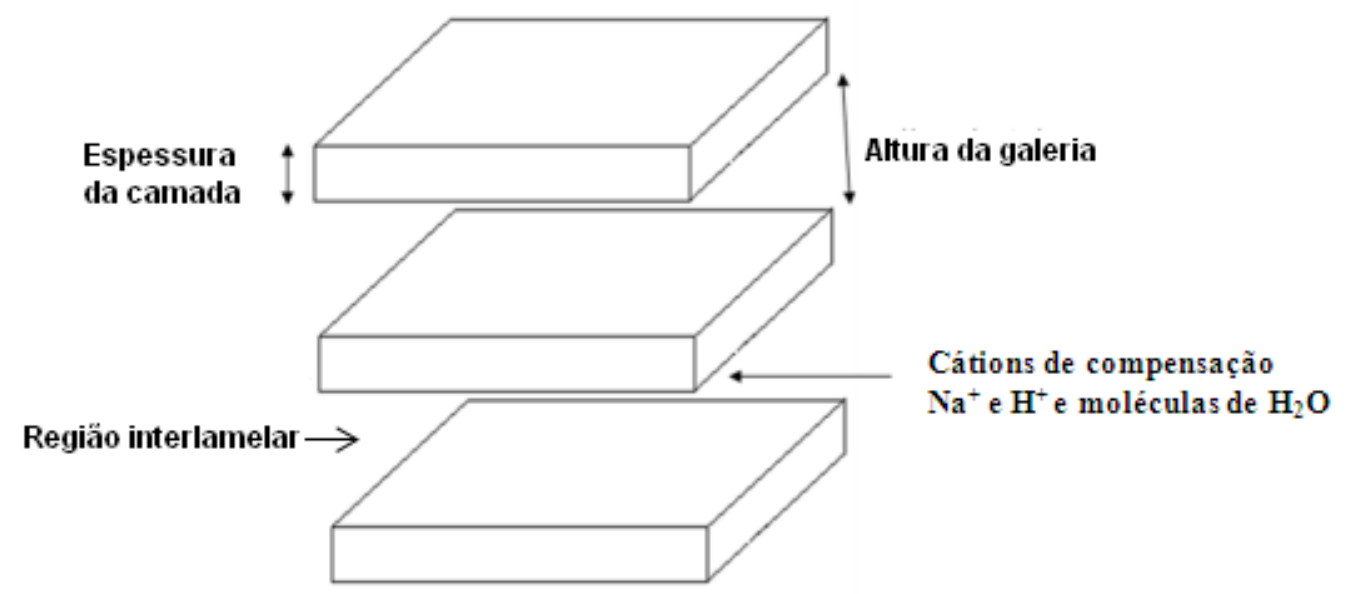

Figura 2.5 - Estrutura em camadas de forma esquemática ilustrando a região (galerias) onde se situam os cátions de compensação e as moléculas de água.

Jardim et al. [5] sintetizaram, utilizando o tratamento hidrotérmico alcalino partindo do precursor areia ilmenítica, nanofolhas de ferrititanato (vide Figura 2.6) com estrutura cristalina tipo lepidocrocita $\mathrm{Na}_{\mathrm{x}-\mathrm{y}} \mathrm{H}_{\mathrm{y}} \mathrm{Ti}_{2-\mathrm{x}} \mathrm{Fe}_{\mathrm{x}} \mathrm{O}_{4} \cdot \mathrm{nH}_{2} \mathrm{O}$ comprovada através de técnicas de Difração de raios-X (DRX) e microscopia eletrônica de transmissão (MET) com espectroscopia de energia dispersiva (EDS).

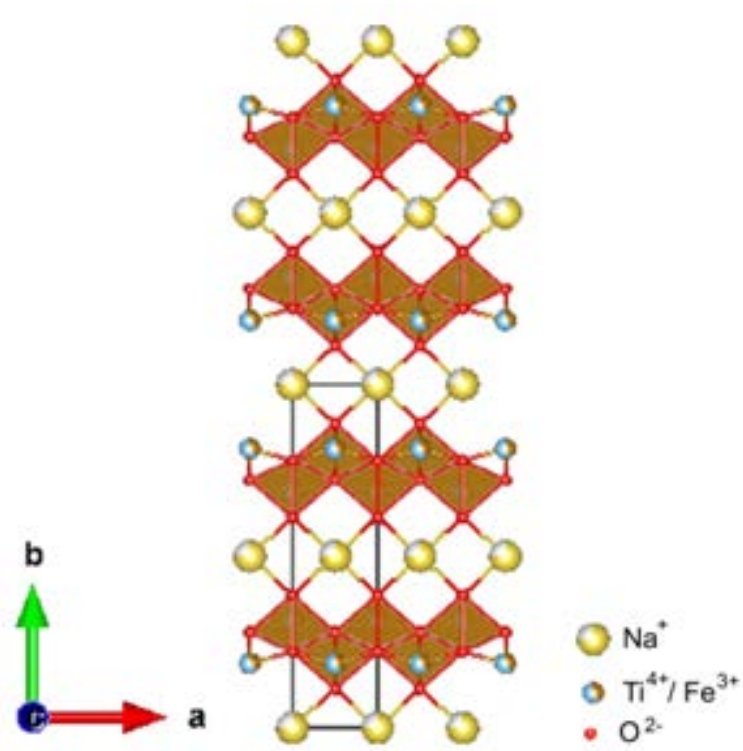

Figura 2.6 - Estrutura de tipo lepidocrocita de nanofolhas de ferrititano [23] .

As nanofolhas de ferrititanato são formadas por várias monofolhas empilhadas (geralmente em torno de 10 a 15), conforme mostrado na imagem de 
MET da Figura 2.7. As nanofolhas apresentam área superficial elevada ( 80 $\left.\mathrm{m}^{2} / \mathrm{g}\right)$ e quando submetidas posteriormente a um processo de lavagem com água destilada, ocorre uma modificação química controlada com a substituição parcial do cátion interlamelar $\mathrm{Na}^{+}$pelo íon $\mathrm{H}^{+}$[5] [20] [24]. A reação de lavagem das nanofolhas de ferrititanato com água é mostrada a seguir:

$$
\mathrm{Na}_{\mathrm{x}} \mathrm{Ti}_{2-\mathrm{x}} \mathrm{Fe}_{\mathrm{x}} \mathrm{O}_{4}+\mathrm{y} \mathrm{H} \mathrm{H}_{2} \mathrm{O} \rightarrow \mathrm{Na}_{\mathrm{x}-\mathrm{y}} \mathrm{H}_{\mathrm{y}} \mathrm{Ti}_{2-\mathrm{x}} \mathrm{Fe}_{\mathrm{x}} \mathrm{O}_{4}+\mathrm{y} \mathrm{NaOH}(1)
$$

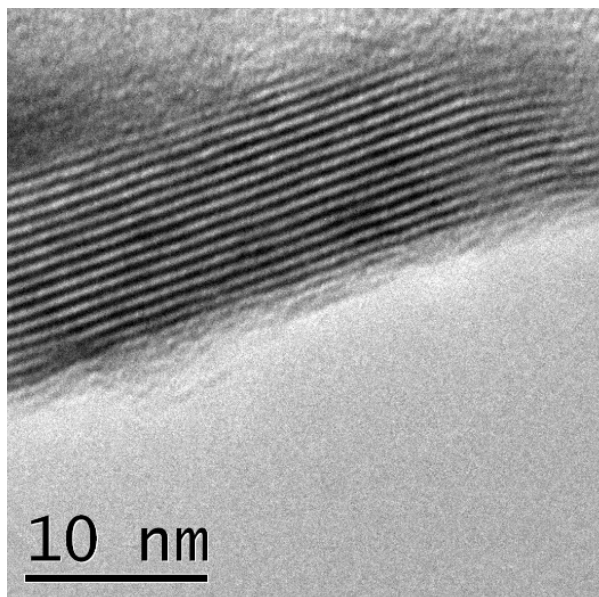

Figura 2.7 - Imagem de MET das nanofolhas de titanatos [18].

De acordo com Wang et al. [25], algumas possíveis aplicações para os titanatos em camadas de estrutura lepidocrocítica são na área de eletroquímica e catálise, fabricação de dispositivos dielétricos e preparação de nanocompósitos para melhorar as propriedades mecânicas do polímero e/ou propriedades de gás de barreira. É importante salientar que estruturas lamelares lepidocrocíticas são geralmente produzidas por reação no estado sólido entre carbonatos de metal alcalino, óxidos de metais com a valência inferior a $4+$ e $\mathrm{TiO}_{2}$, que envolve altas temperaturas entre $800-1300^{\circ} \mathrm{C}$ [26] [27]. Porém, as estruturas lamelares sinetizadas desta forma são de tamanho micrométrico lateral, além de possuir um alto número de monofolhas empilhadas, enquanto as nanofolhas de ferrititanato produzidas pela rota hidrotérmica alcalina já possuem dimensões nanométricas laterais e apenas 10 a 15 monofolhas, mesmo antes do processo de esfoliação. 


\subsection{2.}

\section{Influência do teor de sódio nas propriedades das nanofolhas}

A síntese de nanofolhas de ferrititatanos relatada por Jardim et al. [5] inclui a etapa de lavagem do precipitado obtido após a reação hidrotérmica alcalina com água destilada até obter um $\mathrm{pH}$ neutro. Porém, não tem sido relatada na literatura a lavagem ácida visando à produção de nanofolhas protonizadas, como no caso dos nanotubos de trititanato. De fato, nanotubos de trititanato com baixo teor de sódio sem modificação da sua superfície demonstraram maiores incrementos nas propriedades mecânicas de compósitos de matriz nylon-11 quando comparados com nanotubos de titanato com alto teor de sódio [28]. Em relação às nanofolhas de ferrititanato, compósitos de PEAD foram fabricados utilizando estas nanocargas com um teor de sódio intermediário [18], produzidas seguindo a mesma rota de síntese e lavagem proposta por Jardim et al. [5]. Neste caso, não houve uma melhora significativa nas propriedades mecânicas dos (nano)compósitos, em relação ao PEAD puro, com a inserção das nanofolhas sódicas virgens (sem modificação) e nanofolhas sódicas intercaladas com o cátion dimetil dioctadecilamônio $\left(2 \mathrm{C} 18^{+}\right)$, enquanto somente as nanofolhas de ferrititanato numa fração em peso de $4 \%$ no polímero, modificadas com um agente de acoplamento silano (viniltrimetoxi silano, VTMS), levaram ao incremento nas propriedades mecânicas e térmicas, conforme na seção 2.8. Assim sendo, as nanofolhas de ferrititanato protonizadas poderiam ser uma carga promissora na área de nanocompósitos poliméricos.

$\mathrm{Na}$ literatura a maioria de trabalhos com folhas de titanatos lepidocrocíticos de distintos tipos de elementos químicos, substituindo parcialmente $\mathrm{Ti}^{4+}$ dentro das lamelas nas posições octaédricas, envolve a etapa de troca iônica através de uma reação ácida a fim de sintetizar folhas de titanatos protonizadas. Uma razão para esta tendência é que titanatos na forma protonizada (definida como a forma onde os cátions de compensação de carga são $\mathrm{H}^{+}$) são capazes de fazer a reação de troca iônica com cátions, de diversos tamanhos [29] [30] [31] dando a possibilidade de variadas aplicações, dependendo do tipo do cátion trocado com $\mathrm{H}^{+}$. Sasaki et al. [29] sugeriram que os titanatos lamelares protonizados geralmente apresentam o maior espaço entre as camadas na família dos titanatos lamelares (cerca de 9,4 Å), capaz de acomodar moléculas maiores. Os autores 
descreveram a transformação da fase lepidocrocítica $\mathrm{Cs}_{\mathrm{x}} \mathrm{Ti}_{2-\mathrm{x} / 4} \square_{\mathrm{x} / 4} \mathrm{O}_{4}$ para sua forma protonizada, através da reação de troca iônica notando duas mudanças estruturais: a) aumento da distância entre as camadas de 8,6 para 9,4 $\AA$, principalmente, devido à entrada das moléculas de $\mathrm{H}_{2} \mathrm{O}$, pois a troca ocorre numa solução aquosa de $\mathrm{HCl}$ e b) alojamento de moléculas de água nas regiões interlamelares.

England et al. [30] relataram a troca iônica através de um tratamento ácido utilizando $\mathrm{HCl} 10 \%$ à temperatura ambiente durante a noite sem total dissolução do sólido $\mathrm{Cs}_{0,7} \mathrm{M}_{2} \mathrm{O}_{4}$ e concluiram que $92 \%$ do sólido foi trocado formando $\mathrm{Cs}_{0,05} \mathrm{H}_{0,65} \mathrm{M}_{2} \mathrm{O}_{4} \cdot \mathrm{yH}_{2} \mathrm{O}$. Os resultados da troca catiônica foram comprovados por análises de Termogravimetria (TG), Calorimetria diferencial de varredura (DSC) e DRX.

Sasaki et al. [32] relataram a esfoliação das camadas protonizadas de titanato em camadas individuais (monofolhas) de espessura sub-nanométrica, em uma solução aquosa de hidróxido de tetrabutil amônia (TBA) vide Figura 2.8.

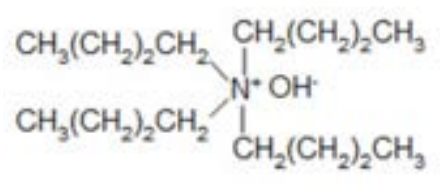

TBAOH

Figura 2.8 - Estrutura molecular do hidróxido de tetrabutil amônio (TBA) [23].

É importante salientar que para os titanatos, o procedimento de troca ácida com $\mathrm{HCl}$ é relatado na literatura como uma reação lenta, que é completada em, aproximadamente, três dias à temperatura de $60^{\circ} \mathrm{C}$, devido às dimensões laterais submicrônicas à micrônicas dos titanatos lamelares comumente sintetizados [33] [34]. 


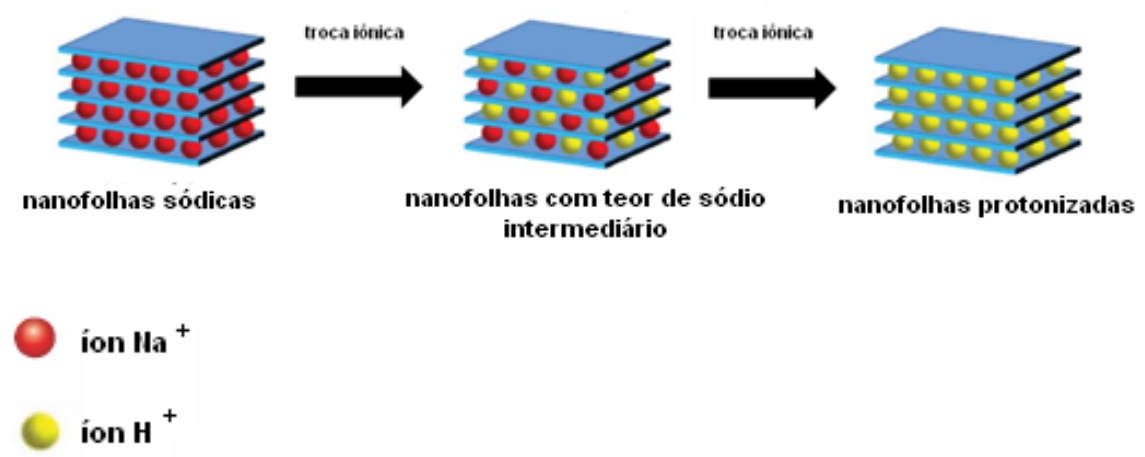

Figura 2.9 - Procedimento de troca iônica de nanofolhas de titanatos [35].

Finalmente, as nanofolhas de ferrititanato tanto na forma sódica como protonizada, apresentam semelhança com as nanoargilas montmorilonitas, que em seu estado natural possuem caráter hidrofílico. Desta forma, para aumentar a compatibilidade entre a matriz polimérica hidrofóbica e as nanofolhas, na produção de nanocompósitos, o uso de um modificador orgânico para reduzir o caráter hidrofílico das nanofolhas torna-se promissor.

\subsection{3. \\ Semelhança entre titanatos lepidocrocíticos e as argilas montmorilonitas}

As argilas montmorilonitas pertencem à família dos filossilicatos, grupo Esmectíta, com a fórmula química geral (Al, Mg, $\mathrm{Fe})_{4}(\mathrm{Si}, \mathrm{Al})_{8} \mathrm{O}_{20}(\mathrm{OH})_{4}(1 / 2 \mathrm{Ca}$, $\mathrm{Na})_{0,7} \cdot \mathrm{nH}_{2} \mathrm{O}$. A superfície das lamelas destas argilas apresenta um excesso da carga negativa , devido à deficiência da carga positiva na estrutura cristalina [36]. Os cátions de compensação $\left(\mathrm{Na}^{+}, \mathrm{Ca}^{2+}, \mathrm{Mg}^{2+}\right.$, etc.) ocupam o espaço entre as lamelas (camadas densas) da argila, denominado de galeria. Sua estrutura cristalina é composta por duas camadas de tetraedros $(\mathrm{T})$ de silício com uma camada central octaédrica de alumínio interligadas pelos vértices. Essas camadas (compostas por lamelas TOT) permanecem empilhadas e unidas por forças de van der Waals, criando, portanto, os espaços interlamelares, conforme mostrado na Figura 2.10, nos quais se situam os cátions de compensação de cargas. 


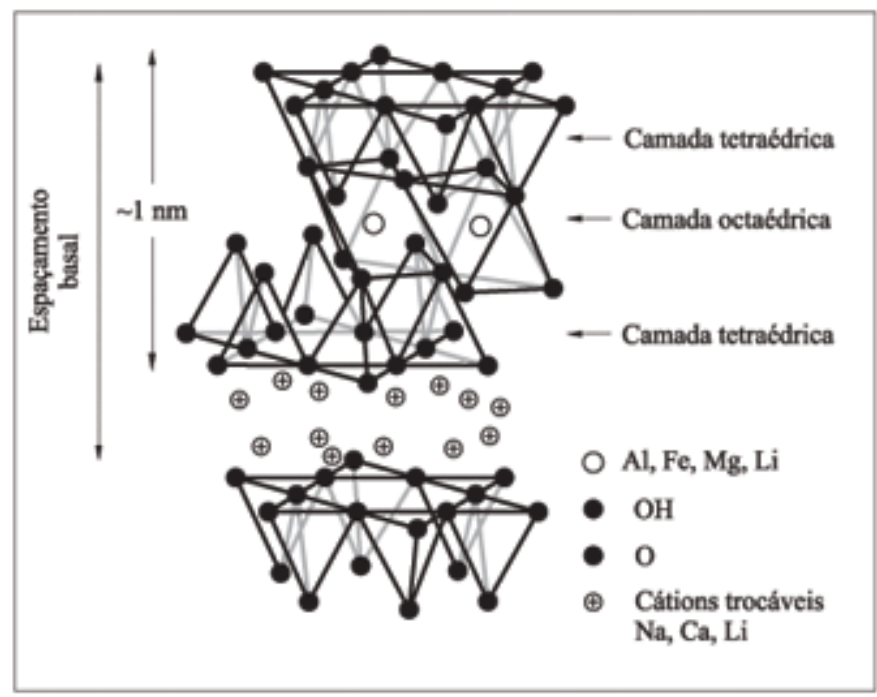

Figura 2.10 - Estrutura dos filossilicatos de estrutura TOT com cátions de compensação entre as lamelas [18].

Existem dois tipos de montmorolinita natural: uma é a montmorolinita sódica com alto grau de inchamento em água e a outra é a montmorolinita cálcica com menor capacidade de inchamento, devido à presença de cálcio divalente, aumentando as forças de atração entre as lamelas (vide Figura 2.11) [37].

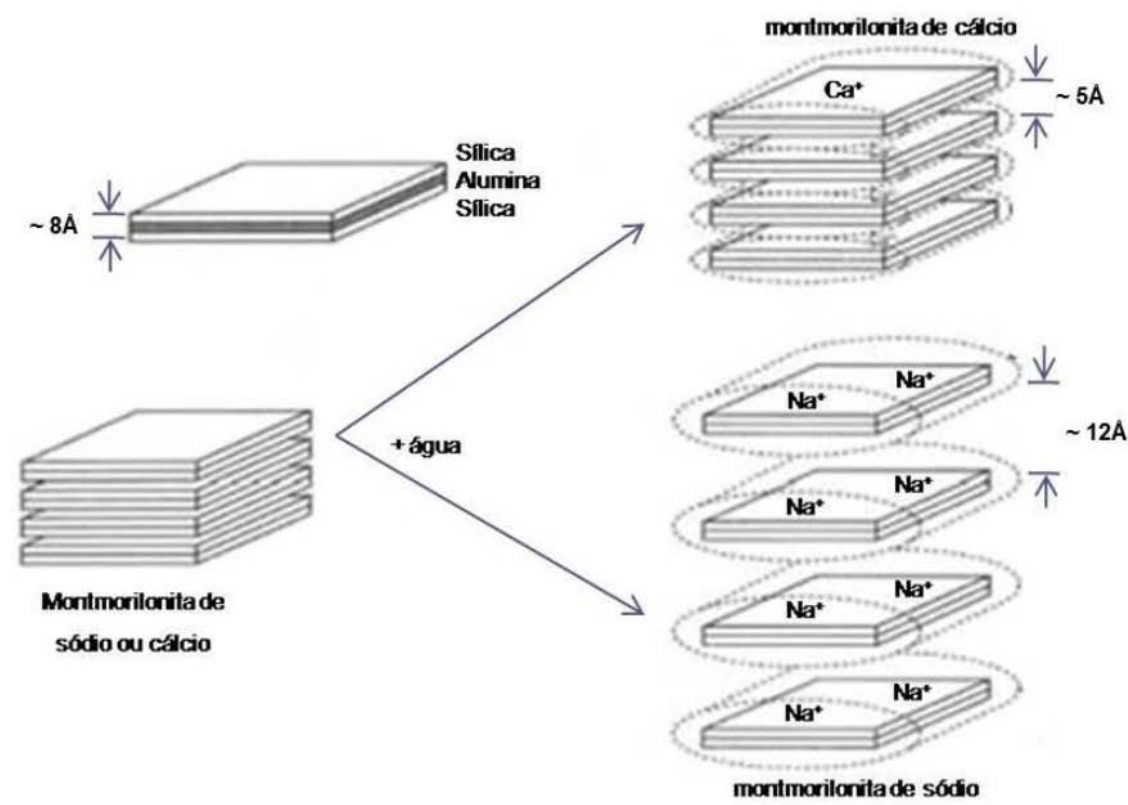

Figura 2.11 - Diferença do grau de hidratação da montmorilonita sódica e cálcica [18]. 
As argilas montmorilonita apresentam algumas características importantes para a fabricação dos nanocompósitos como: alta capacidade de troca catiônica, grande área específica, partículas naturalmente pequenas [38].

Como as camadas das argilas apresentam carga negativa e entre suas camadas (galerias) possuem cátions de compensação (sódio ou cálcio) para suprir a deficiência da carga, os cátions metálicos podem ser trocados por cátions orgânicos. A quantidade de cátions trocáveis é expressa a partir da capacidade de troca catiônica (CTC), em miliequivalentes (definido como peso atômico por valência) por 100 gramas (meq/100g) de material (ex.: argila) [36] [38]. Segundo Barbosa et al. [36] quanto maior a CTC, maior é a capacidade de trocar, por exemplo, o $\mathrm{Na}^{+}$, presente na galeria das argilas, por íons quaternários de amônio [39]. Os valores da CTC das argilas montmorilonitas sódicas estão na faixa de 40 e $150 \mathrm{meq} / 100 \mathrm{~g}$ [7] [40].

Neste trabalho, devido à semelhança estrutural dos ferrititanatos lepidocrocíticos, sintetizados a partir da areia ilmenítica via rota hidrotérmica alcalina, com as argilas montmorilonitas apresentando uma estrutura similar em camadas, vários parâmetros do processo de intercalação e esfoliação foram definidos tomando as argilas organofílicas como modelo.

\section{4. \\ Fundamentos da organofilização baseados nas argilas}

Diversos trabalhos sugerem a inserção de espécies químicas, através da reação de troca iônica utilizando aminas com cadeias alquílicas longas ou sais quaternários de amônio, entre as lamelas das argilas, a fim de aumentar a distância interlamelar ou separar totalmente as camadas e facilitar sua delaminação, devido ao enfraquecimento das forças de van der Waals e forças de ligações eletrostáticas (vide Figura 2.12). Desta forma, promove-se uma maior interface entre a carga esfoliada e/ou intercalada e a matriz polimérica. Outro propósito da organofilização é aumentar a compatibilidade das camadas das nanofolhas hidrofílicas com a matriz hidrofóbica [38] [41]. 


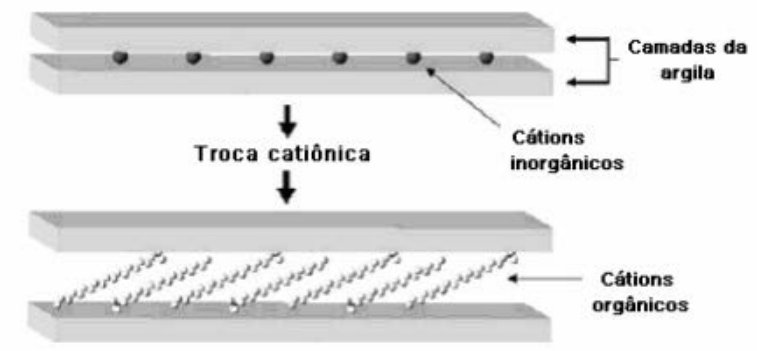

Figura 2.12 - Modificação orgânica das nanofolhas [38].

O uso de argilas montmorilonitas como reforço de nanocompósitos poliméricos tem sido bastante estudado, devido à sua capacidade de troca catiônica nos espaços interlamelares [3] [7] [42]. Vários estudos revelam que o material modificado com sais quaternários de amônio mostra mudanças no espaçamento basal [43]. Kozaki et al. [42] relataram um aumento do espaçamento basal de montmorilonitas organofilizadas com cloreto de dodecildimetil (dodeciloximethil) amônio de 1,23 nm para 1,56 nm, conforme demonstrado por DRX.

Com a organofilização, ocorre uma expansão entre os planos $d(001)$ da argila, que correspondem ao espaçamento basal $1,25 \mathrm{~nm}$, com isso muda sua natureza hidrofílica para hidrofóbica ou organofílica, proporcionando diversas possibilidades de aplicações para as argilas [37].

Um sal largamente utilizado na modificação de montmorilonitas por intercalação é o cloreto de dimetildioctadecilamônio (2C18), cuja estrutura é apresentada na Figura 2.13. Os cátions de 2C18 são atraídos pela superfície das lamelas que possuem carga negativa, substituindo os cátions de $\mathrm{H}^{+}$[38]. Uma das razões para o uso deste sal é atribuído a sua densidade da cadeia de hidrocarbonetos, já que o aumento do número de cadeias dentro das galerias ocasiona um incremento do espaçamento interlamelar levando a uma melhora no módulo de elasticidade dos compósitos de polipropileno reforçado com $3 \% \mathrm{v}$ de argila montomorilonita [44]. 


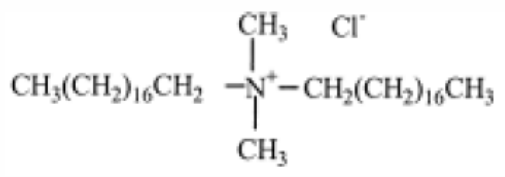

(a)

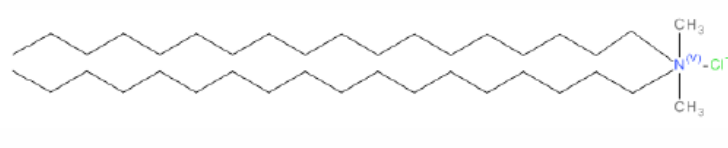

(b)

Figura 2.13 - (a) Fórmula molecular e (b) esquema da estrutura do 2C18 [18].

Existem várias configurações que as moléculas do sal podem adotar quando inseridas no espaço interlamelar das argilas, como mostrado na Figura 2.14 [43].

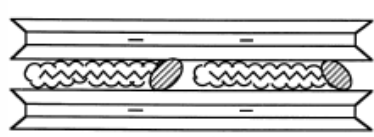

Monocamada

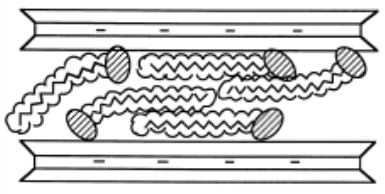

Pseudo-Tricamada

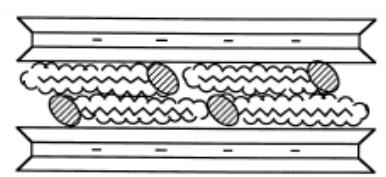

Bicamada

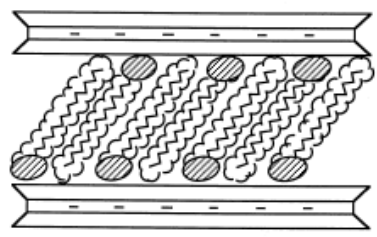

Estrutura tipo parafina

Figura 2.14 - Tipos de configurações das moléculas dos sais quaternários de amônio nas galerias das argilas [45].

\subsection{1. \\ Esfoliação de nanofolhas de titanato}

O processo de esfoliação ocorre com o aumento gradativo da distância das camadas das nanofolhas, devido à inserção de cátions orgânicos em uma etapa similar à organofilização das argilas, causando intercalação até um limite em que as camadas se separam ocasionando a sua completa delaminação. Isso ocorre devido a uma característica estrutural importante das camadas das nanofolhas: tipo de ligações covalentes fortes na estrutura da camada (na mesma lamela) e interações fracas camada-cátion-camada por meio das forças de van der Waals [35].

As nanofolhas passam por um processo estabelecido para esfoliação: a) modificação iônica interlamelar (protonização); b) intercalação do cátion sal quaternário de amônio (Organofilização; aumento da distância interlamelar 
gerando enfraquecimento da atração entre as camadas) e c) esfoliação por meio de esforços mecânicos. As etapas deste processo estão ilustradas na Figura 2.15.

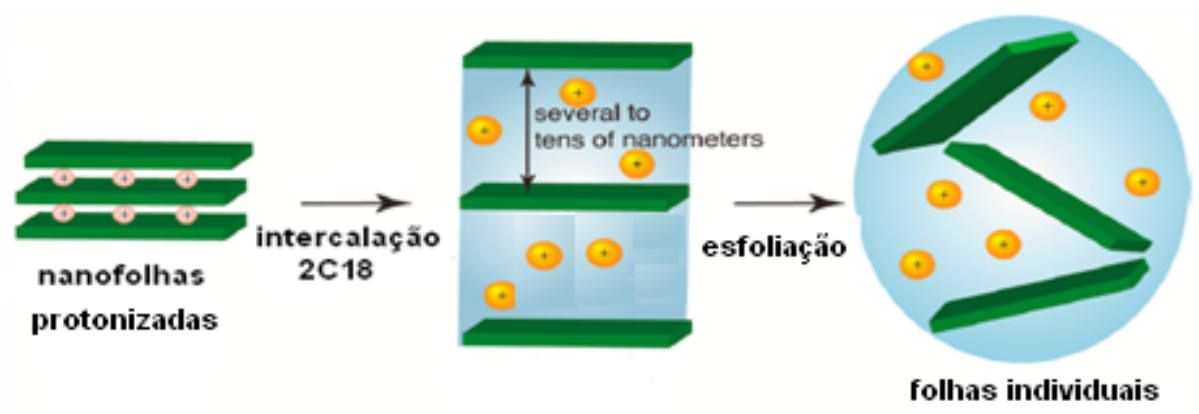

Figura 2.15 - Etapas do processo de esfoliação em folhas individuais [27].

A reação de esfoliação foi relatada por Ma et al. [27] partindo de folhas protonizadas. Os autores conferiram a inserção do cátion de tetrabutil amônio $\left(\mathrm{TBA}^{+}\right)$entre as camadas das nanofolhas, no qual as interações eletrostáticas entre as camadas diminuem e com agitação vigorosa, ocorre a delaminação das camadas formando uma dispersão coloidal de monofolhas. Desta forma, cada camada se comporta como partícula independente.

Sasaki et al. [46] relataram o aumento da distância entre as camadas das nanofolhas de titanato protonizadas de $4,2 \mathrm{~nm}$ para $10 \mathrm{~nm}$, com a redução da concentração do cátion $\mathrm{TBA}^{+}$, sugerindo um aumento da esfoliação das nanofolhas em monofolhas (camadas individuais) com a redução do inchamento. Na Figura 2.16 é apresentado o esquema sugerido por estes autores, no qual foi definida a razão ótima $\mathrm{TBA}^{+} / \mathrm{H}^{+}=5$ para obter a esfoliação total de titanatos lamelares produzidos pela rota de estado sólido, enquanto razões $\geq 10$ induziria ao inchamento pelas moléculas de água. Já razões $\leq 0,5$ causariam somente a intercalação do $\mathrm{TBA}^{+}$dentro das galerias, sem esfoliação [46]. Porém, Yuan et al. sugeriram que não existe o limite inferior da razão $\mathrm{TBA}^{+} / \mathrm{H}^{+}$para atingir a esfoliação com $\operatorname{TBA}^{+}$[47]. 


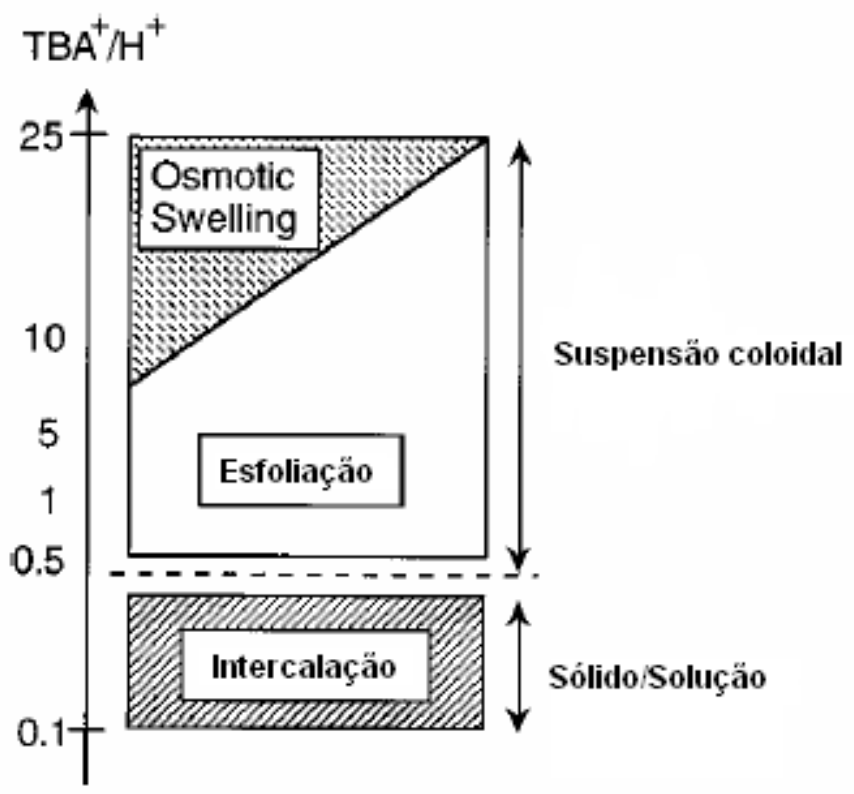

Figura 2.16 - Esquema que organiza os mecanismos de inchamento, intercalação e esfoliação em titatantos lepidocrocíticos protonizados em relação a diferentes razões $\mathrm{TBA}^{+} / \mathrm{H}^{+}[46]$.

Espécies inseridas nas galerias das nanofolhas que apresentam alta polaridade e menor tamanho, como por exemplo, a água, preservam uma estrutura inchada, enquanto íons com menor polaridade e de tamanhos maiores como por exemplo o $\mathrm{TBA}^{+}$, proporcionam a esfoliação, isto é, a estabilidade da estrutura lamelar depende diretamente da polaridade e do tamanho dos íons inseridos entre as camadas das nanofolhas [27].

Nesse trabalho, é mostrada pela primeira vez a esfoliação das nanofolhas de ferrititanato protonizadas com o sal 2C18. 


\section{5 .}

\section{Classe de nanocompósitos com estruturas lamelares}

Embora as argilas sejam muito estudadas como reforço de nanocompósitos, estas não são facilmente dispersas na maioria dos polímeros hidrofóbicos devido ao seu empilhamento camada-a-camada formando aglomerados difíceis de serem quebrados durante os processos de fabricação dos nanocompósitos [41].

Pode-se descrever três tipos de microestruturas argila/polímero obtidas através da distribuição das nanocargas lamelares na matriz polimérica, como representado na Figura 2.17.

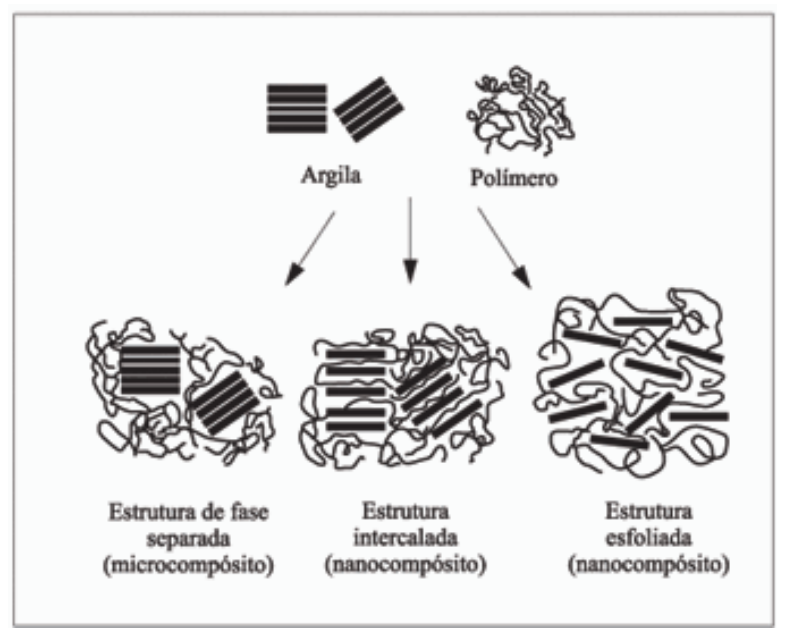

Figura 2.17 - Distribuição do reforço nas distintas estruturas argila/polímero [48].

A microestrutura de fase separada ocorre quando as cadeias da matriz polimérica não intercalam entre as camadas das nanofolhas, produzindo um material com estrutura semelhante a de um compósito convencional (microcompósito). A estrutura intercalada (nanocompósito), ocorre quando a matriz polimérica fica intercalada entre as camadas das nanofolhas aumentando a área de contato das camadas das nanofolhas com o polímero, formando uma estrutura multicamada ordenada, que apresenta melhores propriedades em relação aos compósitos convencionais. Já a estrutura esfoliada (nanocompósitos) apresenta a dispersão completa e uniformemente distribuída das camadas das argilas na matriz polimérica, aumentando ainda mais a interação do polímero com as camadas, levando a uma melhora nas propriedades físicas e mecânicas do material. 
A dispersão uniforme da nanocarga no polímero proporciona uma maior interação interfacial, sendo essa uma característica importante dos nanocompósitos em relação aos compósitos convencionais. Essa característica traz benefícios aos nanocompósitos em relação aos compósitos convencionais e ao polímero puro, como a melhora nas propriedades térmicas, mecânicas, de barreira e retardância à chama [18] [49].

\section{6.}

\section{Polietileno}

O polietileno é um polímero termoplástico, parcialmente cristalino, obtido através da polimerização do monômero etileno $\left(\mathrm{CH}_{2}=\mathrm{CH}_{2}\right)$. É considerado o plástico mais comercializado e reciclado atualmente [50]. Na Figura 2.18 é apresentada a fórmula química do monômero e da unidade estrutural repetida do polietileno.

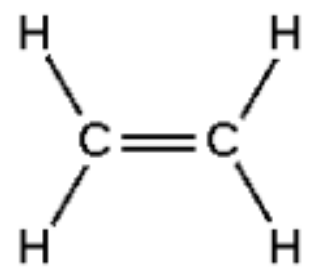

a)

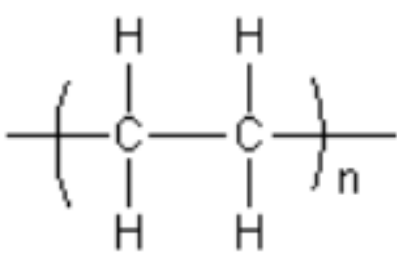

b)

Figura 2.18 - a) molécula do monômero etileno; b) unidade estrutural repetida do polietileno [50].

O polietileno é fabricado por diferentes métodos de polimerização, podendo variar as condições de síntese e do sistema catalítico. Apresenta como vantagens sua versatilidade, facilidade de processamento, baixo custo e não é tóxico.

O polietileno apresenta diferentes classificações e propriedades, antigamente a classificação do polietileno era relacionada ao método de síntese empregado e a densidade do polímero. Atualmente sua descrição é feita por polietilenos ramificados ou polietilenos lineares [51] [52] [53].

O polietileno apresenta a seguinte classificação: 
- Polietileno de baixa densidade (PEBD ou LDPE) com densidade entre 0,910 a $0,925 \mathrm{~g} / \mathrm{cm}^{3}$;

- Polietileno linear de baixa densidade (PEBD ou LLDPE), com densidade entre 0,910 a $0,925 \mathrm{~g} / \mathrm{cm}^{3}$;

- Polietileno de média densidade (PEMD), com densidade entre 0,926 a $0,940 \mathrm{~g} / \mathrm{cm}^{3}$;

- Polietileno de alta densidade (PEAD ou HDPE), com densidade maior que $0,941 \mathrm{~g} / \mathrm{cm}^{3}$.

A grande diferença entre esses polímeros é a presença de ramificações, produzidas a partir de diferentes mecanismos, na cadeia polimérica. Isso pode influenciar nas propriedades do polímero, cristalinidade e a sua densidade. O catalisador utilizado também é um fator importante, pois é a partir dele que se pode controlar o teor de co-monômeros que são inseridos a cadeia polimérica e a distribuição de ramificações [54].

\subsection{1. \\ Polietileno de alta densidade}

O polietileno de alta densidade (PEAD) é o quarto polímero mais vendido do mundo e o segundo mais reciclado. Tem como característica alta resistência ao impacto e boa resistência a reagentes químicos. O PEAD apresenta baixa quantidade de ramificações, alta linearidade e alto grau de cristalinidade. Também apresenta maior ponto de fusão e limites de resistência e a dureza superiores, quando comparado aos outros tipos de polietileno [53].

No segmento da indústria de transformação de plásticos, o PEAD é utilizado nos processamentos de moldagem por sopro, extrusão e moldagem por injeção [53]. Apresenta diversas aplicações entre as quais se pode salientar a fabricação de engradados para bebidas, baldes, tubulações para líquidos e gases, tanques de combustível, geomembranas, etc.

A alta linearidade do PEAD faz com que a orientação, o alinhamento e o empacotamento das cadeias sejam eficientes. Suas forças intermoleculares (forças de van der Waals) agem mais intensamente, promovendo uma maior cristalinidade, elevando seus pontos de fusão a temperaturas mais altas [55]. 
As propriedades do PEAD podem variar de acordo com sua massa molecular, ramificações, cinética de cristalização e orientação das cadeias. Assim sendo, com o aumento das ramificações, diminui-se a cristalinidade e a resistência à tração [56]. Na Tabela 2.1 são apresentadas as principais propriedades físicas do PEAD.

Tabela 2.1 - Principais propriedades físicas do PEAD [53].

PEAD

\begin{tabular}{llc}
\hline Tipo de polimerização & \multicolumn{2}{c}{ Coordenação } \\
Pressão de polimerização, atm & Baixa & $1-30$ \\
Temperatura reacional, ${ }^{\circ} \mathrm{C}$ & Baixa & $50-100$ \\
Tipo de cadeia & Linear & \\
Densidade, $\mathrm{g} / \mathrm{cm}^{3}$ & Alta & $0,94-0,97$ \\
Cristalinidade, $\%$ & Alta & até 95 \\
Tm, ${ }^{\circ} \mathrm{C}$ & Alta & $130-135$ \\
\hline
\end{tabular}

\section{7.}

\section{Geomembranas de PEAD}

As geomembranas são uma classe de geossintético e têm como aplicação a proteção de solos, sistemas impermeabilizantes, estações de tratamento de efluentes (ETEs) e aterros sanitários urbanos e/ou industriais, engenharia civil e geotécnica, incluindo estradas, aeroportos, ferrovias, barragens, estruturas de retenção, reservatórios, canais, barragens, a proteção das margens e da engenharia costeira [57]. As geomembranas comerciais podem ser fabricadas a partir do policloreto de vinila (PVC), borracha de etileno propileno (EPDM), polipropileno (PP), polietileno de baixa densidade linear (LLDPE) e polietileno de alta densidade (PEAD) [58].

As geomembranas de PEAD, são impermeáveis (vide Figura 2.19), e têm sido utilizadas exclusivamente como impermeabilizante em aterros sanitários (como revestimento do solo), capazes de conter resíduos perigosos de atingir o solo, devido à sua resistência elevada a componentes agressivos. São de fato 
materiais compósitos e têm em sua composição: PEAD (96-97,5\%), negro de fumo (2-3\%) e outros aditivos como, por exemplo, antioxidantes (0,5-1,0\%) [58].

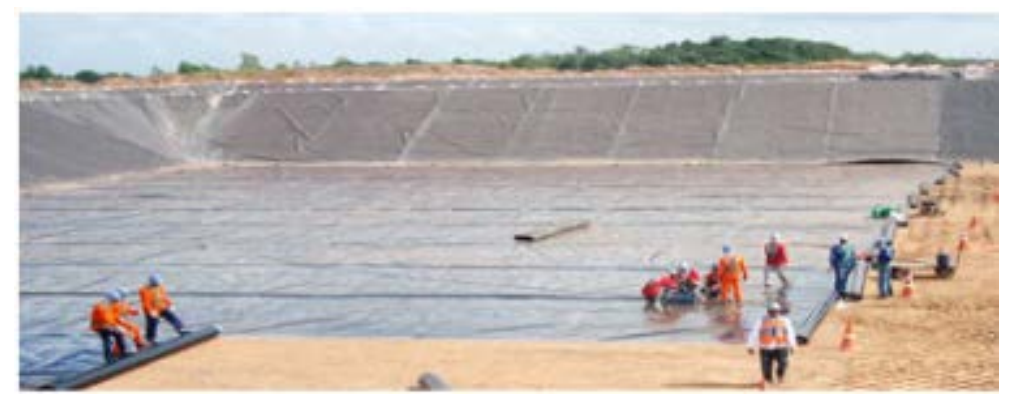

Figura 2.19 - Geomembrana de PEAD [59].

Com a exposição do material a um ambiente de aterro sanitário em longo prazo, as geomembranas sofrem envelhecimento podendo ser afetadas por degradação por inchaço, irradiação ultravioleta ou luz visível (UV-Vis), degradação por extração, degradação biológica e oxidativa [18].

A degradação por inchaço ocorre de forma reversível, as geomembranas adsorvem o líquido aumentando seu volume e quando esse líquido é removido a partir do meio ocorrerá a desadsorção.

$\mathrm{Na}$ degradação por exposição à irradiação UV-Vis, a geomembrana apresenta rachaduras superficiais devido a formação de dobras provocadas pelo alto coeficiente de expansão térmica do PEAD, ocasionando o contato do chorume com o solo, descoloração do material, fragilidade e perda das propriedade mecânicas [58].

A degradação por extração ocasiona a maior fragilidade do material, pois esse processo envolve a extração de um ou mais componentes, como aditivos incorporados ao polímero, devido ao longo tempo de exposição a substâncias químicas e líquidas. A extração de estabilizantes antioxidantes pode deixar o material sem a proteção podendo ocasionar a degradação oxidativa do material [60].

Desta forma, a fim de melhorar as propriedades térmicas e mecânicas do material, este trabalho visa à incorporação de nanofolhas de ferrititanato à matriz de PEAD para a produção de nanocompósitos estruturais com potenciais aplicações em geomembranas. 


\subsection{1. \\ PEAD funcionalizado com anidrido maleico}

Os agentes de acoplamento têm sido usados para melhorar as propriedades mecânicas dos compósitos, via funcionalização química.

A funcionalização é utilizada para tornar duas fases que inicialmente são consideradas incompatíveis, devido às suas características, no caso da matriz polimérica (apolar) e a nanocarga de natureza polar, em compatíveis. Desta forma, através desse tratamento é possível aumentar a molhabilidade (compatibilidade) proporcionando uma maior interface entre as duas fases, alterando a energia interfacial, ou da matriz ou da nanocarga [56].

Uma fraca adesão da nanocarga na matriz polimérica pode resultar em uma dispersão não uniforme e incompatibilidade entre as nanocargas e a matriz polimérica, formando-se vazios ao redor das cargas.

Um dos compatibilizantes largamente utilizados é o polietileno funcionalizado com anidrido maleico (PE-g-MA). O intuito da utilização deste compatilibizante é aumentar a interação da matriz polimérica com as nanocargas, visto que, o PE-g-MA apresenta um grupo funcional de anidrido maleico que aumenta a polaridade do polímero (vide Figura 2.20) e com isso, a afinidade com os grupos hidroxila nas superfícies das nanocargas, mudando parcialmente a natureza hidrobóbica do PEAD para hidrofílica [61].

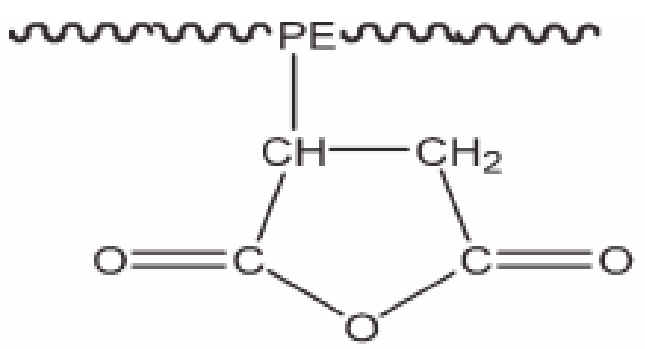

Figura 2.20 - PE grafitizado com anidrido maleico. 
Brito, et al. [9] relataram o uso de argilas organofílicas e do polietileno de alta densidade com a inserção de agente compatibilizante PE-g-MA e observaram uma melhoria na estabilidade térmica e mecânica do PEAD, assim como a formação de nanocompósitos parcialmente esfoliados. Verificou-se também um aumento da adesão entre a matriz-reforço, que foi avaliada através dos ensaios mecânicos.

\section{8 . Nanocompósitos poliméricos reforçados com nanofolhas de titanatos lepidocrocíticos}

A esfoliação de titanatos lamelares, tipo lepidocrocita, é uma forte motivação para a preparação de nanocompósitos poliméricos, onde o principal desafio é a dispersão das nanofolhas de titanato no polímero. Porém, poucos estudos têm sido descritos na literatura, especialmente visando a utilização destas nanofolhas como reforço de matrizes poliméricas para aplicações estruturais. [26]. Entre os nanocompósitos fabricados e relatados na literatura, pode se destacar a preparação de nanocompósitos intercalados, de matrizes tais como óxido de polietileno (PEO) e polivinilpirrolidona (PVP) com folhas de $\mathrm{H}_{\mathrm{x}} \mathrm{Ti}_{2}$ $\mathrm{x} / 4 \square_{\mathrm{x} / 4} \mathrm{O}_{4}\left(\square=\right.$ vacância de Ti), previamente esfoliadas com TBA ${ }^{+}$[62]. Okamoto et al. [63] prepararam com sucesso nanocompósitos de matriz biodegradável: ácido polilático (PLA), mediante extrusão, utilizando como cargas $\mathrm{H}_{\mathrm{x}} \mathrm{Ti}_{2-\mathrm{x} / 4} \square_{\mathrm{x} / 4} \mathrm{O}_{4}$ modificadas com um cátion de alquilamônio. Um processo similar foi realizado pelo mesmo grupo de pesquisadores para fabricar nanocompósitos de poli(fluoreto de vinilideno) com nanofolhas de $\mathrm{H}_{\mathrm{x}} \mathrm{Ti}_{2-\mathrm{x} / 4} \square_{\mathrm{x} / 4} \mathrm{O}_{4}$ [64].

Em relação à utilização de nanofolhas de ferrititanato como nanocargas de compósitos poliméricos, o único trabalho descrito na literatura foi realizado por Resende [18]. Nesse caso, nanofolhas de ferrititanato sódicas foram utilizadas como reforço de nanocompósitos de PEAD. Foram utilizadas nanofolhas sódicas virgens, nanofolhas sódicas funcionalizadas com viniltrimetoxisilano (VTMS) tanto por meio da extrusão normal como através da extrusão reativa, sendo relatada também, pela primeira vez, a utilização do sal quaternário de amônio 2C18 na intercalação nas galerias das nanofolhas sódicas de ferrititanato. Foram empregadas as seguintes porcentagens de carga: 0,5 - 2 - 5 \% p. 
Os resultados mais relevantes dessa pesquisa estão resumidos na Figura 2.21. Os compósitos fabricados com $2 \%$ p de nanofolhas funcionalizadas com VTMS mostraram um incremento no módulo de Young de 13,6\% em relação ao PEAD puro. Já para a tensão de escoamento o maior incremento foi observado nos compósitos reforçados com $0,5 \%$ de nanofolhas sódicas modificadas com VTMS e preparados por extrusão reativa e com 2\% p VTMS. Além disso, o compósito fabricado com 2\% de nanofolhas funcionalizadas VTMS apresentou uma redução no CET de aproximadamente 3,7\%. Porém as nanofolhas intercaladas com 2C18 não levaram a resultados favoráveis, conduzindo a um decréscimo nas propriedades mecânicas, como se pode verificar nas Figuras 2.21 e inclusive levando a um incremento do CET da matriz como indicado na Figura 2.22 .

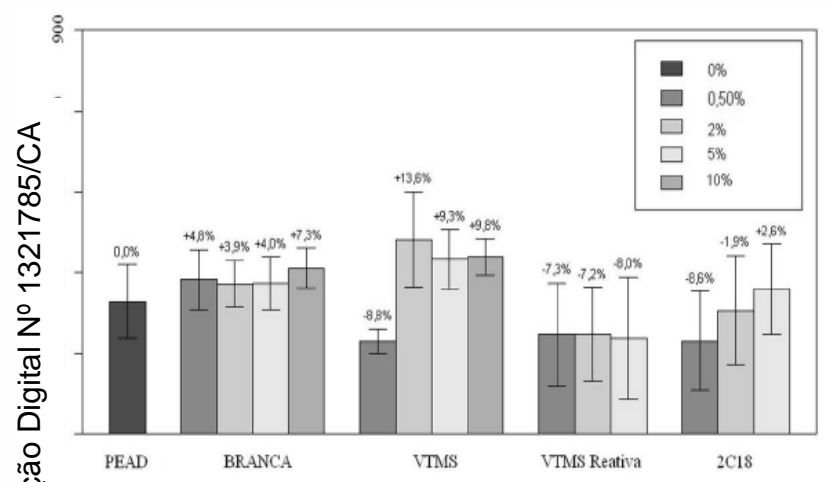

(a)

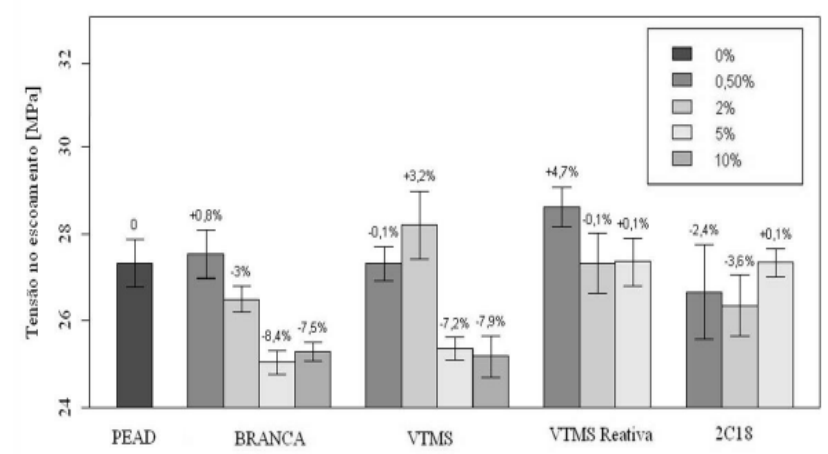

(b)

Figura 2.21 - Ensaio de tração dos nanocompósitos (a) Módulo de elasticidade e (b) Tensão de escoamento [18].

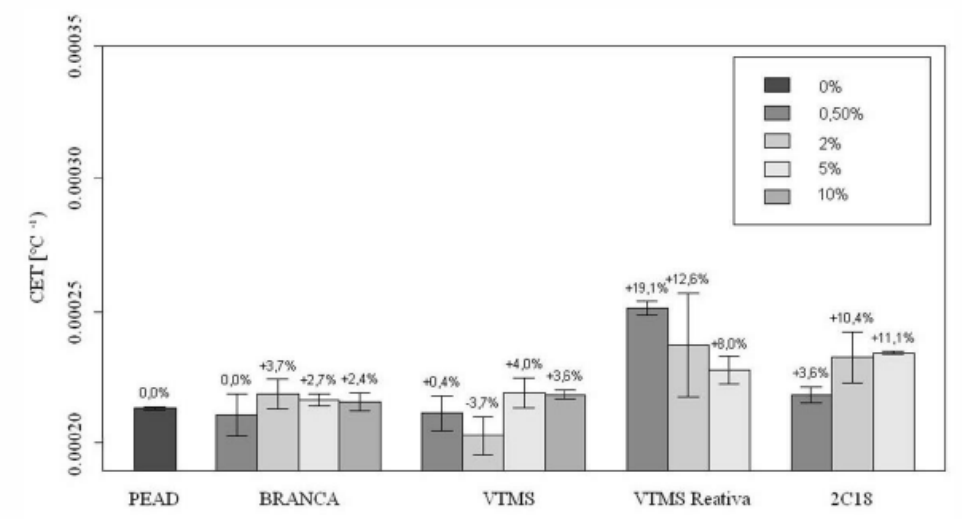

Figura 2.22 - Coeficiente de expansão térmica dos nanocompósitos [18]. 
É importante notar, também, que a temperatura de degradação dos compósitos não foi afetada significativamente pela incorporação dos distintos tipos de nanofolhas de ferrititanato. No entanto, um incremento significativo (de aproximadamente $13,3 \%$ ) no grau de cristalinidade foi observado para os compósitos reforçados com 2 \%p de nanofolhas funcionalizadas com VTMS, enquanto aqueles compósitos fabricados com nanofolhas organofilizadas com 2C18, apresentaram um decréscimo de 19,3 \% no grau de cristalinidade, o qual explica o decréscimo no módulo de Young [18].

Neste contexto, o presente trabalho relata pela primeira vez a utilização do sal quaternário de amônio 2C18 para a esfoliação das nanofolhas de ferrititanato protonizadas e a sua aplicação como reforço para a fabricação de nanocompósitos à base de PEAD. A diferença principal com o trabalho previamente descrito por Resende [18] está na utilização de nanofolhas de titanato protonizadas e não sódicas, que é fundamental para a obtenção de estruturas completamente esfoliadas em lugar de intercaladas, como será posteriormente justificado.

De fato, a importância da esfoliação com o sal 2C18 reside no desenvolvimento de um nanomaterial híbrido orgânico-inorgânico, capaz de ser utilizado como nanocarga com alta afinidade química com os polímeros hidrofóbicos sendo, também, capaz de suportar temperaturas de processamento, com aproximadamente $190^{\circ} \mathrm{C}$ no caso do PEAD, além de temperaturas mais altas ainda, como no caso das poli-amidas [39] e das policetonas de 420 e $430{ }^{\circ} \mathrm{C}$, respectivamente, conforme será demonstrado na seção 5.1.6. 


\section{3 \\ Objetivos}

\section{1.}

\section{Objetivo geral}

Desenvolver procedimento para organofilizar e esfoliar nanofolhas de ferrititanato protonizadas com sal quaternário de amônio (2C18) em monofolhas subnanométricas, visando utilizá-las como reforço de nanocompósitos de PEAD para melhorar as propriedades térmicas e mecânicas desta matriz, assim como avaliar o efeito de PE-g-MA nas propriedades dos nanocompósitos fabricados.

\section{2.}

\section{Objetivos específicos}

- Sintetizar nanofolhas de ferrititanato com diferentes teores de sódio e caracterizá-las através de várias técnicas experimentais.

- Organofilizar e esfoliar as nanofolhas de ferrititanato com o sal quaternário de amônio (2C18).

- Avaliar o efeito do teor de sódio na formação de nanoestruturas esfoliadas/intercaladas com o sal 2C18.

- Obter nanocompósitos de matriz de PEAD reforçados com nanofolhas virgens protonizadas e nanohíbridos, como também nanocompósitos de matriz PEAD com adição de um agente compatibilizante (PE-g-MA) por meio dos processos de microextrusão e microinjeção, utilizando distintas porcentagens de nanocargas.

- Caracterizar os nanocompósitos obtidos através da avaliação de suas propriedades mecânicas, térmicas e microestruturais. 


\section{4 \\ Materiais e Métodos}

\section{1.}

\section{Síntese das nanofolhas de ferrititanato de partida}

A partir do precursor mineral à base de areia ilmenítica, as nanofolhas foram sintetizadas via rota hidrotérmica alcalina utilizando o equipamento High Preactor BR-500 (Berghof) na Figura 4.1, sob agitação e temperatura controlada como relatado no procedimento desenvolvido por Jardim et al [5]. Essa autoclave possui um vaso interno de teflon permitindo a utilização de um reagente altamente alcalino.

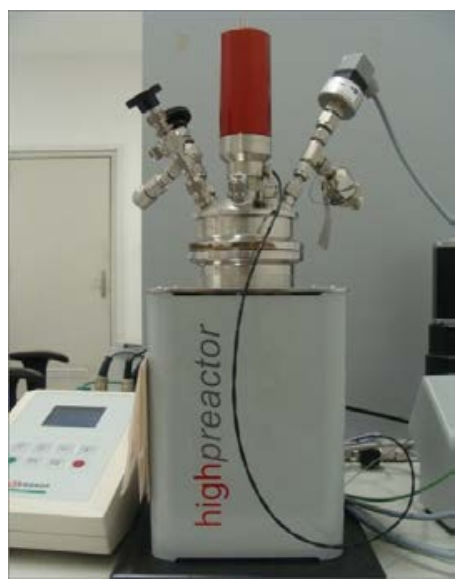

Figura 4.1 - Autoclave de alta pressão BR-500.

Inicialmente, vários lotes de 4g de areia precursora foram moídos por 60 minutos no moinho de alto impacto com bolas de carbeto de tungstênio, SPEX 8000-115 Mixer Mill.

A síntese das nanofolhas foi realizada aquecendo-se uma mistura de 8,75g de areia ilmenítica, previamente moída, em $350 \mathrm{~mL}$ de solução de $\mathrm{NaOH} 10$ mol.L ${ }^{-1}$, à temperatura de $130^{\circ} \mathrm{C}$ por $72 \mathrm{~h}$ sob agitação de $320 \mathrm{rpm}$. As condições de síntese foram monitoradas através do programa de software que o equipamento possui.

Após o procedimento da síntese das nanofolhas, iniciou-se o processo de lavagem. Para obtenção de dois materiais com diferentes teores de sódio sendo um 
com alto teor de sódio e o outro material com baixo teor de sódio, isto é protonizado, os materiais passaram por diferentes processos de lavagem.

Para obtenção do material com alto teor de sódio foi feito lavagem do sólido, com água destilada, até alcançar $\mathrm{pH}$ 9,0, para medição do $\mathrm{pH}$ da água de lavagem utilizou-se o pHmetro SP1800.

Para sintetizar a amostra com baixo teor de sódio (material protonizado) foi realizado um procedimento de lavagem ácida nas nanofolhas sódicas, por um método de troca iônica rápido com ácido, no qual a reação ocorre com o ajuste do pH até alcançar pH 1,5 com solução de $\mathrm{HCl} 1 \mathrm{~mol} . \mathrm{L}^{-1}$ e é mantido sob agitação magnética por 1 hora, à temperatura ambiente. Esse procedimento foi repetido uma vez.

Após isso, o material foi centrifugado e levado à estufa da marca Labconte, modelo $440-\mathrm{D}$, e mantido por $5 \mathrm{~h}$ à temperatura de $100^{\circ} \mathrm{C}$.

Desta forma, obtiveram-se duas amostras: nanofolhas protonizadas ( $\mathrm{pH}$ 1,5, pLTs) e nanofolhas com alto teor de sódio (pH 9,0, NaLTs).

O esquema do procedimento experimental utilizado está apresentado na Figura 4.2.Figura 4.2 - Esquema experimental utilizado para síntese das nanofolhas. 


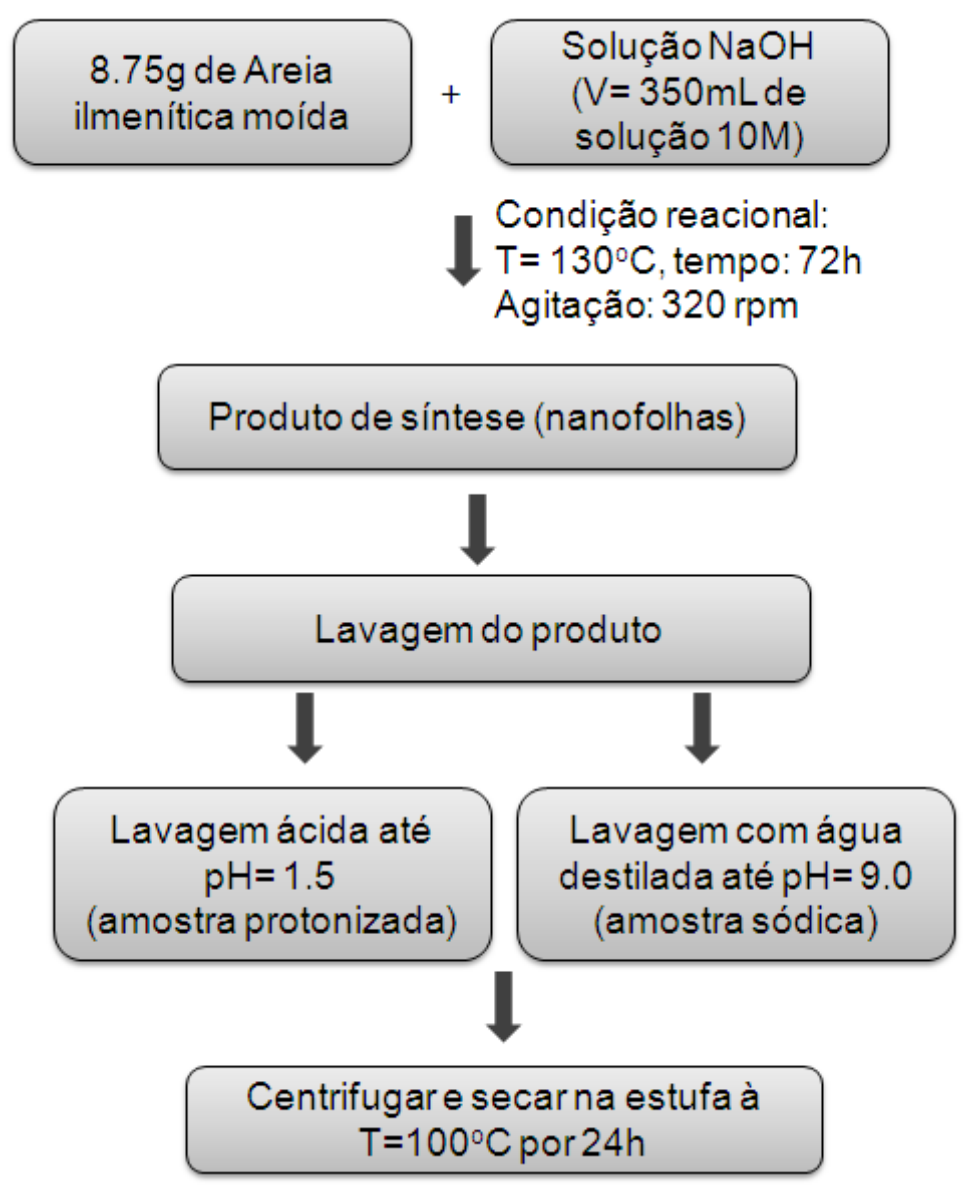

Figura 4.2 - Esquema experimental utilizado para síntese das nanofolhas.

\section{2.}

\section{Capacidade de Troca Catiônica (CTC)}

Para realizar a organofilização dos materiais protonizado (pLTs) e sódico (NaLTs), nos quais é inserido um cátion quaternário de amônio $\left(2 \mathrm{C} 18^{+}\right)$entre as camadas das nanofolhas, é importante avaliar o CTC das amostras.

Este ensaio foi realizado, seguindo a norma ASTM C837-99 com o objetivo de se verificar a capacidade das nanofolhas de trocar cátions. Esse dado é importante para calcular a quantidade de sal (2C18) que é necessário para a intercalação e/ou esfoliação das nanofolhas.

O método usado foi o da saturação com azul de metileno $\left[\mathrm{C}_{16} \mathrm{H}_{18} \mathrm{~N}_{3} \mathrm{SCl}\left(3 \mathrm{H}_{2} \mathrm{O}\right)\right]$ (vide Figura 4.3), pelo método da mancha. Este método baseia-se no fato do azul de metileno quando em solução aquosa e em contato com materiais de superfície carregadas negativamente, ter as suas moléculas rapidamente adsorvidas, mediante um mecanismo de troca iônica irreversível. 
<smiles>CN(C)c1ccc2nc3ccc(=[N+](C)C)cc-3sc2c1</smiles>

Figura 4.3 - Estrutura do cátion do corante azul de metileno.

Primeiramente foi feito a secagem das nanofolhas seguindo o procedimento ASTM C324, no qual seca-se na estufa $2,5 \mathrm{~g}$ de nanofolhas à temperatura $100^{\circ} \mathrm{C}$ por $24 \mathrm{~h}$.

Em seguida, seguindo a ASTM C837-99, prepara-se uma suspensão com 2,0g de nanofolhas em 300 mL de água destilada sob agitação magnética. Verifica-se o pH da dispersão e deve -se ajustar o pH na faixa de 2,5-3,8, com $\mathrm{H}_{2} \mathrm{SO}_{4}(0,1 \mathrm{~N})$. Continua-se agitando após o ajuste e verifica-se o $\mathrm{pH}$ novamente após 10 minutos. Foi feito o ajuste novamente até alcançar o pH desejado.

Mantendo a dispersão sob agitação, enche-se a bureta com uma solução de azul de metileno $(0,01 \mathrm{M})$, adiciona-se $5 \mathrm{~mL}$ de solução à dispersão e agita-se por 1-2 minutos.

Coleta-se, com um bastão de vidro, uma gota da suspensão, e pinga-se no papel de filtro (vide Figura 4.4). Observa-se a aparência da gota no papel. Esse procedimento foi realizado até aparecer uma coloração azul clara ao redor da gota, neste momento suspende-se o procedimento.

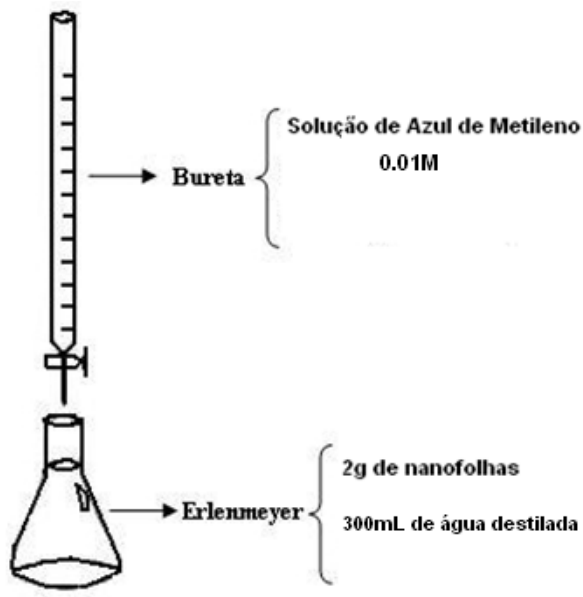

(a)

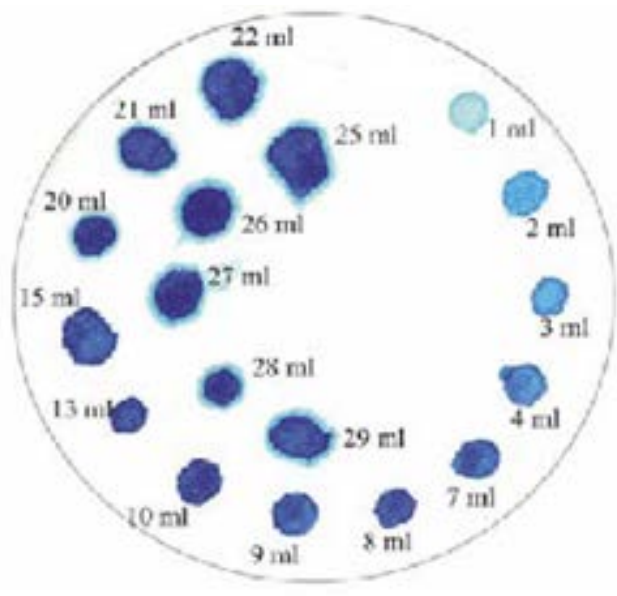

(b)

Figura 4.4 - Procedimento de titulação com azul de metileno, (b) modelo de aparecimento da coloração azul claro ao redor da gota [65] . 
Para o cálculo da capacidade de troca catiônica das amostras pLTs e NaLTs foi utilizado o cálculo [66]:

$$
C T C=\frac{V \times C \times 100}{M}
$$

$\mathrm{CTC}=\mathrm{meq} / 100 \mathrm{~g}$

$\mathrm{V}=$ Volume da solução de azul de metileno gasto $(\mathrm{mL})$

$\mathrm{C}=$ Concentração da solução de azul de metileno (meq/mL)

$\mathrm{M}=$ Massa de nanofolhas (g)

Desta forma para a amostra NaLTs, o volume gasto de $9 \mathrm{~mL}$ de solução de azul de metileno resulta na CTC de 4,5 meq/100g de nanofolhas e para a amostra pLTs obteve-se CTC= 2,1 meq/100g de nanofolhas.

\section{3.}

\section{Organofilização das nanofolhas}

A organofilização das nanofolhas com diferentes teores de sódio foi realizado com o cloreto de dimetildioctadecilamônio (2C18), com fórmula química $\mathrm{C} 38 \mathrm{H} 80 \mathrm{NCl}$ e pureza $\geq 97 \%$, fornecido pela Sigma-Aldrich.

O procedimento de organofilização das nanofolhas de titanato contendo diferentes teores de sódio foi realizado dispersando, inicialmente, 1,0g das nanofolhas sintetizadas em $50 \mathrm{~mL}$ de água deionizada à temperatura $60^{\circ} \mathrm{C}$ por 1 hora sob agitação magnética. Em outro bécher, dissolveu-se 1,15g de 2C18 em 50 $\mathrm{mL}$ de água deionizada à temperatura de $60^{\circ} \mathrm{C}$. Em seguida, a dispersão e a solução de 2C18 foram misturadas e mantidas sob agitação magnética por 1h à $60^{\circ} \mathrm{C}$.

A reação de organofilização prosseguiu sob agitação no dispersor UltraTurrax Ika, modelo T25, por 6h à temperatura de $60^{\circ} \mathrm{C}$ ( vide Figura 4.5). Após a mistura, a solução é retirada da agitação e mantida em repouso por 5 minutos à temperatura ambiente. Em seguida, é separado o sobrenadante do resíduo no fundo do bécher e as duas partes são lavadas com água deionizada, na qual foram testadas duas temperaturas da água para lavagem, sendo uma à temperatura $60^{\circ} \mathrm{C} \mathrm{e}$ outra à temperatura ambiente, removendo assim todo o excesso de sal e centrifugada por 20 minutos a $6000 \mathrm{rpm}$. Esse procedimento de lavagem é repetido 3 vezes. Por fim, a amostra é seca à temperatura ambiente na capela com 
exaustão por 24 h. O esquema do procedimento experimental utilizado está apresentado na Figura 4.6.

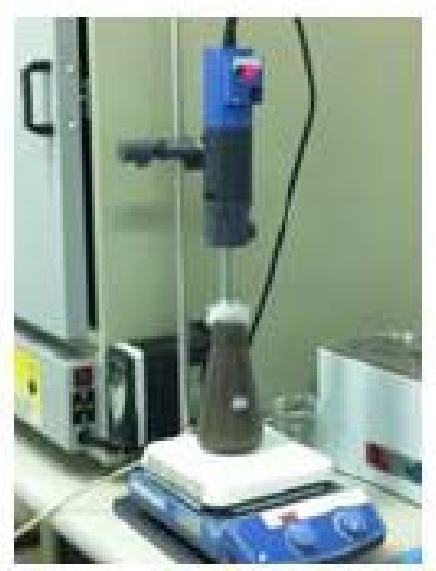

Figura 4.5 - Processo de esfoliação das nanofolhas, Ultra-Turrax Ika, modelo T25.

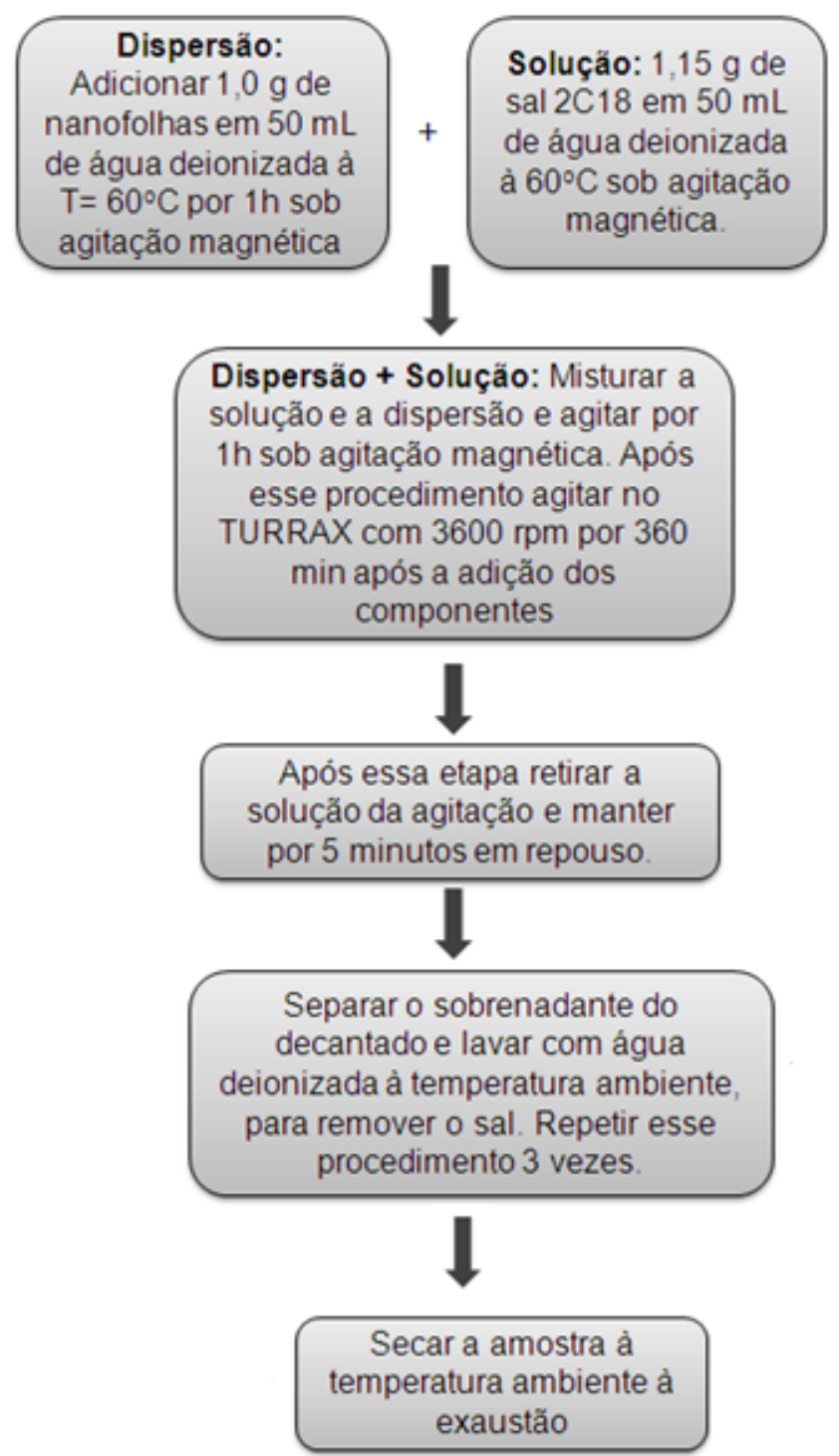

Figura 4.6 - Esquema procedimento de esfoliação das nanofolhas. 


\section{4. Caracterização das nanofolhas virgens e organofilizadas}

As nanofolhas virgens sintetizadas denominadas pLTs e NaLTs, com baixo e alto teor de sódio respectivamente, e as amostras organofilizadas pLTs-0-2C18 e NaLTs-o-2C18 foram caracterizadas por diversas técnicas a fim de se compreender a influência do sódio nas nanofolhas e do modificador orgânico 2C18 sobre o processo de organofilização. A partir das caracterizações das diferentes nanofolhas foi feito a escolha do melhor material para fabricação dos nanocompósitos.

\subsection{1.}

\section{Fotometria de chama}

Essa técnica foi utilizada a fim de obter o teor de sódio nas amostras virgens pLTs e NaLTs virgens. As amostras foram dissolvidas em $\mathrm{H}_{2} \mathrm{SO}_{4}$ concentrado, em seguida diluídas para a faixa apropriada de calibração e analisadas utilizando um espectrômetro Micronal B462.

\subsection{2. \\ Difração de raios $X(D R X)$}

A formação das nanofolhas de titanatos e a esfoliação das nanofolhas pelo processo de organofilização, foi verificada através da técnica de DRX, pelo método do pó. Para isso, foi utilizado um difratômetro do fabricante Bruker, modelo D8 Discover, operando com radiação CuKa a 40kV e $40 \mathrm{~mA}$, varrendo o ângulo $2 \theta$ na faixa de 2 a $40^{\circ}$ com um passo de $0,02^{\circ}$ ( 1 s por passo).

\subsection{3.}

\section{Espalhamento de raios-X a baixo ângulo (SAXS)}

Essa técnica foi utilizada para verificar a obtenção de uma material esfoliado, após a inserção do sal quaternário de amônio 2C18, nas amostras pLTso-2C18 e NaLTs-o-2C18. A amostra pLTs-o-2C18 e NaLTs-o-2C18 foram analisadas no equipamento de SAXS modelo nanostar do fabricante Bruker, 
equipado com detector Vantec 2000, operando com radiação CuKa a $40 \mathrm{kV}$ e 35 $\mathrm{mA}$.

\subsection{4. \\ Microscopia eletrônica de transmissão (MET)}

A formação das nanofolhas, após a síntese via rota hidrotérmica alcalina, e a esfoliação em monofolhas foram avaliadas por MET. As amostras foram previamente dispersas em álcool isopropílico e mantidas no ultra-som por $30 \mathrm{~min}$ para dispersão. Três gotas desta dispersão foram depositadas sobre uma grade de cobre, recoberta de um filme furado de carbono. As imagens foram obtidas em um microscópio eletrônico de transmissão, JEOL 2010, equipado com uma câmera CCD da Gatan, operando numa voltagem de 200 kV.

Uma análise química elementar por espectroscopia de raios-X por dispersão de energia (EDS) foi realizada.

\subsection{5. \\ Espectroscopia no infravermelho por transformada de Fourier (FTIR)}

Através dessa técnica foi possível identificar os grupos funcionais orgânicos na superfície das nanofolhas modificadas através da técnica de organofilização.

Com este objetivo, os espectros de FTIR das nanofolhas virgens, pLTs, NaLTs, pLTs-o-2C18 e NaLTs-o-2C18 foram obtidos num equipamento Perkin Elmer, modelo Spectrum 400, com uma resolução de $4 \mathrm{~cm}^{-1}$ e 16 scans.

Para a análise as amostras foram secas a $80^{\circ} \mathrm{C}$ durante $12 \mathrm{~h}$ e misturadas com pó fino de $\mathrm{KBr}$ (previamente seco nas mesmas condições). A mistura foi prensada. Foi investigada a faixa do espectro compreendida entre 500 e $4000 \mathrm{~cm}^{-1}$, que corresponde à região do infravermelho médio.

\subsection{6.}

\section{Medições de área superficial específica}

Essa técnica foi utilizada para avaliar a área superficial específica das nanofolhas. Desta forma, é possível ver a influência da modificação química sobre este parâmetro de superfície. Deste modo, a área superficial específica das 
amostras foi medida por adsorção de $\mathrm{N}_{2}$ a $-196^{\circ} \mathrm{C}$ no equipamento TriStar II 3020 aplicando a equação clássica de BET. Na realização da análise foram utilizadas massas de amostra de aproximadamente $350 \mathrm{mg}$. As amostras foram pré-tratadas à temperatura de $100{ }^{\circ} \mathrm{C}$ sob vácuo.

\subsection{7. \\ Análise termogravimétrica (TGA)}

A análise foi realizada num analisador térmico simultâneo no equipamento modelo STA 6000, do fabricante Perkin Elmer. As amostras foram colocadas em cadinho de alumina na faixa de temperatura de $25^{\circ} \mathrm{C}$ a $650^{\circ} \mathrm{C}$, com taxa de aquecimento de $10^{\circ} \mathrm{Cmin}^{-1}$, em atmosfera de $\mathrm{N}_{2}$ com vazão de $50 \mathrm{mLmim}^{-1}$.

Essa técnica é utilizada para verificar a perda de massa em função da temperatura. Desta forma, pode-se verificar a perda de massa nas amostras de nanofolhas atribuída a perda de água, grupos hidroxila e do sal.

\subsection{8. \\ Microscopia de Força Atômica (AFM)}

A análise foi realizada no equipamento Bruker Multimode-8 equipado com JV-scanner (125x125x5 $\mu \mathrm{m})$.

Sonda OTESPA (constante da mola $\sim 42 \mathrm{~N} / \mathrm{m}$ ) foi usado para adquirir imagens no modo. As amostras foram preparadas por drop-casting $20 \mu \mathrm{l}$ de uma dispersão aquosa de nanofolhas esfoliadas em uma pastilha de silício de uma gota. Após a secagem em ar imagens 2D e 3D AFM foram registrados em uma taxa de baixa resolução.

\section{5.}

\section{Fabricação dos nanocompósitos}

Na fabricação dos nanocompósitos foi utilizado como matriz polimérica o Polietileno de alta densidade, com índice de fluidez 7,3 g10 $\mathrm{mim}^{-1}$ e densidade $0,960 \mathrm{gcm}^{-3}$, fornecido pela empresa Braskem.

Os corpos de prova, para as caracterizações de ensaio de tração, dilatometria e TG/DSC, foram obtidos na microextrusora de dupla rosca co- 
rotante DSM Xplore 5cc Microcompounder e em seguida levado para o molde da microinjetora DSM Xplore 5,5cc equipada com um molde de aço inoxidável.

Os nanocompósitos obtidos foram:

- PEAD puro

- PEAD reforçado com pLTs virgens 1,0- 2,0 - 4,0 \%p

- PEAD reforçado com pLTs esfoliadas 1,0- 2,0 - 4,0 \%p

Finalmente, foi fabricada uma série utilizando como compatibilizante PE-g-MA fornecido pelo Sigma Aldrich, que possui um teor de anidrido maléico enxerto de 2,7-3,1 \% p. Assim sendo, foi adicionado 5 \%p de PE-g-MA à matriz de PEAD para obter a seguinte série:

- PEAD com 5\% PE-g-MA reforçado com pLTs virgem 1,0- 2,0 - 4,0 $\% p$

\subsection{1.}

\section{Condições de processamento}

Os parâmetros de processamento dos nanocompósitos definidos para a microextrusora foram: temperaturas de aquecimento do barril, velocidade de rotação das roscas e o tempo de residência do material alimentado no barril.

- Temperatura de aquecimento do barril nas três zonas: $190^{\circ} \mathrm{C}$

- Velocidade de rotação das roscas: 50 rpm por 5 minutos

- Velocidade de rotação das roscas: 100 rpm por 5 minutos

- Tempo total de residência do material no barril: 10 minutos

Na microinjetora os parâmetros ajustados foram: Temperatura do melt, Temperatura de injeção e pressão de injeção.

- Temperatura do melt: $185^{\circ} \mathrm{C}$

- Temperatura de injeção: $80^{\circ} \mathrm{C}$

- Pressão de injeção: 7 bar

Primeiramente todos os parâmetros da microextrusão e microinjetora foram ajustados, como descrito acima. Para a fabricação dos nanocompósitos o polímero na forma de pellets e o reforço foram inseridos na microextrusora simultaneamente através de um funil. $O$ material foi mantido dentro do equipamento, no qual é fundido e misturado pela rotação das duas roscas durante 
10 minutos. Após esse procedimento, o material foi coletado da microextrusora, através da peça Melt da injetora, e inserido na microinjetora. Um pistão empurra o material que está dentro do Melt para encher a cavidade do molde previamente aquecido. O molde é removido da injetora e o corpo de prova é obtido.

\section{6.}

\section{Caracterização dos nanocompósitos}

\subsection{1. \\ Ensaio de tração}

O ensaio de tração foi realizado a fim de obter as curvas tensão-deformação, tensão na ruptura, deformação no escoamento, deformação na ruptura e módulo de elasticidade, dos corpos de prova fabricados na microextrusora e microinjetora. Os ensaios de tração foram realizados numa máquina universal de ensaio do fabricante Oswaldo Filizola, modelo AME-2KN (200kgf), de acordo com a norma ASTM D638.

Foram realizadas medições da largura e espessura dos corpos de prova, a fim de medir a seção útil dos corpos de prova e determinar a área transversal para os cálculos de tensão. As dimensões obtidas dos corpos de prova, tipo gravatinha, foram:

- Espessura do corpo de prova $3 \mathrm{~mm}$;

- Largura na parte mais fina do corpo de prova: 3,1mm;

- Comprimento total do corpo de prova: 61,3mm;

- Comprimento área útil: 27,1 mm

- Velocidade do ensaio: $50 \mathrm{~mm} / \mathrm{min}$

Para cada amostra de nanocompósito, de matriz PEAD reforçados com pLTs, pLTs-o-2C18 (material esfoliado) e pLTs virgem com agente de acoplamento PE-g-MA foram fabricados 6 corpos de prova para o ensaio de tração. 


\subsection{2.}

\section{Análise térmica simultânea (TGA/DSC)}

A análise dos nanocompósitos foi realizada num analisador térmico simultâneo do fabricante Perkin Elmer, modelo STA 6000. Essa técnica fornece os resultados de Termogravimetria (TG) e de calorimetria diferencial de varredura (DSC).

As amostras foram colocadas num cadinho de alumina na faixa de temperatura de $25^{\circ} \mathrm{C}$ a $650^{\circ} \mathrm{C}$, com taxa de aquecimento de $10^{\circ} \mathrm{C} \cdot \mathrm{min}^{1}$, em atmosfera de $\mathrm{N}_{2}$ com vazão de $50 \mathrm{~mL} \cdot \mathrm{mim}^{1}$, a massa de amostra utilizada foi aproximadamente $2 \mathrm{mg}$.

Essa análise nos fornece a perda de massa em função da temperatura, com o objetivo de verificar a estabilidade térmica dos nanocompósitos.

\subsection{3.}

\section{Dilatometria}

Essa técnica nos fornece o coeficiente de expansão térmica (CET) dos nanocompósitos fabricados. Para essa análise foram fabricados 3 corpos de prova para cada amostra.

A dilatometria dos nanocompósitos, com dimensões 3,1 x 3,2 x $10 \mathrm{~mm} \pm$ 20\%, foi realizada no equipamento modelo DIL 402C, do fabricante NETZSCH, com o porta-amostra de sílica fundida, na faixa de temperatura de $25^{\circ} \mathrm{C}$ a $100^{\circ} \mathrm{C}$ ao ar e com taxa de aquecimento $2^{\circ} \mathrm{Cmim}^{-1}$.

Uma isoterma a $30^{\circ} \mathrm{C}$ por 25 min foi definida, a fim de obter o início da medição sem influências externas e com a mesma temperatura para todas as análises. 
5

\section{Resultados e Discussão}

\section{1.}

\section{Caracterização das nanofolhas virgens e organofilizadas}

\subsection{1. \\ Fotometria de chama}

Os resultados obtidos da análise de fotometria de chama estão apresentados na Tabela 5.1 - . A amostra protonizada (pLTs) passou por um tratamento de troca iônica pelo procedimento de lavagem ácida, com $\mathrm{HCl} 1 \mathrm{M}$ durante $1 \mathrm{~h}$, dentro do $\mathrm{pH}$ 1,5, enquanto a amostra NaLTs foi lavada com água destilada até pH 9,0, conforme o procedimento descrito no item 4.1.

Tabela 5.1 - Teores de $\mathrm{Na}^{+}$das amostras sintetizadas via rota hidrotérmica alcalina com diferentes tratamentos de lavagem, comparados com o teor no precursor mineral (areia ilmenítica).

\begin{tabular}{|c|c|}
\hline Amostra & Teor de $\mathbf{~ N a}^{+}$(\%) \\
\hline Areia ilmenítica precursora & 0,03 \\
\hline pLTs & 0,08 \\
\hline NaLTs & 4,89 \\
\hline
\end{tabular}

A partir desses resultados pode-se confirmar uma troca iônica eficiente e rápida através da lavagem ácida, para a remoção completa do sódio na amostra protonizada (pLTs), já que para titanatos lamelares, de estrutura lepidocrocita, e de dimensões laterais submicrônicas este processo de troca ácida é comumente efetuada por completo apenas após vários dias de processamento seguidos [33] [34]. 


\subsection{2. \\ Difração de raios-X (DRX)}

Primeiramente, foi realizada a caracterização por DRX das amostras sintetizadas via rota hidrotérmica alcalina, para identificar as linhas de difração que denotam a formação das nanofolhas de ferrititanato com estrutura do tipo lepidocrocita.

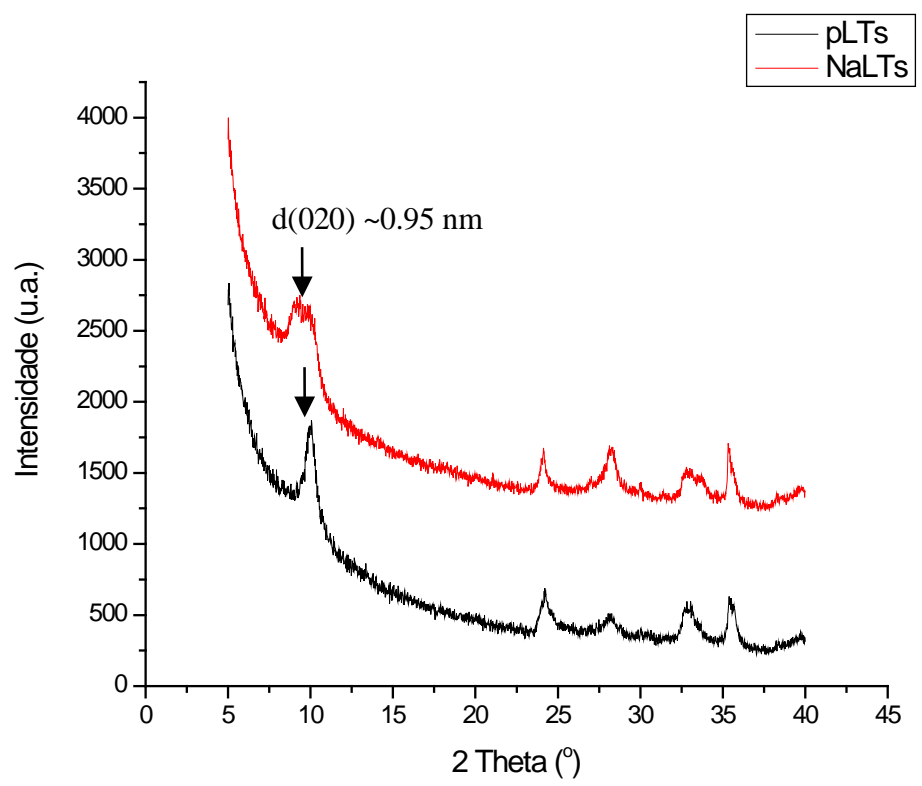

Figura 5.1 - Difratograma das amostras pLTs e NaLTs.

Na Figura 5.1 pode-se verificar em ambos os casos que há a formação das nanofolhas, devido à presença dos picos característicos em $2 \theta=10,24,28,34$, $38^{\circ}$ previamente descritos na literatura [20]. Jardim et al. [5] sugeriram a fórmula química das nanofolhas do tipo NaLTs como sendo $\mathrm{Na}_{\mathrm{x}-\mathrm{y}} \mathrm{H}_{\mathrm{y}} \mathrm{Ti}_{2-\mathrm{x}} \mathrm{Fe}_{\mathrm{x}} \mathrm{O}_{4} \cdot \mathrm{nH}_{2} \mathrm{O}$, visto que as mesmas foram preparadas em ambiente aquoso e submetidas a lavagem com água destilada, ocorrendo uma troca limitada dos íons de $\mathrm{Na}^{+}$por $\mathrm{H}^{+}$ nas galerias das nanofolhas de ferrititanato.

As amostras de nanofolhas virgens NaLTs e pLTs apresentaram linha de difração largas com quase mesmo espaçamento interlamelar de $\sim 0,95 \mathrm{~nm}$, que corresponde à distância interplanar (020), visto que os dois materiais foram sintetizados em condições de abundância de água.

As camadas densas de ferrititanato das nanofolhas, compostas por octaedros ligados pelas arestas, apresentam espessura de 0,75 nm [67]; desta forma é 
possível afirmar que o espaçamento das galerias tem $\sim 0,2 \mathrm{~nm}$ de espessura, como ilustrado esquematicamente na Figura 5.2.

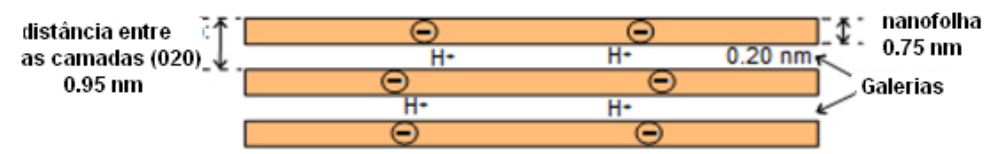

Figura 5.2 - Esquema ilustrativo das dimensões das nanofolhas protonizadas ao longo do eixo $b$.

Segundo os difratogramas de DRX e utilizando o método de refinamento de LeBail, Jardim et al. [5] identificaram três fases tipo lepidocrocita nas nanofolhas sintetizadas a partir de areias ilmeníticas com teor de sódio intermediário ( $\mathrm{pH}$ 7,0

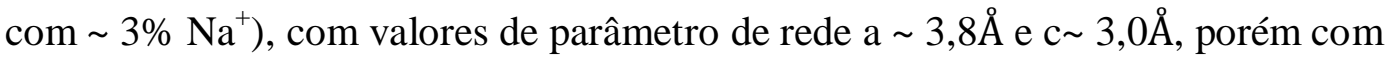
diferentes espaçamentos interlamelares (b/2) que podem variar de 0,9 até 1,1 nm, Desta forma, os espaçamentos interlamelares obtidos a partir dos difratogramas da Figura 5.1 condizem com os relatados pelos autores.

Portanto, atribui-se as nanofolhas com menores espaçamentos interlamelares a presença predominante dos íons $\mathrm{Na}^{+} / \mathrm{H}^{+}$, enquanto maiores espaçamentos interlamelares indicam a incorporação de moléculas de água somadas aos íons $\mathrm{Na}^{+} / \mathrm{H}^{+}$, visto que o diâmetro da molécula de água é $0,28 \mathrm{~nm}$.

Na Figura 5.3 estão apresentados os difratogramas tanto das nanofolhas virgens com diferentes teores de sódio (pLTs e NaLTs), como das esfoliadas (pLTs-o-2C18) e intercaladas (NaLTs-o-2C18). A esfoliação total na pLTs-o2C18 foi sugerida com base na ausência da linha de difração no ângulo $2 \theta=10^{\circ}$, que está presente nos outros difratogramas das amostras de pLTs, NaLTs e NaLTs-o-2C18 e é relacionada com a distância interplanar (020), ou seja na direção de empilhamento de lamelas. 


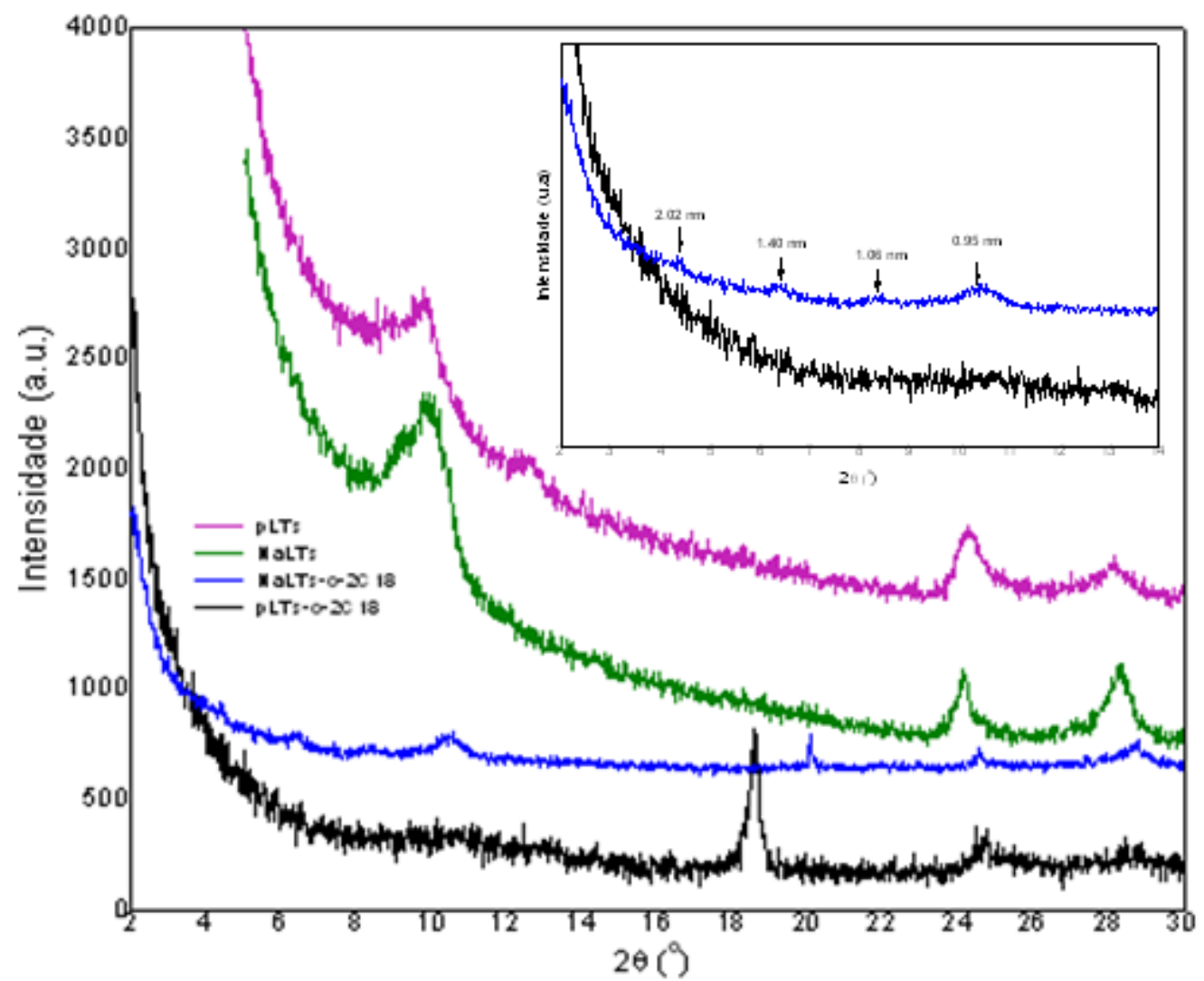

Figura 5.3 - DRX das nanofolhas virgens (pLTs e NaLTs), esfoliadas (pLTs-o-2C18) e intercaladas (NaLTs-0-2C18).

Vale ressaltar, que o procedimento de lavagem da amostra pLTs-o-2C18 foi realizado com água deionizada à temperatura ambiente, pois à temperaturas mais altas (por exemplo $60^{\circ} \mathrm{C}$ ) foi observado que o cátion $2 \mathrm{C} 18^{+}$foi removido da estrutura promovendo reempilhamento com $\mathrm{H}^{+}$novamente, estes servindo de cátions de compensação, como pode ser observado na Figura 5.4, pela presença da linha de difração em $2 \theta=10^{\circ}$, referente à distância interlamelar das nanofolhas. Provavelmente, houve uma re-dissolução dos cátions do sal, favorecida pela lavagem conduzida na mesma temperatura em que a reação ocorre a dissolução do sal 2C18. O pico aparente da amostra pLTs-o-2C18 em aproximadamente $2 \theta=19^{\circ}$ é referente ao sal que não reagiu, que apareceu nas primeiras amostras antes do processo de lavagem ter sido otimizado. 


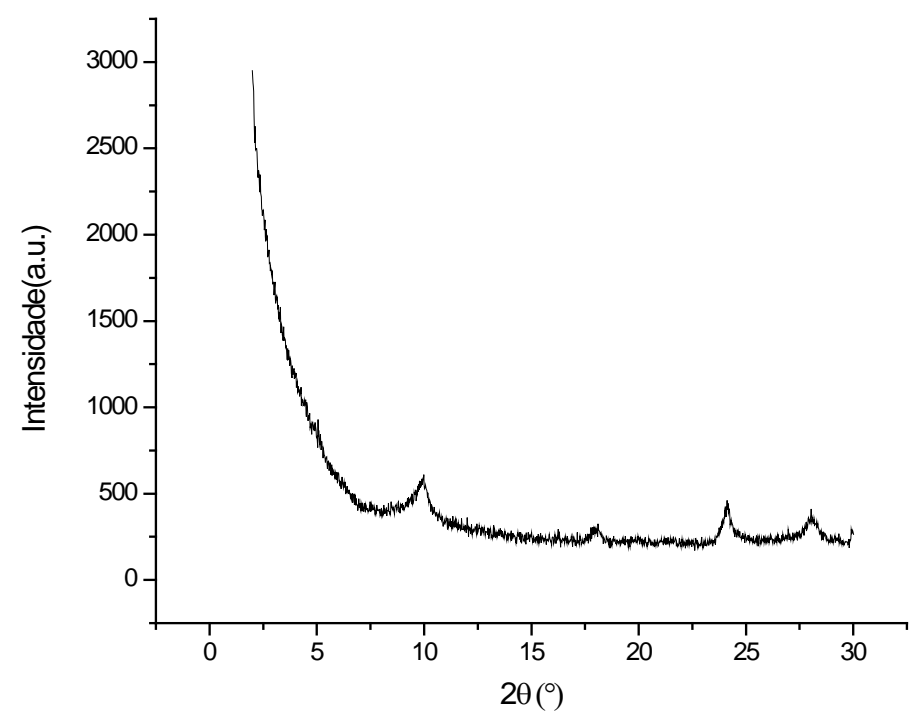

Figura 5.4 - Difratograma da amostra pLTs-o-2C18 lavada com água à temperatura de $60^{\circ} \mathrm{C}$.

Entretanto, como conferido na Figura 5.3, a amostra NaLTs-o-2C18 apresentou três linhas de difração em baixos ângulos, $2 \theta=4,5^{\circ} ; 6,5^{\circ} ; 8,4^{\circ}$, relacionadas à distância interlamelares do plano (020) de 2,02-1,40-1,06 nm respectivamente, além do pico original do espaçamento da intercamada de 0,95 $\mathrm{nm}$, indicando uma substituição parcial e heterogênea do cátion $\mathrm{Na}^{+}$pelo $2 \mathrm{C} 18^{+}$ dentro das galerias das nanofolhas, sugerindo a entrada do cátion $2 \mathrm{C} 8^{+}$em diferentes orientações (ângulos) entre as galerias das nanofolhas [23]. Alguns trabalhos atribuem essa variação à formação de bicamadas e pseudo-tricamadas com a entrada do sal quaternário de amônio [18] [29] [45].

Neste trabalho sugere-se a variação dos espaçamentos intercamadas devido à orientação das cadeias do cátion $2 \mathrm{C} 8^{+}$dentro das nanofolhas em relação as camadas densas compostas de octaedros de $\mathrm{Ti}(\mathrm{Fe}) \mathrm{O}_{6}$. No difratograma analisado da amostra NaLTs-o-2C18 a distância intercamadas com 2,02 nm é atribuído a inclinação da estrutura, em monocamada, do $2 \mathrm{C} 18^{+}$orientadas no ângulo $\sim 30^{\circ} \mathrm{em}$ relação as camadas das nanofolhas. Já a distância 1,4 nm está relacionada à orientação do cátion $2 \mathrm{C}^{+} 8^{+}$na horizontal (paralelamente às camadas de $\mathrm{Ti}(\mathrm{Fe}) \mathrm{O}_{6}$ ), na forma de estrutura em monocamadas, que são geralmente encontradas nas argilas esmectíticas [41]. 
Em relação a linha de difração em $2 \theta=8,4^{\circ}$, a distância do plano (020) com $1,06 \mathrm{~nm}$, atribui-se às galerias com ausência de $2 \mathrm{C} 18^{+}$e com a presença de íons de $\mathrm{Na}^{+} / \mathrm{H}^{+}$e com moléculas de $\mathrm{H}_{2} \mathrm{O}$ de acordo com Jardim et al. [5].

Izawa et al. [33] discutiram as orientações de cátions de alquilamônio na intercalação com camadas de titanato, argumentando que as cadeias de alquil são aumentadas em $1,27 \AA ̊$ para cada carbono adicionado. Desta forma estima-se que o tamanho do cátion 2C18 é de 2,5 nm sendo que com base neste dado era possível estimar as orientações das cadeias alquil do 2C18 em relação ás camadas de ferrititanatos.

\subsection{3.}

\section{Espalhamento de raios-X a baixo ângulo (SAXS)}

As amostras de pLTs-0-2C18 e NaLTs-o-2C18 foram igualmente analisadas por espalhamento de raios-X a baixo ângulo e seus padrões de difração estão apresentados na Figura 5.5. A técnica de SAXS é de extrema importância para identificação inequívoca de eventuais espaçamentos interplanares maiores ou para a confirmação da ausência dos mesmos.

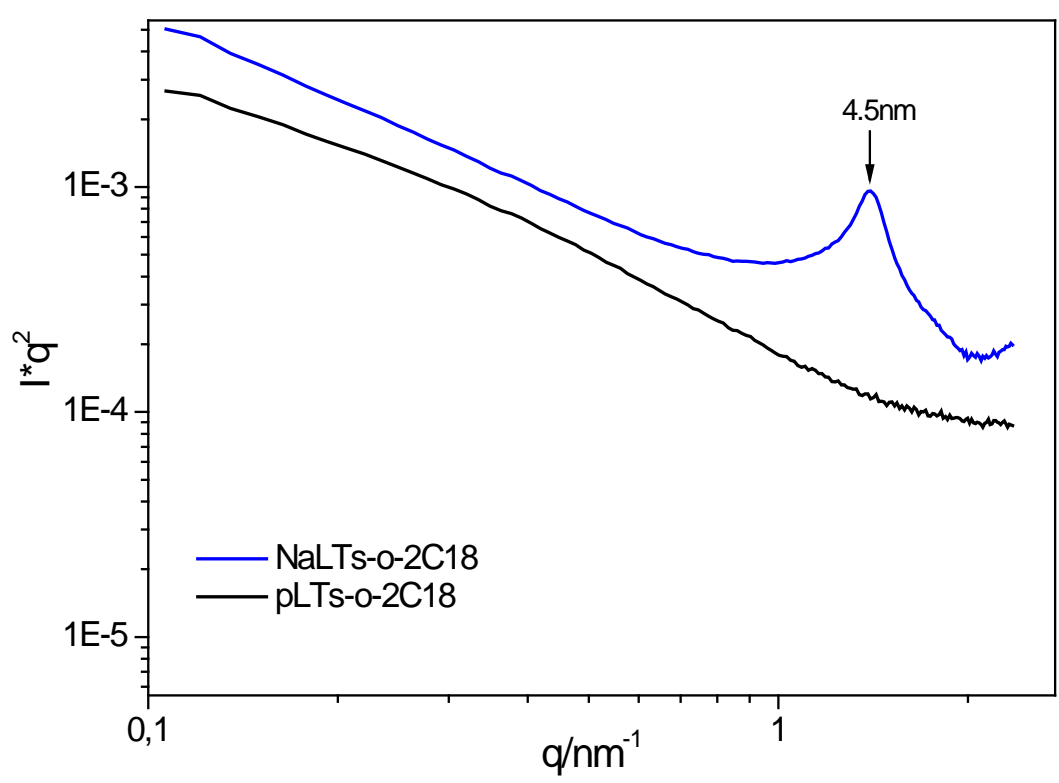

Figura 5.5 - Padrão de espalhamento de SAXS das amostras pLTs-o-2C18 e NaLTs-o$2 \mathrm{C} 18$. 
Na Figura 5.5 é observada, a ausência do pico referente à maiores distâncias entre as camadas das nanofolhas na amostra pLTs-o-2C18, enquanto na amostra NaLTs-o-2C18 um pico está presente a 4,5 nm. Através dos resultados obtidos na análise de SAXS não foi possível encontrar as evidências de inchamento/intercalação dentro das galerias da amostra pLTs-o-2C18, uma vez que nenhum pico foi observado para distâncias interlamelares de até $60 \mathrm{~nm}$. Desta forma, pode-se afirmar que foi possível esfoliar as nanofolhas em camadas individuais formando o material esfoliado pLTs-0-2C18, utilizando o procedimento descrito no item 4.2.

Já na amostra NaLTs-o-2C18 encontra-se um pico em 4,5 nm referente ao espaçamento das camadas das nanofolhas. Desta forma, esse pico pode indicar a intercalação do cátion $2 \mathrm{C} 18^{+}$nas galerias das nanofolhas e atribui-se a esse espaçamento a formação da estrutura bicamada do cátion $2 \mathrm{C} 18^{+}$na posição mais vertical com ângulo de inclinação de $49^{\circ}$ em relação as camadas horizontais das nanofolhas. Essa inclinação é esperada para estruturas bicamadas, cuja estrutura é formada com a orientação da carga catiônica da cadeia do cátion $2 \mathrm{C} 8^{+}$voltada para a carga negativa das camadas das nanofolhas e as cadeias de hidrocarboneto orientadas uma para a outra, como representado na Figura 5.6 [23].

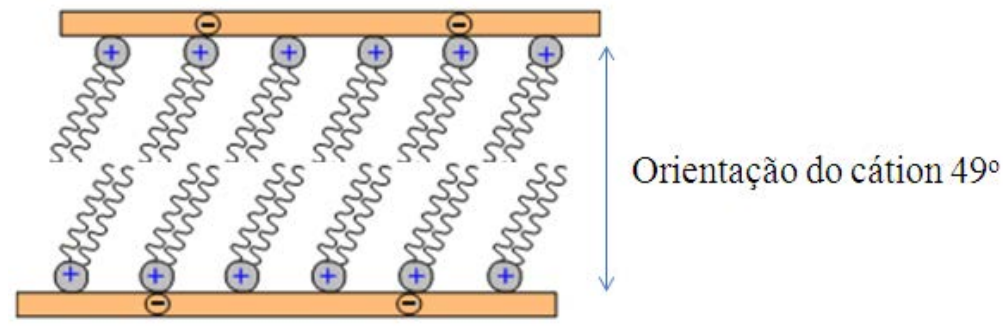

Figura 5.6 - Representação da configuração da intercalação dos cátions $2 \mathrm{C} 18^{+}$como estrutura bicamada para distâncias interlamelares de 4,5 nm.

Uma outra possibilidade para a existência deste pico seria o inchamento devido ao alojamento de várias camadas de moléculas de $\mathrm{H}_{2} \mathrm{O}$ nas galerias [46]. 


\subsection{4.}

\section{Espectroscopia de FTIR}

A Figura 5.7 apresenta os espectros de FTIR para as amostras: virgem (NaLTs), pLTs-o-2C18 e NaLTs-o-2C18. Através dessa técnica foi possível verificar a presença do cátion $2 \mathrm{C} 8^{+}$nas camadas das nanofolhas.

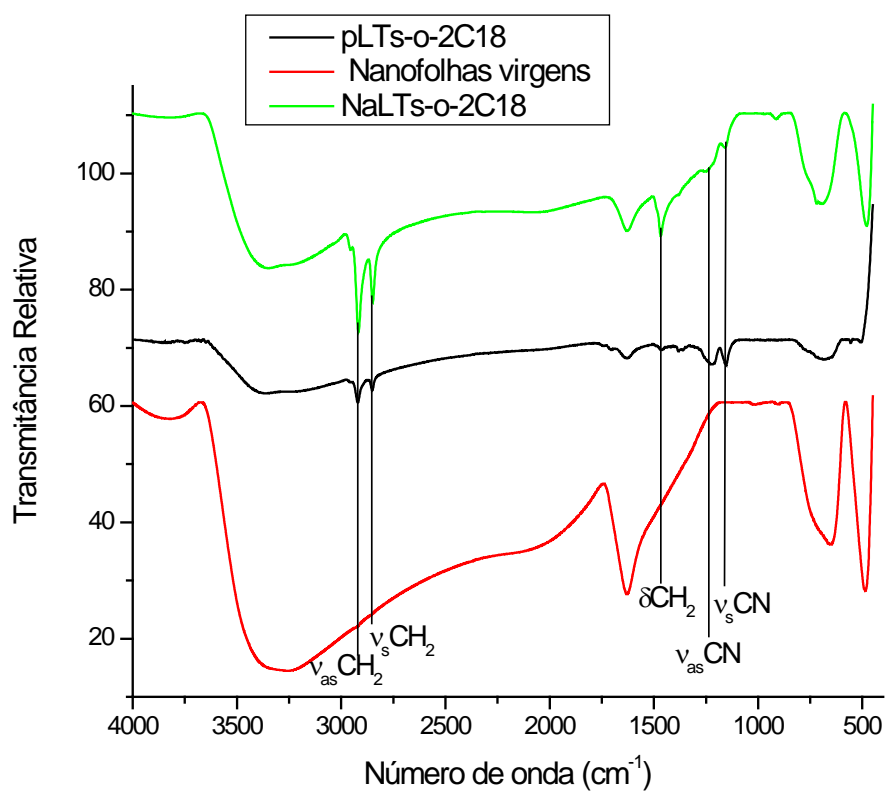

Figura 5.7 - Espectros de FTIR das nanofolhas virgem, esfoliada e intercalada.

Nos espectros de FTIR representados na Figura 5.7 pode-se verificar em todas as amostras uma banda larga e intensa com o mínimo em torno de $3400 \mathrm{~cm}^{-1}$ referente à presença de hidroxilas nas nanofolhas correspondendo à vibração de estiramento assimétrico e simétrico $\mathrm{O}-\mathrm{H}$ e outra em $1630 \mathrm{~cm}^{-1}$, relacionada às vibrações da deformação angular $\mathrm{H}-\mathrm{O}-\mathrm{H}$, devido à presença de moléculas de água adsorvidas na superfície das nanofolhas [68] [69] [70].

As bandas de adsorção nas regiões $2918 \mathrm{~cm}^{-1}$ e $2848 \mathrm{~cm}^{-1}$ correspondem aos estiramentos assimétrico e simétrico das ligações $\mathrm{C}-\mathrm{H}$ (dos grupos $\mathrm{CH}_{2}$ e $\mathrm{CH}_{3}$ ) referentes ao sal 2C18 e estão ausentes na amostra de nanofolhas virgem que não passaram pelo processo de organofilização. Também, foi observada a banda na região $1466 \mathrm{~cm}^{-1}$, encontrada nas amostras pLTs-o-2C18 e NaLTs-o-2C18, que correspondem a deformação angular do grupo metileno $\left(-\mathrm{CH}_{2}\right)$ pertencente ao cátion dimetildioctadecilamônio [45] [68] [70]. 
A presença do sal quaternário de amônio na superfície das nanofolhas também foi identificada por meio do aparecimento das bandas 1220 e $1156 \mathrm{~cm}^{-1}$ relacionados as estiramento dos grupos C-N, comprovando a eficiência do procedimento de inserção do sal quaternário de amônio [45] [71].

\subsection{5. \\ Medições de área superficial específica (BET)}

As amostras sintetizadas pLTs virgem, NaLTs virgem, pLTs-o-2C18 foram caracterizadas por medições da área superficial específica e os resultados obtidos estão apresentados na Tabela 5.2.

Tabela 5.2 - Área superficial específica.

\begin{tabular}{|c|c|}
\hline Amostra & $\begin{array}{c}\text { Área superficial } \\
\text { específica }\left(\mathbf{m}^{\mathbf{2}} \mathbf{/ g}\right)\end{array}$ \\
\hline pLTs virgem & 84,99 \\
\hline NaLTs virgem & 68,02 \\
\hline pLTs-o-2C18 & 26,27 \\
\hline
\end{tabular}

Estes resultados são similares a aqueles obtidos para nanotubos de titanatos com diferentes teores de sódio, já que quanto maior teor de $\mathrm{H}^{+}$maior a área superficial específica [72], como foi conferido na Tabela 5.2.

Já no caso das nanofolhas esfoliadas houve um decréscimo da área superficial específica devido à presença da bicamada do cátion $2 \mathrm{C} 8^{+}$ligado às nanofolhas que corresponde a $\sim 26 \%$ da massa das folhas esfoliadas, conforme será discutido no 5.1.6 com base nos dados adquiridos por TGA. Desta maneira, considerando que esta medida é por grama, a área específica vai se reduzida conforme aumenta o peso da amostra analisada. Porém, o decréscimo foi maior do que o esperado, visto que com a delaminação das nanofolhas existiria uma maior superfície livre para adsorção do nitrogênio na parte que não foi recoberta pelo cátion. Isso ocorre porque os agregados dos sais quaternários de amônio impedem a entrada de moléculas de nitrogênio, devido ao tamanho e a massa do cátion adsorvida [45]. Descréscimos na área superficial específica depois da modificação da superfície de outras nanocargas (como por exemplo nanotubos de titanato 
modificados com 3-aminopropiltrietoxisilano) têm sido observados na faixa de 29-44\% [17]. Para as nanofolhas sódicas relatada por Resende, foi observado uma redução de 43\% na área superficial [18]. Para as argilas MMT, há também uma tendência de redução da área específica das argilas após tornarem-se organofílicas [45]. No presente trabalho esta redução foi de $69 \%$.

\subsection{6.}

\section{Análise termogravimétrica (TGA)}

A análise de TGA foi utilizada para avaliar a estabilidade térmica dos materiais sintetizados e verificar as interações dos cátions inseridos $2 \mathrm{C}^{+} 8^{+}$nas camadas das nanofolhas, como demonstrado nas Figuras 5.8 a Figura 5.11.

Na Figura 5.8 observa-se a curva de perda de massa da amostra protonizada pLTs, que ocorre em duas etapas [29]. A etapa 1 corresponde à perda de massa na faixa de temperatura ambiente até $150^{\circ} \mathrm{C}$ referente à perda de água da intercamada e da superfície das nanofolhas estimada em 4,9\%p. Já na etapa 2 ocorre uma perda de massa de 3,1\%p na faixa de temperatura de $150-650^{\circ} \mathrm{C}$, atribui-se esse efeito à desidroxilação, resultando possivelmente na amorfização da estrutura lepidocrocita e a posterior recristalização do anatásio [29].

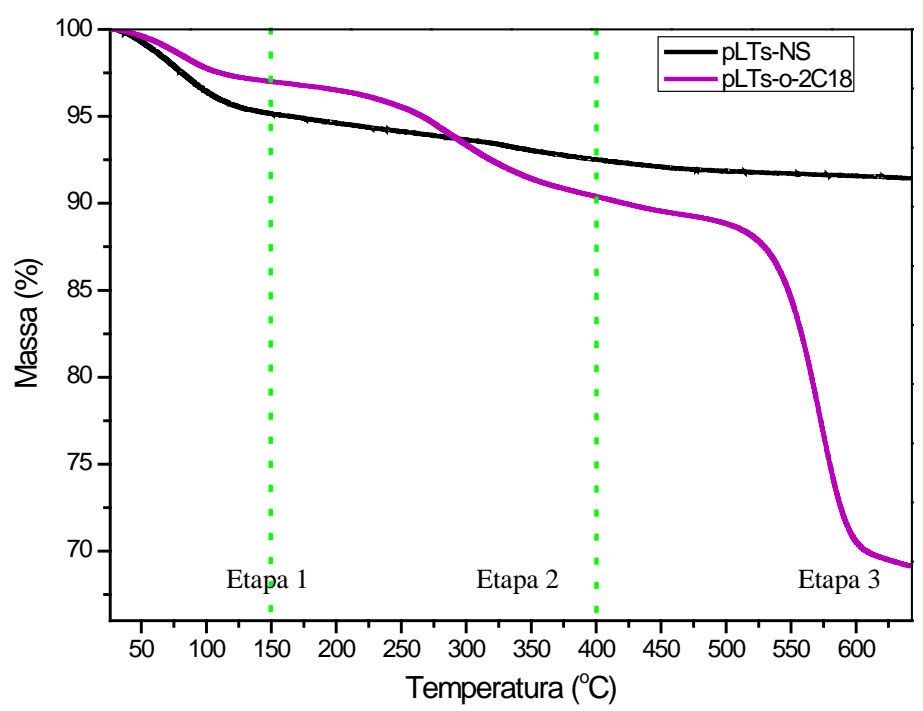

Figura 5.8 - Curva de TGA da amostra pLTs e pLTs-0-2C18. 
Na amostra esfoliada pLTs-o-2C18 a perda de massa ocorre em 3 etapas. Na Etapa 1 há uma perda de massa menor do que na amostra precursora pLTs, na faixa de temperatura ambiente até $150^{\circ} \mathrm{C}$ estimada em $3,1 \%$, indicando que com a entrada do sal 2C18 gera-se uma superfície mais hidrofóbica [73]. Na etapa 2 referente à perda de massa na faixa de temperatura entre $150^{\circ}-400^{\circ} \mathrm{C}$ observa-se uma perda de 6,4\%p na amostra esfoliada (pLTs-o-2C18), o qual atribui-se à perda da camada mais externa do cátion $2 \mathrm{C} 8^{+}$com a quebra das ligações químicas entre os dipolos permanentes $2 \mathrm{C} 8^{+}-2 \mathrm{C} 18^{+}$[74], como está demonstrado na Figura 5.9. Já na etapa 3 uma perda de massa de aproximadamente 20\%p é observada na faixa de $400-600^{\circ} \mathrm{C}$, atribuída à quebra das ligações fortes entre 0 cátion e a camada das nanofolhas $\mathrm{Ti}_{2-\mathrm{x}} \mathrm{FexO}_{2}{ }^{\mathrm{x}-}-2 \mathrm{C} 18^{+}$, representado na Figura 5.9.

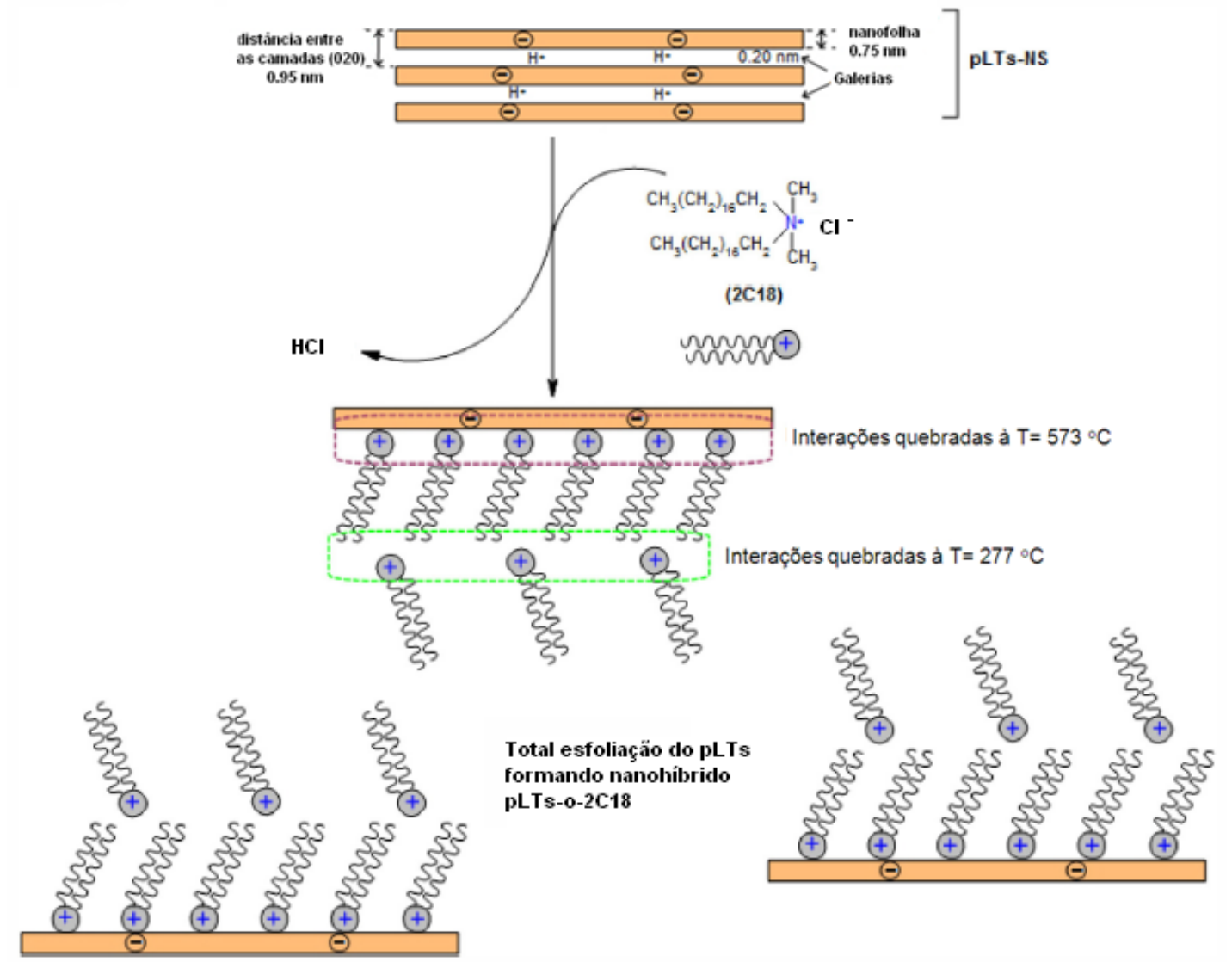

Figura 5.9 - Esquema ilustrativo das interações do cátion $2 \mathrm{C} 18^{+}$na amostra esfoliada [23].

A curva de TGA das amostras NaLTs e NaLTs-o-2C18 está apresentada na Figura 5.10. Neste gráfico para a amostra de NaLTs podem-se observar também 
duas etapas para a perda de massa. A etapa 1 ocorre na faixa de temperatura ambiente até $150^{\circ} \mathrm{C}$ referente a perda de água na superfície e entre as camadas das nanofolhas, estimada em 7\%. Já na etapa 2 ocorre a perda de massa na faixa de $150^{\circ}$ - $450^{\circ} \mathrm{C}$ estimada em 2,4\%, que atribui-se à desidroxilação [75].

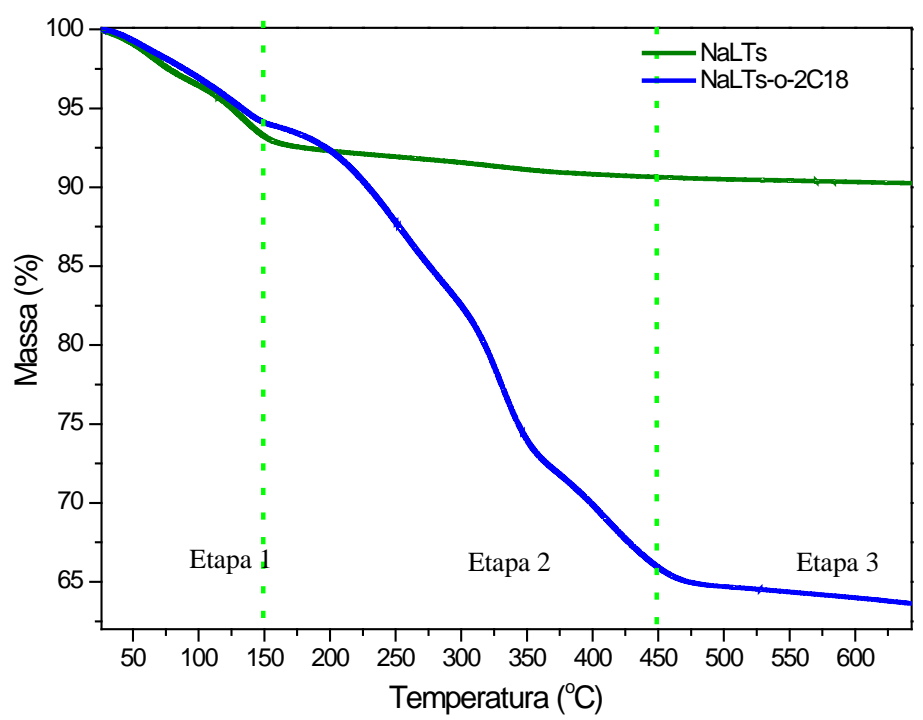

Figura 5.10 - Curva de TGA das amostras sódica e intercalada.

Já para a perda de massa da amostra NaLTs-o-2C18 observa-se um comportamento diferente quando comparado a amostra pLTs-o-2C18. Pode-se verificar na Figura 5.10 a grande perda de massa estimada em $28 \%$ na faixa de temperatura de $150^{\circ}-450^{\circ} \mathrm{C}$, referente a total decomposição do cátion $2 \mathrm{C} 18^{+}$. Um comportamento similar foi observado em argilas hectorita [73], intercaladas com o mesmo sal quaternário de amônio.

Na Figura 5.11 referente a curva de TGA do sal puro 2C18, a decomposição do 2C18 ocorre em faixas baixas de temperatura e termina em $400^{\circ} \mathrm{C}$. Desta forma, a intercalação do cátion $2 \mathrm{C} 8^{+}$com as camadas das nanofolhas (NaLTs-o2C18) é mais fraca do que quando comparada com as interações na amostra pLTso-2C18, já que a decomposição do sal nesta última amostra começa $\sim 500^{\circ} \mathrm{C}$ ). 


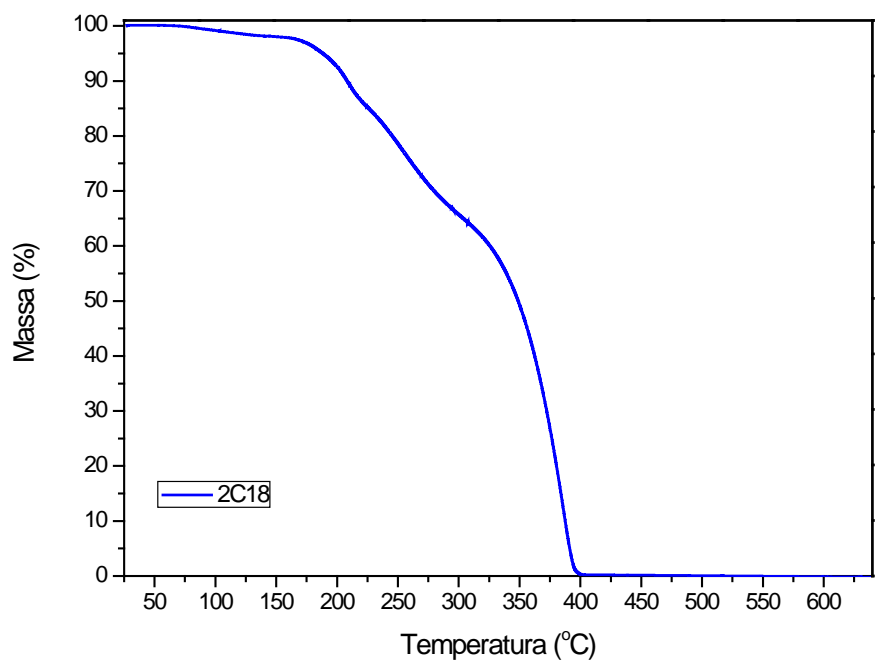

Figura 5.11 - TGA do sal puro 2C18.

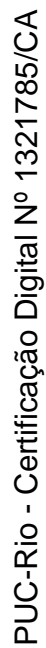

5.1.7.

Calorimetria diferencial de varredura (DSC)

Os resultados obtidos para as curvas de DSC estão representadas na Figura 5.12 para as amostras pLTs e pLTs-o-2C18. 


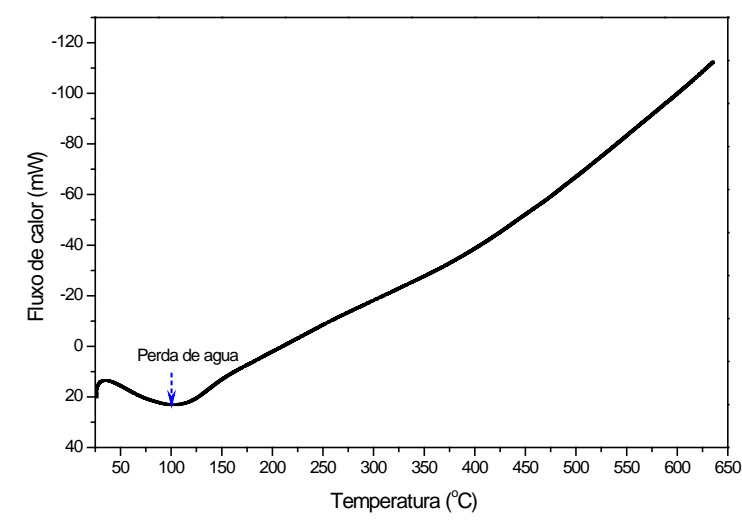

(a)

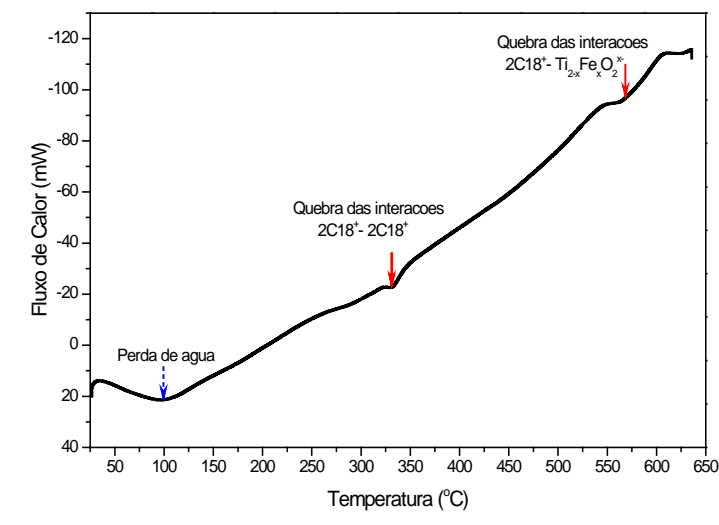

(b)

Figura 5.12 - Curvas de DSC das amostras (a) pLTs e (b) pLTs-o-2C18.

Na Figura 5.12(a), a curva de DSC da amostra pLTs apresenta somente um evento endotérmico por volta de $100^{\circ} \mathrm{C}$, atribuído a perda de água.

Já a amostra pLTs-o-2C18 apresenta três eventos em $100^{\circ} \mathrm{C}, 320^{\circ} \mathrm{C}$ e $570^{\circ} \mathrm{C}$, como demonstrado na Figura 5.12(b), não aparentes na amostra pLTs. Esses eventos estão atribuídos à perda de água à $100^{\circ} \mathrm{C}$, à quebra das interações secundárias entre os dipolos de $2 \mathrm{C} 8^{+}$em $320^{\circ} \mathrm{C}$ referente a ligação $2 \mathrm{C} 18^{+}-2 \mathrm{C} 18^{+}$ como representado na Figura 5.9 e finalmente, à quebra das ligações fortes do cátion com a camada das nanofolhas $\mathrm{Ti}_{2-\mathrm{x}} \mathrm{FexO}_{2}{ }^{\mathrm{x}-}-2 \mathrm{C} 18^{+}$em $\sim 570^{\circ} \mathrm{C}$.

Esses resultados estão de acordo com os eventos de perda de massa observados na análise de TGA da amostra pLTs-o-2C18. 


\subsection{8. \\ Microscopia de força atômica (AFM)}

Essa técnica foi utilizada para verificação da espessura do nanomaterial sintetizado pelo processo de esfoliação. A análise foi realizada no modo "tapping” (contato intermitente) [76].

Na Figura 5.13 estão mostradas as imagens 2D e 3D da amostra pLTs-o2C18, assim como o perfil de altura medido ao longo de uma seção transversal.
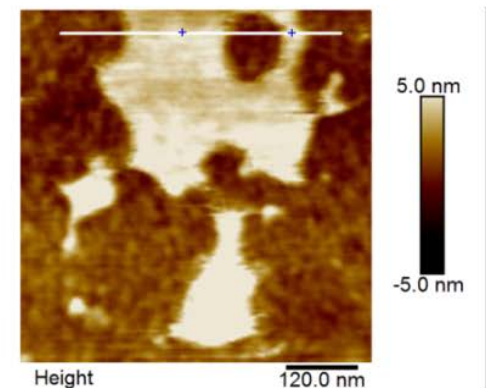

(a)

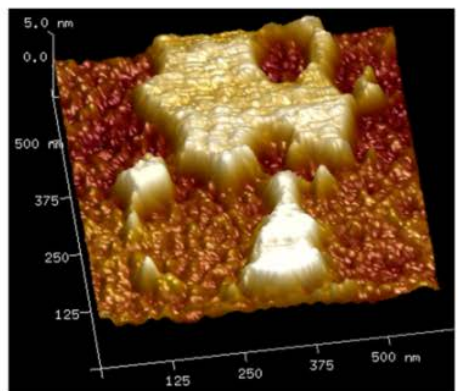

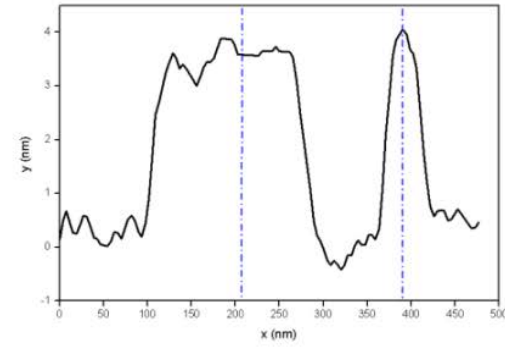

(b)

Figura 5.13 - Imagens de AFM da amostra esfoliada (a) 2D e 3D e (b) perfil da seção transversal ao longo da linha branca desenhada em (a).

Portanto, a partir desses resultados para a amostra pLTs-o-2C18 constatouse uma rugosidade de $0,28 \mathrm{~nm}$ e espessura da monofolha de 3,8 $\mathrm{nm}$, tamanho muito superior a da camada octaédrica dos ferrititanatos cuja espessura é de 0,75nm, o que permite entender que a camada octaédrica é acrescentada por uma bicamada do sal levando à formação de nanohíbridos inorgânico-orgânicos conforme ilustrada na Figura 5.9.

\subsection{9. \\ Microscopia eletrônica de transmissão (MET)}

Primeiramente essa técnica foi realizada para a comprovação da formação das nanofolhas das amostras sintetizadas via rota hidrotérmica alcalina, a partir do precursor areia ilmenítica. As imagens de MET confirmaram a formação das nanofolhas consistindo de poucas camadas empilhadas (em torno de 10 folhas individuais) como mostrado na Figura 5.14. Também, foi realizada a análise de EDS para determinar a razão $\mathrm{Ti}^{4+} / \mathrm{Fe}^{3+}$ dentro das amostras NaLTs e pLTs. 
(b)

(a)

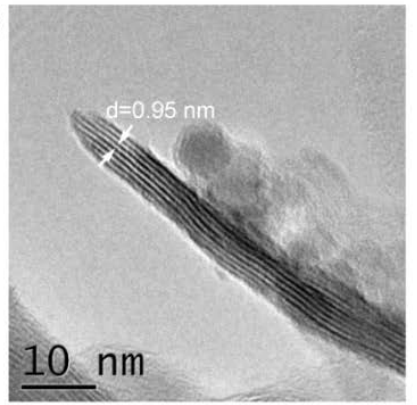

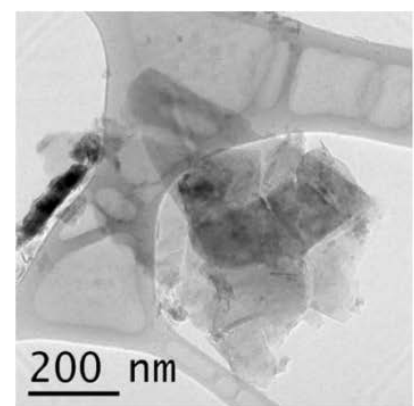

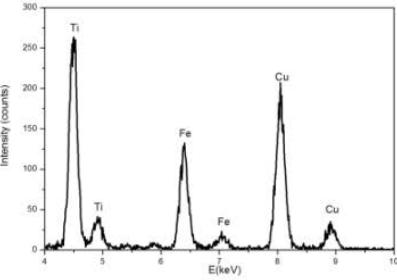

(c)
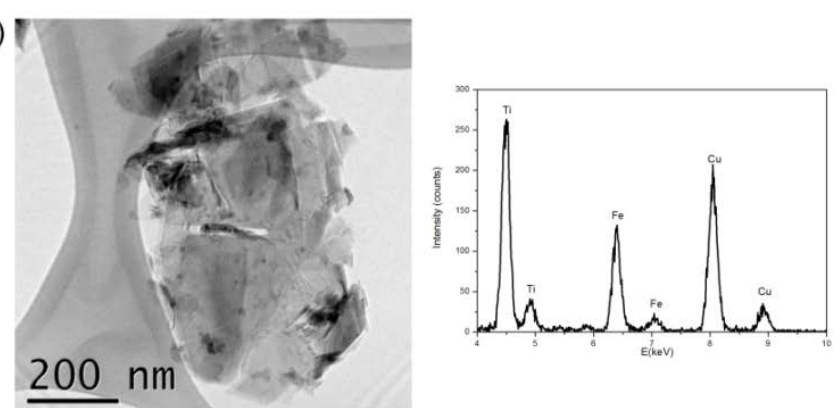

Figura 5.14 - a) Imagen de MET da amostra NaLTs; imagens de MET e EDS das amostras (b) NaLTS e (c) pLTs.

Pode-se concluir que a razão $\mathrm{Ti}^{4+} / \mathrm{Fe}^{3+}$ nas duas amostras com alto e baixo teor de $\mathrm{Na}^{+}$foi mantida. Verificou-se também que a razão não foi alterada após a reação de troca ácida, enquanto em outros materiais à base de titanatos lamelares foram observadas mudanças, como por exemplo, os materiais em $\mathrm{Cs}_{\mathrm{x}} \mathrm{Ti}_{2}$ ${ }_{\mathrm{x} / 2} \mathrm{Mg}_{\mathrm{x} / 2} \mathrm{O}_{4}$ [77] e $\mathrm{Cs}_{\mathrm{x}} \mathrm{Ti}_{2-\mathrm{x} / 2} \mathrm{Zn}_{\mathrm{x} / 2} \mathrm{O}_{4}$ [78] sintetizados por reação no estado-sólido, no qual houve uma perda quase completa do $\mathrm{Mg}^{2+}$ e $\mathrm{Zn}^{2+}$ por lixiviação durante o longo processo de troca catiônica, surgindo vacâncias.

Os resultados mostram a eficiência do procedimento de lavagem ácida das nanofolhas, sintetizadas neste trabalho, no qual a reação de troca ácida do íon $\mathrm{Na}^{+}$ por $\mathrm{H}^{+}$foi completa em algumas horas, enquanto para titanatos lamelares de dimensões laterais micrométricas, como relatado por Gao et al. [77] [78] são finalizados após alguns dias.

Na Figura 5.15 é mostrada uma imagem de MET da amostra esfoliada, onde se pode sugerir existência de apenas uma camada individual orientada na horizontal. Foi observada a tendência das nanofolhas esfoliadas se sobreporem, dificultando a visualização de uma única folha individual durante a aquisição das imagens. 

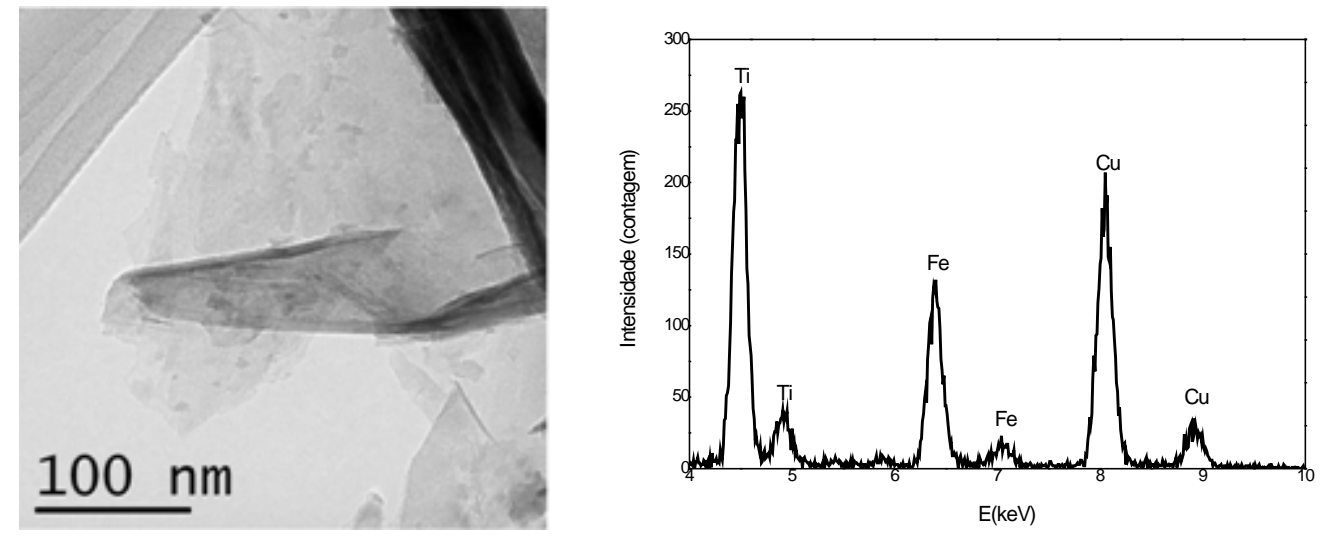

Figura 5.15 - Imagem de MET da amostra pLTs-o-2C18 e seu respectivo espectro de EDS.

\section{2. \\ Caracterização dos nanocompósitos}

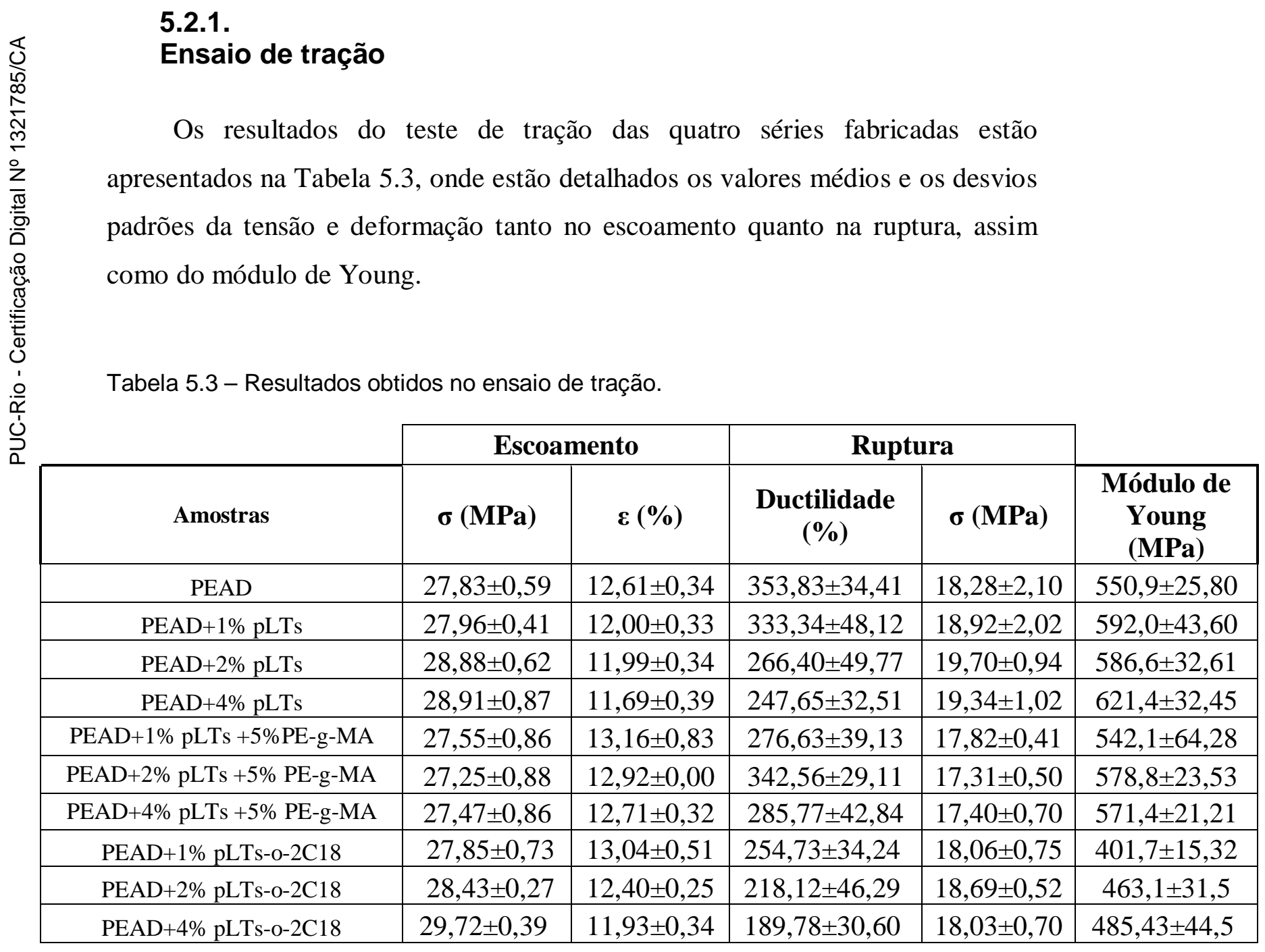


A Figura 5.16 representa o gráfico da tensão no escoamento em função da porcentagem em peso do reforço e do tipo de reforço ou da matriz. Pode-se observar que os nanocompósitos de PEAD reforçados com 2 e $4 \%$ p de pLTs virgem apresentaram um aumento na tensão no escoamento de $~ 3,9 \%$ em ambos os casos, quando comparados com o PEAD puro. Porém, os nanocompósitos contendo o compatibilizante PE-g-MA com 2\%pLTs virgem, mostraram um decréscimo na tensão no escoamento em torno de 2,1\% em relação ao PEAD puro. Já no caso dos nanocompósitos fabricados com 4\% p de pLTs-0-2C18 houve incremento na tensão no escoamento que foi o máximo obtido, correspondendo a 6,8\% em relação ao PEAD puro.

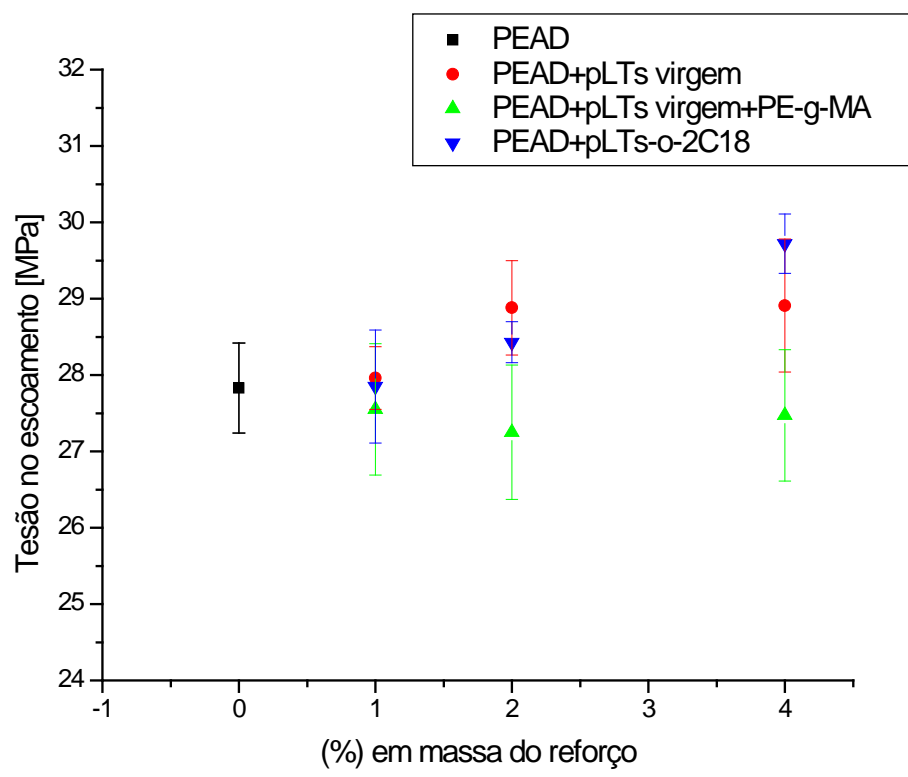

Figura 5.16 - Tensão no escoamento dos nanocompósitos fabricados em função da porcentagem em massa das nanocargas.

Em sistemas onde a adesão interfacial não é boa, a descolagem (debonding) das nanocargas da matriz poderia ocorrer em tensões menores do que a tensão no escoamento da matriz pura. Já que as nanocargas descoladas não recebem nenhuma carga, a tensão no escoamento decresce [79] . Isto sugere que no caso dos nanocompósitos reforçados com pLTs virgem pode existir uma ligação interfacial de tipo mecânica (mechanical interlocking) entre as cadeias da matriz e as reentrâncias (rugosidades) da superfície das nanofolhas, levando a uma melhor 
adesão e consequentemente, a um aumento da tensão no escoamento. O efeito da rugosidade na escala nanométrica de cargas inorgânicas no incremento das propriedades mecânicas de nanocompósitos poliméricos, tem sido observado em nanoplaquetas de grafeno, onde a rugosidade superficial desempenha um papel fundamental na transferência de carga [80]. Porém, nos nanocompósitos reforçados com pLTs virgem mas fabricados com adição de PE-g-MA, a tensão no escoamento foi praticamente preservada (considerando o desvio padrão), o que significa que o compatibilizante não levou a uma melhora substancial da interface. Um estudo mais aprofundado sobre a quantidade de PE-g-MA em função da porcentagem de nanocarga deveria ser realizado para otimizar este parâmetro. Por outro lado, o tamanho das moléculas de PE-g-MA poderia ocasionar um impedimento estérico para as moléculas interagirem com os grupos $-\mathrm{OH}$ disponíveis na superfície das nanofolhas durante a extrusão. Desta forma, a compatibilidade entre a matriz e a nanocarga não foi aumentada como esperado. No caso dos nanocompósitos fabricados com pLTs-o-2C18 o maior incremento na tensão no escoamento pode-se atribuir à melhor adesão interfacial, devido à compatibilidade melhorada pela presença da dupla camada de $2 \mathrm{C}{ }^{+}$.

A deformação no escoamento dos nanocompósitos produzidos é apresentada na Figura 5.17. Houve um decréscimo na faixa de 4,8-7,3 \% para os nanocompósitos reforçados com as nanofolhas virgens, condizente com os resultados do módulo de Young que serão apresentados posteriormente. Por outro lado, os nanocompósitos fabricados com adição de PE-g-MA exibiram um incremento 4,4 \% unicamente para uma porcentagem de $1 \%$ p de pLTs virgem. Os nanocompósitos reforçados com pLTs-o-2C18 apresentaram um incremento, dentro do desvio padrão, na deformação no escoamento quando reforçados com 1\% p pLTS-o-2C18 e para as amostras reforçadas com 2 e 4\%p de pLTs-o-2C18 observou-se um decréscimo de 1,6 e 5,4\%, respectivamente. 


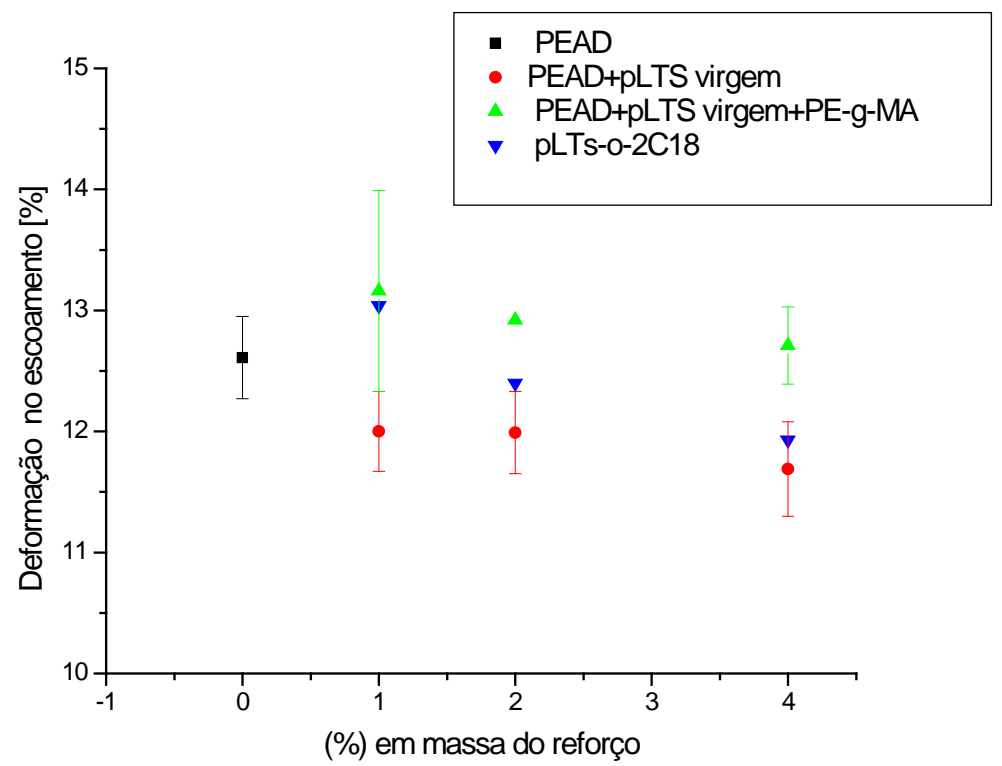

Figura 5.17 - Deformação no escoamento em função da porcentagem em massa do reforço.

Na Figura 5.18 estão detalhados os resultados do módulo de Young dos nanocompósitos em função da porcentagem de carga. Os nanocompósitos reforçados com pLTs virgem apresentaram incrementos nesta propriedade de 6,5 até $12,8 \%$ em relação à matriz PEAD pura. Isto poderia ser explicado pela interação interfacial de tipo mecânica entre ambos os componentes do nanocompósito, conforme mencionado anteriormente. Já no caso dos nanocompósitos preparados com adição de PE-g-MA, o incremento máximo no módulo de Young foi de 5,1 \% para 2 \% p de nanocarga, demonstrando novamente que o efeito da incorporação do compatibilizante não permitiu melhorar substancialmente a interface. Para os nanocompósitos fabricados com pLTs-o-2C18 observa-se um decréscimo no módulo de Young para todas as porcentagens variando de 12\% para 4\%p de pLTs-o-2C18 até 27\% com 1\%p de pLTs-o-2C18. Porém, verifica-se a tendência de aumento no Módulo de Young a partir de 1\% p de pLTs-o-2C18 conforme o teor de nanocarga é incrementado. Possivelmente teores de nanofolhas esfoliadas maiores a $4 \%$ p permitiriam uma melhora desta propriedade em relação ao PEAD. O decréscimo no módulo de Young poderia ser explicado, levando em conta o efeito que a dupla camada de $2 \mathrm{C}{ }^{+}$poderia ter na ordenação das cadeias de $\mathrm{PEAD}$ durante a cristalização, 
além da possibilidade desta dupla camada (que representa $~ 26 \%$ em peso das nanofolhas esfoliadas) agir como um plastificante. Isto é, afastar as cadeias do polímero e com isso reduzir as interações de van der Waals entre as cadeias, levando a um decréscimo no módulo de Young, apesar da compatibilidade entre as nanocargas e a matriz ter sido melhorada. Resultados similares de decréscimo no módulo de elasticidade foram observados por Resende [18] para nanocompósitos produzidos com nanofolhas sódicas intercaladas com 2C18, onde este comportamento foi atribuido provavelmente a uma falta de esfoliação nos compósitos, redução na cristalinidade ou que o sal teve papel de plastificante.

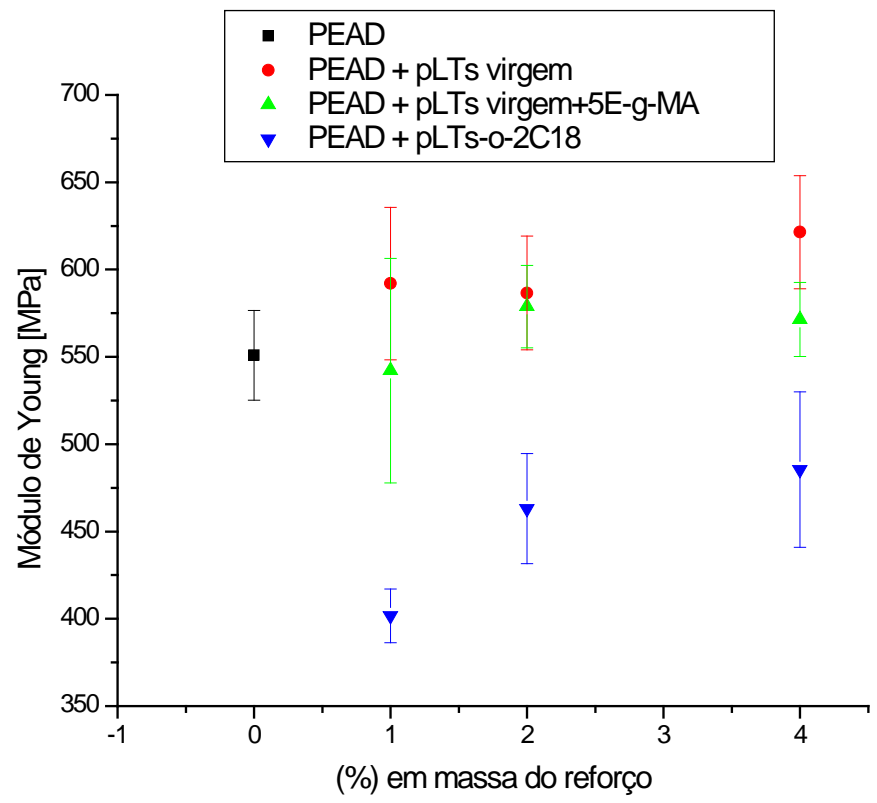

Figura 5.18 - Módulo de Young dos nanocompósitos em função da porcentagem em massa do reforço.

No caso da ductilidade, foi observada uma redução nesta propriedade na faixa de 5,8 a $30 \%$ conforme foi incrementada a porcentagem do pLTs virgem (vide Figura 5.19). Estes resultados são esperados, devido ao efeito de adição das nanocargas que agem como barreiras para a movimentação das cadeias poliméricas durante a deformação plástica, levando a um decréscimo na ductilidade, condizente com o aumento no módulo de Young. Esta redução na ductilidade também foi observada na série fabricada com PE-g-MA. No entanto, o decréscimo foi menor (3,2-21,8\%). Para os nanocompósitos reforçados com pLTs-o-2C18, verifica-se uma redução da ductilidade para todas as amostras dessa 
série, variando de 28,0\% para os nanocompósitos reforçados com 1\%p de pLTs-o2C18 e 46,4\% para aqueles nanocompósitos preparados com 4\%p de pLTs-0$2 \mathrm{C} 18$.

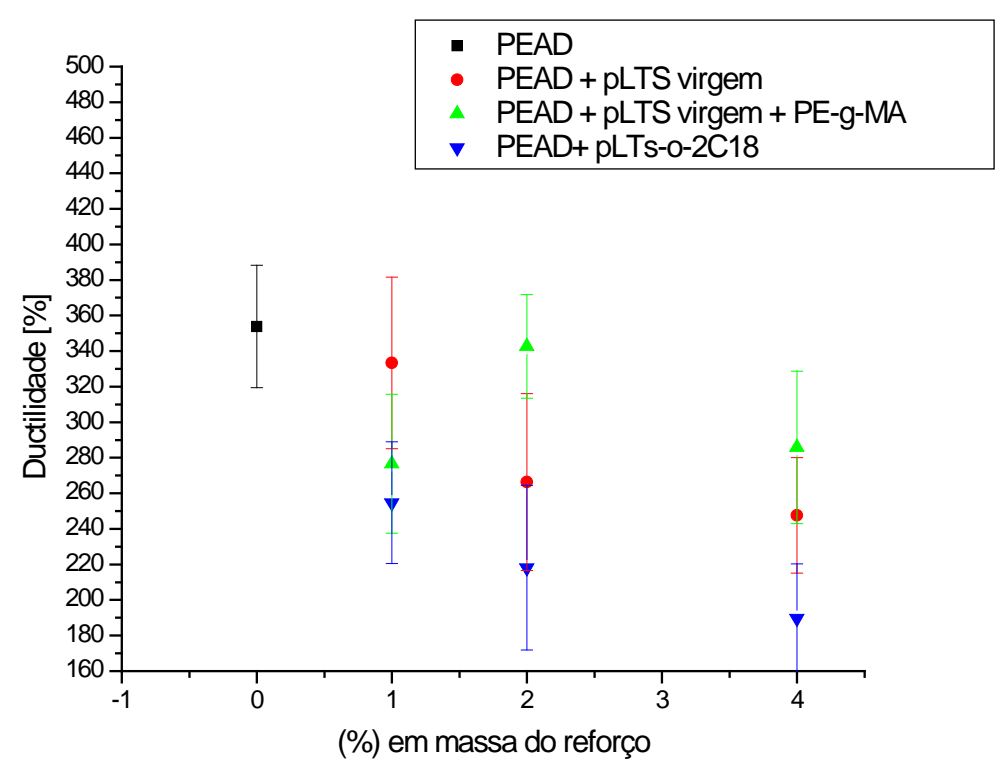

Figura 5.19 - Ductilidade dos nanocompósitos em função da porcentagem em massa do reforço.

Por outro lado, a tensão na ruptura (vide Figura 5.20) dos nanocompósitos não foi afetada significativamente pela adição das nanocargas pLTs virgem, nanofolhas esfoliadas e pela incorporação do agente compatibilizante. 


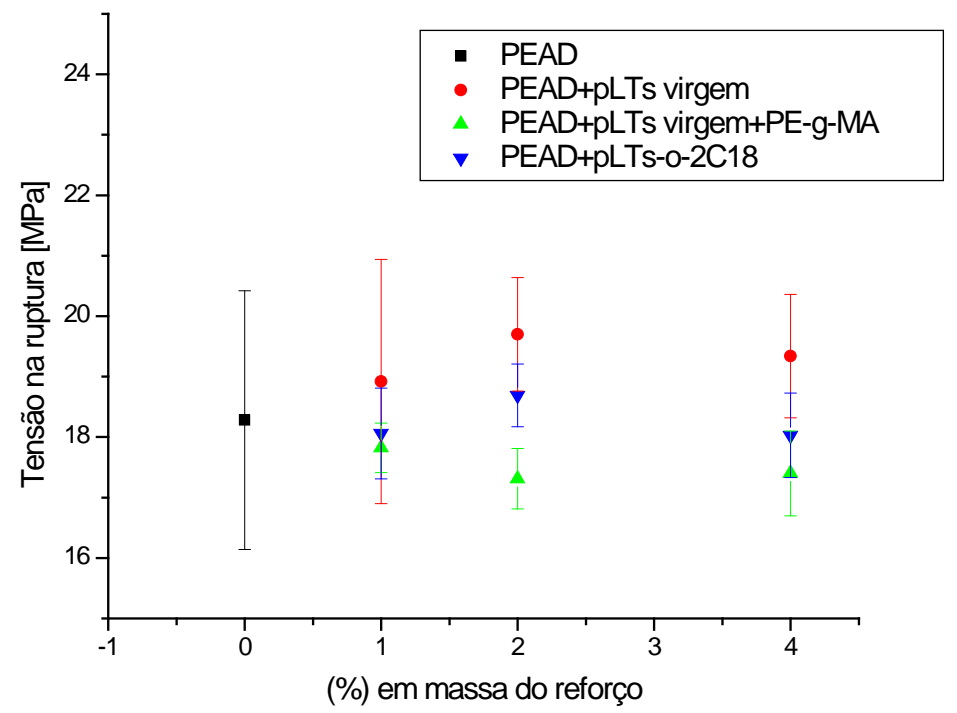

Figura 5.20 - Tensão de ruptura dos nanocompósitos em função da porcentagem em massa do reforço.

Finalmente, é importante salientar que os incrementos na tensão no escoamento e no módulo de Young obtidos neste trabalho utilizando 4 \% p pLTs foram superiores àqueles relatados por Resende [18], utilizando $5 \% \mathrm{p}$ de nanofolhas sódicas virgens (Tabela 5.4). Porém, a ductilidade não foi reduzida quando utilizadas nanofolhas sódicas, o que sugeriria uma diferente ancoragem mecânica da matriz na nanocarga, dependendo do teor de sódio. Ao comparar os resultados das propriedades mecânicas dos compósitos preparados com 5\% p NaLTs-o-2C18 e 4\% p pLTs-o-2C18, o efeito da compatibilidade melhorada pela presença da dupla camada do sal nas nanofolhas esfoliadas é observado pelo incremento na tensão no escoamento. Porém, o decréscimo acentuado no módulo de Young pode ser atribuido ao efeito plastificante do $2 \mathrm{C}^{+} 8^{+}$. Já no caso do trabalho de Resende [18] a quantidade incorporada de 2C18 foi menor ( $16 \%$ ), o que explica à diferença nos módulos de Young entre ambos os nanocompósitos. 
Tabela 5.4 - Variações percentuais nas propriedades mecânicas de nanocompósitos produzidos com nanofolhas com diferentes teores de sódio, tanto virgens quanto organofilizadas com 2C18 em relação ao PEAD puro.

\begin{tabular}{|l|c|c|c|}
\hline \multicolumn{1}{|c|}{ Amostra } & $\begin{array}{c}\text { Tensão no } \\
\text { escoamento }\end{array}$ & Ductilidade & $\begin{array}{c}\text { Módulo de } \\
\text { Young }\end{array}$ \\
\hline PEAD + 4\% pLTs & 3,90 & $-30,0$ & 12,80 \\
\hline PEAD + 4\% pLTs-0-2C18 & 6,80 & $-46,36$ & $-11,9$ \\
\hline PEAD + 5\% NaLTs [18] & $-8,38$ & 14,10 & 4,02 \\
\hline PEAD+5\% NaLTs-0-2C18 [18] & $-0,01$ & $-29,94$ & 2,64 \\
\hline
\end{tabular}

\subsection{2. \\ Dilatometria}

Os resultados do coeficiente de expansão térmica (CET) tanto do PEAD puro quanto dos nanocompósitos fabricados estão representados na Tabela 5.5 - e na Figura 5.21.

Tabela 5.5 - CET do PEAD puro e dos nanocompósitos produzidos.

\begin{tabular}{|c|c|c|c|}
\hline Amostras: & $\begin{array}{c}\text { CET médio } \\
{\left[\times 10^{-4}\right]}\end{array}$ & $\begin{array}{c}\text { Desvio } \\
\text { padrão }\end{array}$ & $\begin{array}{c}\text { Variação em } \\
\text { relação ao } \\
\text { PEAD [\%] }\end{array}$ \\
\hline PEAD & 2,09 & $3,0 \times 10^{-6}$ & 0,0 \\
\hline PEAD $+1 \%$ pLTs & 1,97 & $5,6 \times 10^{-6}$ & $-5,5$ \\
\hline PEAD+2\%pLTs & 2,08 & $8,9 \times 10^{-6}$ & $-0,7$ \\
\hline $\mathrm{PEAD}+4 \% \mathrm{pLTs}$ & 2,01 & $5,5 \times 10^{-7}$ & $-3,9$ \\
\hline PEAD+1\% pLTs+5\%PE-g-MA & 2,27 & $6,9 \times 10^{-6}$ & 8,5 \\
\hline PEAD+2\% pLTs+5\% PE-g-MA & 2,22 & $5,3 \times 10^{-7}$ & 6,4 \\
\hline PEAD+4\% pLTs+5\% PE-g-MA & 2,16 & $2,0 \times 10^{-6}$ & 3,3 \\
\hline PEAD+1\% pLTs-o-2C18 & 2,15 & $5,6 \times 10^{-6}$ & 2,9 \\
\hline PEAD+2\% pLTs-o-2C18 & 2,20 & $4,9 \times 10^{-6}$ & 5,3 \\
\hline PEAD+4\% pLTs-o-2C18 & 2,24 & $3,6 \times 10^{-6}$ & 7,3 \\
\hline
\end{tabular}




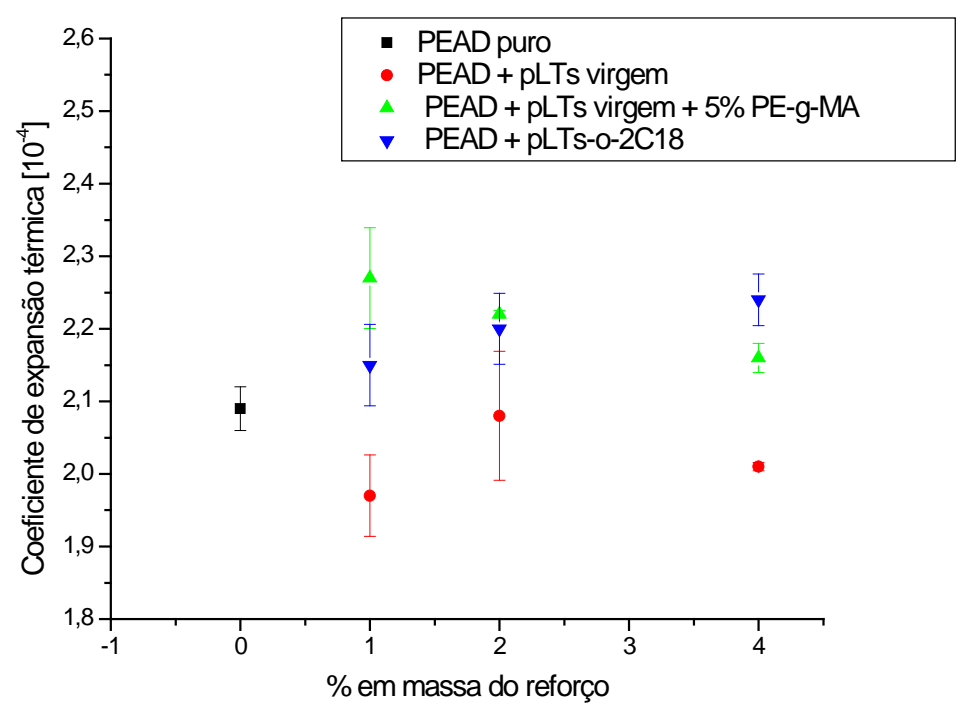

Figura 5.21 - CET dos nanocompósitos.

Rao et al. [81] fabricaram nanocompósitos de poli(óxido) de etileno (PEO) reforçados com argila montmorilonita e relataram uma limitada redução do CET, devido à dificuldade de esfoliação das argilas na matriz. Para a redução do CET, vários tratamentos têm sido realizados em nanocompósitos de matriz polimérica para avaliar o efeito do grau de cristalinidade, orientação das cadeias do polímero e adição de reforços com baixa expansão térmica. Em regiões com maior grau de cristalinidade ocorre uma redução do CET, devido à restrição dos movimentos das cadeias poliméricas por apresentar uma estrutura mais ordenada, ao contrário das regiões amorfas [18].

Nos nanocompósitos com pLTs virgens houve uma ligeira redução do CET em relação ao $\mathrm{PEAD}$ puro, porém não muito significativa. No trabalho de Resende [18], o mesmo PEAD foi testado com nanofolhas sódicas virgens e não foi possível alcançar uma redução do CET com porcentagens de reforço de 2, 5 e $10 \%$ p.

Já nos resultados obtidos para os nanocompósitos com o compatibilizante PE-g-MA e para os nanocompósitos com pLTs-o-2C18 (nanofolhas esfoliadas) foi observado um aumento nos valores do CET, o qual está de acordo com os resultados do grau de cristalinidade (seção 5.2.3), visto que nessas amostras há um aumento da região amorfa. 
Além disso, o incremento do CET pode ser atribuído à aglomeração e falta de dispersão das monofolhas, pois nanofolhas esfoliadas forneceriam um incremento nas propriedades térmicas, enquanto um material não esfoliado e aglomerado dificultaria essa redução do CET [81].

\subsection{3.}

\section{Análise térmica simultânea}

Primeiramente foi avaliada a temperatura em que ocorre a taxa máxima de degradação ( $T_{d}$ máx), que é definida pela primeira derivada da curva porcentagem em massa versus temperatura. Também foi analisada a temperatura de início do processo de degradação ( $\left.T_{\text {onset }}\right)$ e os resultados estão apresentados na - .

Tabela 5.6 - Resultados obtidos da Td máx e $T_{\text {onset }}$ para o PEAD puro e os nanocompósitos fabricados.

\begin{tabular}{|c|c|c|}
\cline { 2 - 3 } \multicolumn{1}{c|}{} & $\mathbf{T d}_{\text {máx }}\left[{ }^{\mathbf{0}} \mathbf{C}\right]$ & $\left.\mathbf{T}_{\text {onset }}{ }^{\mathbf{0}} \mathbf{C}\right]$ \\
\hline PEAD & 482,00 & 462,83 \\
\hline PEAD+ 1\%pLTs virgem & 482,09 & 465,79 \\
\hline PEAD+ 2\%pLTs virgem & 482,11 & 466,21 \\
\hline PEAD+ 4\%pLTs virgem & 482,12 & 465,56 \\
\hline PEAD+ 1\% pLTs-0-2C18 esfoliada & 480,62 & 462,24 \\
\hline PEAD+ 2\% pLTs-0-2C18 esfoliada & 482,19 & 461,11 \\
\hline PEAD+ 4\% pLTs-o-2C18 esfoliada & 480,62 & 462,47 \\
\hline PEAD+ 1\%pLTs virgem+5\%PE-g-MA & 485,28 & 464,13 \\
\hline PEAD+ 2\%pLTs virgem+5\%PE-g-MA & 483,61 & 461,60 \\
\hline PEAD+ 4\%pLTs virgem+5\%PE-g-MA & 483,61 & 465,75 \\
\hline
\end{tabular}

Para ambos os parâmetros não houve uma variação significativa quando comparados com PEAD puro, demonstrando que a estabilidade térmica não foi substancialmente melhorada com a incorporação dos distintos tipos de nanocargas.

Neste trabalho também foi avaliada a estabilidade térmica em função dos parâmetros $T_{10}$ e $T_{50}$, que correspondem às temperaturas nas quais o compósito perde $10 \%$ e $50 \%$ de massa, respectivamente [56]. Estes parâmetros estão detalhados na Tabela 5.7 - para os nanocompósitos preparados com as nanofolhas virgens, nanofolhas esfoliadas e com a adição do agente de acoplamento PE-g-MA. De acordo com os resultados obtidos, observa-se que $\mathrm{T}_{10}$ 
apresentou valores mínimo e máximo de $451^{\circ} \mathrm{C}$ e $457^{\circ} \mathrm{C}$ para nanocompósito com 2\% de nanofolhas esfoliadas e 4\% nanofolhas virgens, respectivamente. Já para $\mathrm{T}_{50}$ apresentou valores de mínimo e máximo de $476^{\circ} \mathrm{C}$ e $479^{\circ} \mathrm{C}$ para nanocompósitos com 1\% de nanofolhas esfoliadas e 1\% de nanofolhas virgens com agente de acoplamento PE-g-MA, respectivamente. Contudo, os incrementos observados não foram significativos visto que para o PEAD puro $T_{10}$ e $T_{50}$ foram $454^{\circ} \mathrm{C}$ e $478^{\circ} \mathrm{C}$, respectivamente (vide Tabela 5.7).

Tabela 5.7 - Parâmetros $T_{10}$ e $T_{50}$ para o PEAD puro e os nanocompósitos fabricados.

\begin{tabular}{|c|c|c|}
\cline { 2 - 3 } \multicolumn{1}{c|}{} & $\mathbf{T}_{\mathbf{1 0}}\left[{ }^{\mathbf{0}} \mathbf{C}\right]$ & $\mathbf{T}_{\mathbf{5 0}}\left[{ }^{\mathbf{0}} \mathbf{C}\right]$ \\
\hline PEAD & 454,01 & 477,86 \\
\hline PEAD+ 1\%pLTs virgem & 456,74 & 478,26 \\
\hline PEAD+ 2\%pLTs virgem & 457,67 & 478,98 \\
\hline PEAD+ 4\%pLTs virgem & 457,83 & 478,99 \\
\hline PEAD+ 1\% pLTs-o-2C18 esfoliada & 451,86 & 476,83 \\
\hline PEAD+ 2\% pLTs-o-2C18 esfoliada & 451,50 & 476,89 \\
\hline PEAD+ 4\% pLTs-o-2C18 esfoliada & 453,96 & 477,38 \\
\hline PEAD+ 1\%pLTs virgem+5\%PE-g-MA & 456,04 & 479,49 \\
\hline PEAD+ 2\%pLTs virgem+5\%PE-g-MA & 453,76 & 478,45 \\
\hline PEAD+ 4\%pLTs virgem+5\%PE-g-MA & 454,09 & 478,81 \\
\hline
\end{tabular}

Além disso, foi estudado o efeito da incorporação de nanocargas virgens, esfoliadas e da adição do agente de acoplamento na temperatura de fusão e no grau de cristalinidade $\left(\mathrm{x}_{\mathrm{c}}\right)$ da matriz polimérica de PEAD e os resultados obtidos estão apresentados na Tabela 5.8.

Tabela 5.8 - Temperatura de fusão, entalpia de fusão e grau de cristalinidade do PEAD puro e dos nanocompósitos produzidos.

\begin{tabular}{|c|c|c|c|c|}
\cline { 2 - 5 } \multicolumn{1}{c|}{} & $\left.\mathbf{T}_{\text {fusã }}{ }^{\mathbf{0}} \mathbf{C}\right]$ & $\Delta \mathbf{H}\left[\mathbf{J . g}^{-\mathbf{1}}\right]$ & $\mathbf{X}_{\mathbf{c}}$ & $\mathbf{X c}[\mathbf{~ \% ]}$ \\
\hline PEAD & 137,15 & 125,37 & 0,46 & 0 \\
\hline PEAD+ 1\%pLTs virgem & 139,06 & 123,24 & 0,46 & 0 \\
\hline PEAD+ 2\%pLTs virgem & 140,22 & 93,35 & 0,35 & $-23,91$ \\
\hline PEAD+ 4\%pLTs virgem & 139,76 & 97,58 & 0,37 & $-19,56$ \\
\hline PEAD+ 1\%pLTs esfoliada & 137,07 & 114,82 & 0,42 & $-8,69$ \\
\hline PEAD+ 2\%pLTs esfoliada & 140,56 & 119,16 & 0,44 & $-4,35$ \\
\hline PEAD+ 4\%pLTs esfoliada & 138,89 & 112,19 & 0,43 & $-6,52$ \\
\hline PEAD+ 1\%pLTs virgem+5\%PE-g-MA & 136,07 & 103,99 & 0,38 & $-17,39$ \\
\hline PEAD+ 2\%pLTs virgem+5\%PE-g-MA & 137,78 & 120,99 & 0,45 & $-2,17$ \\
\hline PEAD+ 4\%pLTs virgem+5\%PE-g-MA & 137,92 & 89,26 & 0,34 & $-26,09$ \\
\hline
\end{tabular}


O grau de cristalinidade foi calculado para todos os nanocompósitos fabricados de acordo com a equação 5.1 [82] :

$$
x_{c}=\frac{\Delta H}{\Delta H^{*}\left(1-w_{f}\right)}
$$

Sendo:

$\Delta H^{*}=$ Entalpia de fusão do PEAD $100 \%$ cristalino

$\Delta H=$ Entalpia de fusão do PEAD

$w_{f}=$ fração em massa da nanocarga

Um decréscimo significativo (de até 23,91\%) no grau de cristalinidade foi observado para os nanocompósitos reforçados com 2 \% p de nanofolhas virgens, enquanto aqueles fabricados com 4\% p de nanofolhas pLTs-o-2C8 esfoliadas apresentaram um decréscimo de 6,52 \% no grau de cristalinidade No caso dos nanocompósitos fabricados com 4\% p de nanofolhas virgens com adição de PE-gMA o decréscimo foi de 26,09\%. O esperado para esses resultados seria um incremento do grau de cristalinidade dos nanocompósitos, pois as nanocargas geralmente agem como agente de nucleação para a cristalização da matriz polimérica [82] [83]. Porém esse efeito não foi observado, pois neste caso as nanocargas também podem servir como barreira atuando como impedimento estérico no crescimento e na ordenação das cadeias.

Finalmente é importante salientar, que durante o processo de microextrusão pode ter ocorrido uma dispersão não homogênea das nanofolhas na matriz. Isto por exemplo, pode ser observado no caso dos nanocompósitos fabricados com adição de PE-g-MA e 2 \% p de pLTs virgem e o nanocompósito reforçado com $1 \%$ p pLTs virgem, cujo grau de cristalinidade é praticamente igual ao PEAD puro. Portanto, um estudo mais aprofundado sobre técnicas de dispersão e desaglomeração das nanofolhas na matriz deveria ser contemplado para futuros trabalhos nesta área. 


\section{6 Conclusões}

Neste trabalho, foi demonstrado que as nanofolhas de ferrititanato sintetizadas via rota hidrotérmica alcalina e posteriormente submetidas a uma reação de troca-ácida, a partir de um precursor de baixo custo de areia ilmenítica, são rapidamente e totalmente esfoliadas em folhas individuais com a inserção do composto quaternário de amônio $\left(2 \mathrm{C} 18^{+}\right)$. Assim sendo, foi relatada pela primeira vez a esfoliação completa e bem-sucedida das nanofolhas protonizadas de espessura atômica utilizando o sal quaternário de amônio 2C18.

Através dos resultados obtidos pode-se concluir que os cátions de $2 \mathrm{C}^{+} 8^{+}$ interagem fortemente com as camadas das nanofolhas no material esfoliado, permintindo uma maior estabilidade térmica da amostra à temperatura de $500^{\circ} \mathrm{C}$. Desta forma, amplia-se a aplicação desse material na área de nanocompósitos, visto que pode ser utilizado como carga em matrizes com maiores temperaturas de processamento, na faixa de $190^{\circ}-430^{\circ} \mathrm{C}$, incluindo o PEAD

Nanocompósitos de matriz PEAD foram preparados utilizando nanofolhas protonizadas virgens, esfoliadas e adicionando um agente compatibilizante (PE-gMA). O máximo incremento no módulo de Young ( 12,8\%) foi observado para os nanocompósitos preparados com 4\%p de nanofolhas protonizadas virgens, enquanto o maior aumento na tensão no escoamento foi verificado para os nanocompósitos fabricados com $4 \%$ de nanofolhas esfoliadas. Diferentes tipos de interações entre as nanocargas e a matriz são responsáveis por estes comportamentos. Porém, houve um decréscimo na ductilidade para todos os nanocompósitos fabricados. O PE-g-MA na quantidade adicionada neste trabalho não promoveu uma melhora significativa na compatibilidade com a matriz polimérica, o qual foi refletido nas propriedades mecânicas.

A presença da dupla camada de $2 \mathrm{C}^{+} 8^{+}$nas nanofolhas esfoliadas melhorou a compatibilidade com o PEAD, mas teve um efeito plastificante devido a que o 2C18 representa $\sim 26 \%$ da massa das nanofolhas esfoliadas.

O coeficiente de expansão térmica somente foi reduzido no caso dos nanocompósitos reforçados com nanofolhas protonizadas virgens. A presença 
tanto do compatibilizante e do sal quaternário de amônio contribuiu ao incremento da expansão térmica da matriz

A temperatura de fusão e de degradação de todos os nanocompósitos produzidos não apresentou variações significativas quando comparadas com o PEAD puro e o grau de cristalinidade foi reduzido para todos os nanocompósitos produzidos. 


\section{7 \\ Sugestões para trabalhos futuros}

- Aprimorar o estudo da quantidade de sal incorporada durante o processo de esfoliação, pois neste trabalho foi definida uma quantidade fixa do sal durante o processo de modificação;

- Realizar análises da distribuição do tamanho de partículas das nanofolhas esfoliadas, para avaliar o estado de aglomeração das nanofolhas produzidas;

- Avaliar distintas técnicas de secagem durante as etapas de síntese das nanofolhas e esfoliação visando reduzir a formação de aglomerados;

- Otimizar o processamento de fabricação dos nanocompósitos através do estudo de outras técnicas de dispersão das nanofolhas no PEAD;

- Realizar análises de microscopia de força atômica para determinar se a rugosidade superficial teria o efeito proposto no melhoramento da interface;

- Realizar análises de microscopia eletrônica de transmissão para conferir se houve intercalação e/ou esfoliação das nanofolhas esfoliadas;

- Otimizar a quantidade do compatibilizante levando em conta às hidroxilas disponíveis na superfície das nanofolhas. 


\section{8 \\ Referências Bibliográficas}

[1] F. Hussain, M. Hojjati, M. Okamoto e R. E. Gorga, "Review article: Polymer-matrix Nanocomposites, Processing, Manufacturing, and Application: An Overview," Journal of COMPOSITE MATERIALS, vol. 40, n. 17, pp. 1511-1575, 2006.

[2] Y. Kojima, A. Usuki, M. Kawasumi, A. Okada, Y. Fukushima, T. Kurauchi e O. Kamigaito, "Mechanical properties of nylon 6-clay hybrid," J. Mater. Res., vol. 8, n. 5, pp. 1185-1189, 1993.

[3] I. F. Leite, A. P. S. Soares, O. M. L. Malta e S. M. Silva, "Influência do tipo de argila no comportamento térmico dos nanocompósitos de PET,” Revista Eletrônica de Materiais e Processos, vol. 8, n. 2, p. 80 -86, 2013.

[4] R. Scaffaro, M. C. Mistretta e F. P. La Mantia, “Compatibilized polyamide 6/polyethylene blend-clay nanocomposites:," Polymer Degradation and Stability, vol. 93, p. 1267-1274, 2008.

[5] P. M. Jardim, L. Mancic, B. A. Marinkovic, O. Milosevic e F. Rizzo, "NaxyHyTi2-xFexO4 . nH2O nanosheets with lepidocrocite-like layered structure synthesized by hydrothermal treatment of ilmenite sand," Cent. Eur. J. Chem., vol. 9, n. 3, pp. 415-421, 2011.

[6] A. M. L. M. Costa, B. A. Marinkovic, N. M. Suguihiro, D. J. Smith, M. E. Da Costa e S. Paciornik, “ Fe-doped nanostructured titanates synthesized in a single step route,” Materials Characterization, vol. 99, pp. 150-159, 2015.

[7] R. Barbosa, E. M. Araújo, A. D. de Oliveira e T. J. A. de Melo, "Efeito de sais quaternários de amônio na organofilização de uma argila bentonita nacional," Cerâmica, vol. 52, pp. 264-268, 2006.

[8] J. v. m. Silva, Síntese e caracterização de nanocompósitos polietilenoargila, Porto Alegre, 2010. 
[9] G. F. Brito, A. D. de Oliveira, E. M. Araújo e T. J. Melo, "Nanocompósitos de Polietileno/Argila bentonita nacional: Influência da argila e do agente compatibilizante PE-g-MA nas propriedades mecânicas e de inflamabilidade," Polímeros: Ciência e Tecnologia, vol. 18, n. 2, pp. 170177, 2008.

[10] M. Alexandre e P. Dubois, "Polymer-layered silicate nanocomposites: preparation, properties and uses of a new class of materials," Materials Science and Engeneering, vol. 28, pp. 1-63, 2000.

[11] L. Folgelstrom, Polymer nanocomposites in thin film applications, Madrid, 2010.

[12] P.-C. Ma, N. A. Siddiqui, G. Marom and J.-K. Kim, "Dispersion and functionalization of carbon nanotubes for polymer-based nanocomposites: A review," Composite Part A: Applied Science and Manufacturing, vol. 41, pp. 1345-1367, 2010.

[13] A. Olad, "Polymer/Clay Nanocomposites," em Advances in Diverse Industrial Applications of Nanocomposites, 2011.

[14] D.-h. Lee, H.-s. Kim, K.-b. Yoon, K. E. Min, K. H. Seo e S. K. Noh, "Polyethylene/MMT nanocomposites prepared by in situ polymerization using supported catalyst systems," Science and Technology of Advanced Materials, vol. 6, pp. 457-462, 2005.

[15] A. C. Esteves, A. Barros-Timmons e T. Trindade, "NANOCOMPÓSITOS DE MATRIZ POLIMÉRICA: ESTRATÉGIAS DE SÍNTESE DE MATERIAIS HÍBRIDOS,” Quim. Nova, vol. 27, n. 5, pp. 798-806, 2004.

[16] P. Anadão, H. Wiebeck e F. R. Valenzuela-Díaz, "Panorama da Pesquisa Acadêmica Brasileira em Nanocompósitos Polímero/Argila e Tendências para o Futuro,” Polímeros, vol. 21, pp. 443-452, 2011.

[17] P. I. BRAVO, Funcionalização de nanotubos de titanato e sua aplicação como reforço de nanocompósitos de matriz náilon-11, Rio de Janeiro: Dissertação de mestrado, 2013.

[18] J. M. Resende, Nanocompósitos com matriz de polietileno de alta densidade (PEAD) reforçados por nanofolhas de titanatos sintetizadas a partir das areias minerias ilmeníticas, dissertação de mestrado, 2014. 
[19] Xplore, "Xplore," Xplore DSM, 2012. [Online]. Available: http://www.xplore-together.com/micro-compounders.html. [Accessed 1212 2012].

[20] A. M. L. M. Costa, Síntese, controle morfológico e caracterização de titanatos nanoestruturados produzidos a partir da areia ilmenítica, Rio de Janeiro: Tese de doutorado, 2013.

[21] X. Wu, G. Steinle-Neumann, O. Narygina, I. Kantor, C. McCammon, S. Pascarelli, G. Aquilanti, V. Prakapenka e L. Dubrovinsky, "Iron oxidation state of FeTiO3 ubder high pressure,” Phys. Rev. B, vol. 79, n. 9, 2009.

[22] A. F. Reid, W. G. Mumme e A. D. Wadsley, Acta Crustallogr., p. 1228, 1968.

[23] B. A. Marinkovic, P. I. Pontón, J. M. Resende, S. Letichevsky, M. Habran, J. B. Viol, O. Pandoli e L. Mancic, "Lepidocrocite-like ferrititanate nanosheets and their full exfoliation with quaternary ammonium compounds," Materials and Design , vol. 85, pp. 197-204, 2015.

[24] T. Tao, A. M. Glushenkov, H. Liu, Z. Liu, X. J. Dai, H. Chen, S. P. Ringer e Y. Chen, "Ilmenite FeTiO3 Nanoflowers and Their Pseudocapacitance," J. PhysChem C, vol. 115, pp. 17297-17302, 2011.

[25] L. Wang e T. Sasaki, "Titannium Oxide Nanosheets: Graphene Analogues with Versatile Functionalities,” Chem Rev, vol. 114, pp. 9455-9486, 2014.

[26] Y. Ide, M. Sadakane e M. Ogawa, "Functionalization of layered titanates,” J. Nanosci Nanotechnol, vol. 14, pp. 2135-2147, 2014.

[27] R. Ma e T. Sasaki, "Two-Dimension Oxide and Hydroxide Nanosheets: Controllable High-Quality Exfoliation, Molecular Assembly, and Exploration of Functionality," Acc. Chem. Res., Vols. \%1 de \%2136-143, p. 48, 2015.

[28] L. Mancic, R. F. Osman, A. M. L. M. Costa, J. R. M. d'Almeida, B. A. Marinkovic e F. C. Rizzo, "Thermal and mechanical properties of polyamide 11 based composites reinforced with surface modified titanate nanotubes," Materials e Design, vol. 83, pp. 459-467, 2015.

[29] T. Sasaki, M. Watanabe, Y. Michiue, Y. Komatsu, F. Izumi e S. Takenouchi, Chem. Mater., vol. 7, p. 1001, 1995. 
[30] W. A. England, J. E. Birkett, J. B. Goodenough e P. J. Wiseman, “Ion exchange in the Csx[Ti2-x/2Mgx/2]O4," Journal of solid state chemistry, vol. 49, pp. 300-308, 1983.

[31] T. Gao, H. Fjellvag e P. Norby, "Raman Scattering Properties of a Protonic Titanate HxTi2-xVx/4O4 . H2O (V, vacancy; x=0.7) with LepidocrociteTyper Layered Structure,” J. Phys. Chem. B , vol. 112, pp. 9400-9405, 2008.

[32] T. Sasaki, M. Watanabe, H. Hashizume, H. Yamada e H. Nakazawa, "Macromolecule-like Aspects for a Colloidal Suspension of an Exfoliated Titanate. Pairwise Association of Nanosheets and Dynamic Reassembling Process Iniciated from It,” J. Am. Chem. Soc., vol. 118, pp. 8329-8335, 1996.

[33] H. Izawa, S. Kikkawa e M. Koizumi, "Formation and properties of nalkylammonium complexes with layered tri- and tetra-titanates," Polyhedron, vol. 2, pp. 741-744, 1983.

[34] T. Sasaki, Y. Komatsu e Y. Fujiki, "A New Layered Hydrous Titanium Dioxide HxTi2 - x/4O4.H2,” J. Chem. Soc., Chem. Commun., pp. 817-818, 1991.

[35] V. Nicolosi, M. Chhowalla, M. G. Kanatzidis, M. S. Strano e J. N. Coleman, "Liquid Exfoliation of Layered Materials," Science, vol. 340, 2013.

[36] R. Barbosa, D. D. S. Morais, E. M. Araújo e R. J. Mélo, “Caracterizações de argilas bentoníticas e síntese de argilas organofílicas para uso em nanocompósitos poliméricos - Parte II,” Cerâmica, vol. 58, pp. 495-499, 2012.

[37] M. Kozak e L. Domka, “Adsorption of the quaternary ammonium salts on montmorillonite,” Journal of Physics of solids, vol. 65, pp. 441-445, 2004.

[38] C. P. D. Coelho, Obtenção e caracterização de nanocompósitos de poliestireno e argilas esmectíticas, São Paulo: Dissertação de mestrado, 2008.

[39] J. W. Cho e D. R. Paul, "Nylon 6 nanocomposites by melt compounding," Polymer, vol. 42, pp. 1083-1094, 2001. 
[40] M. G. Neumann, F. Gessner, A. P. Cione, R. A. Sartori e C. C. Cavalheiro, "Interações entre corantes e argilas em suspensão aquosa," Química nova, vol. 23, pp. 818-824, 2000.

[41] P. C. Lebaron, Z. Wang e T. J. Pinnavaia, "Polymer-layered silicate nanocomposites:an overview," Applied Clay Science, vol. 15, pp. 11-29, 1999.

[42] M. Kozak e L. Domka, “Adsorption of the quaternary ammonium salts on montmorillonite," Journal of Physics and Chemistry of Solids, vol. 65, pp. 441-445, 2004.

[43] L. B. Paiva, A. R. Morales e F. R. V. Díaz, "Organoclays: Properties, preparation and applications,” Applied Clay Science, vol. 42, pp. 8-24, 2008.

[44] V. Mital, Advances in Polyolefin nanocomposites, Boca Raton: Taylor \& Francis Group, 2011.

[45] L. B. d. Paiva, A. R. Morales e F. R. V. Díaz, "Argilas organofílicas: características, metodologias de preparação, compostos de intercalação e técnicas de caracterização,” Cerâmica, vol. 54, pp. 213-226, 2008.

[46] T. Sasaki e M. Watanabe, "Osmotic Swelling to Exfoliation. Exceptionally High Degrees of Hydration of a Layered Titanate,” J. Am. Chem. Soc., vol. 120, pp. 4682-4689, 1998.

[47] T. Tanaka, Y. Ebina, K. Takada, K. Kurashima e T. Sasaki, "Oversized titania nanosheet crystallites derived from flux-grown layered titanate single crystals,” Chem Mater, vol. 15, pp. 3564-3568, 2003.

[48] M. L. Mignoni, Síntese, caracterização e aplicações de nanocompósitos polímero-argila, Porto Alegre, 2008.

[49] L. B. d. Paiva, A. R. Morales e T. R. Guimarães, "Propriedades mecânicas de nanocompósitos de polipropielno e montmorilonita organofílica," Polímeros: Ciência e Tecnologia, vol. 16, n. 2, pp. 136-140, 2006.

[50] M. Munaro, Desenvolvimento de blendas de polietileno com desempenho aperfeiçoado para utilização no setor elétrico, Curitiba: Tese de doutorado, 2007. 
[51] L. M. Candian, Estudo do polietileno de alta densidade reciclado para uso em elementos estruturais, São Carlos, 2007.

[52] G. A. Martins, Informações sobre o Manuseio e Estocagem de Polietilenos e Polipropilenos, Boletim Técnico no14- OPP Petroquímica S.A. , 1999.

[53] F. M. B. Coutinho, I. L. Mello e L. C. de Santa Maria, "Polietileno: Principais tipos, propriedades e aplicações,” Polímeros: Ciência e Tecnologia, vol. 13, n. 1, pp. 1-13, 2003.

[54] B. G. F. Lontra, Reciclagem mecânica de polietileno de alta densidade obtido a partir de sacolas plásticas, Rio de Janeiro, 2011.

[55] R. Guitián, “Plástico Moderno,” 1995, p. 45.

[56] A. R. Soares, Nanocompósito de matriz polimérica termoplástica de polietileno de alta densidade com adição de nanocargas com expansão térmica baixa de Al2Mo3O12, Volta Redonda: Dissertação de mestrado, 2013.

[57] A. S. Filshill, J. Di e J. M. Logsdon, “Geotechnical applications of improved nanocomposites,” PCT/US2010/021771, Janeiro 2010.

[58] R. K. Rowe e H. P. Sangam, "Durability of HDPE geomembranes," Geotextiles and Geomembranes, vol. 20, pp. 77-95, 2002.

[59] "Reservatório Geomembrana PEAD,” Engepol Geossintéticos, 2012. [Online]. Available: http://www.engepol.com/geomembrana/geomembranas.html. [Acesso em 17 Maio 2015].

[60] S. Rimal, R. K. Rowe e S. Hansen, "Durability of geomembrane exposed to jet fuel A-1," em 57TH CANADIAN GEOTECHNICAL CONFERENCE, Québec, 2004.

[61] T. J. Keener, R. K. Stuart e T. K. Brown, "Maleated coupling agents for natural fiber composites,” Composites: Part A, vol. 35, pp. 357-362, 2004.

[62] N. Sukpirom e M. M. Lerner, "Preparation of organic-inorganic nanocomposites with a Layered titanate," Chem Mater, vol. 13, pp. 21792185, 2001. 
[63] R. Hiroi, S. S. Ray, M. Okamoto e T. Shiroi, “Oragnically modified layered titanate: A new nanofiller to improve the performance of biodegradable polylactide,” Macromol. Rapid Commun., vol. 25, pp. 1359-1364, 2004.

[64] K. Asai, M. Okamoto e K. Tashiro, "Crystallization behavior of nanocomposite based on poly(vinylidene fluoride) and organocally modified layered titanate,” Polymer, vol. 49, pp. 4298-4306, 2008.

[65] L. V. Santos, H. Polivanov, R. C. J. Alamino e V. H. G. Silva, "Adsorção de Cloreto e Potássio em Solos Tropicais,” Anuário do Instituto de Geociências, vol. 29, n. 2, pp. 101-121, 2006.

[66] S. F. Castro, Incorporação de resíduos de caulim em solo-cimento para construções civis, Campina Grande: dissertação de mestrado, 2008.

[67] F. Geng, R. Ma, A. Nakamura, Y. Ebina, Y. Yamauchi, N. Miyamoto, Y. Tateyama e T. Sasaki, "Unusually Stable 100-fold Reverible and Instantaneous Swelling of Inorganic Layered Materials," Nat Commun, vol. 4, p. 1632, 2013.

[68] W. Xie, Z. Gao, W. -P. Pan, D. Hunter, A. Singh e R. Vaia, “Thermal Degradation Chemistry of Alkyl Quaternary Ammonium Montmorillonite,” Chem. Mater., vol. 13, pp. 2979-2990, 2001.

[69] Q. Li, H. Zhang, T. Zhengkai, J. Yu, C. Xiong and M. Pan, "Impregnation of amine-tailored titanate nanotubes in polymer electrolyte membranes," Journal of Membrane Science, pp. 284-292, 2012.

[70] R. A. d. Paz, A. M. Leite, E. M. Araújo, T. J. A. Melo e L. A. Pessan, “Avaliação do comportamento térmico por DSC na região da pele e do núcleo de amostras injetadas de nanocompósitos de poliamida 6/argila organofílica,” Polímeros: Ciência e Tecnologia, vol. 20, pp. 258-263, 2010.

[71] B. H. Stuart, Infrared Spectrocopy: Fundamentals and Applications, Wiley, 2004.

[72] E. J. Morgado, M. A. De Abreu, O. R. Pravia, B. A. Marinkovic, P. M. Jardim, F. C. Rizzo and A. S. Araújo, "A study on the structure and thermal stability of titanate nanotubes as a function of sodium content," Solid State Sciences, vol. 8, pp. 888-900, 2006. 
[73] Y. Andriani, K. S. Jack, E. P. Gilbert, G. A. Edwards, T. L. Schiller, E. Strounina, A. F. Osman e D. J. Martin, "Organization of mixed dimethyldioctadecylammonium and choline modifiers on the surface of synthetic hectorite," Journal of Colloid and Interface Science, vol. 409, pp. 72-79, 2013.

[74] Y. Xi, W. Martens e R. L. Frost, "Thermogravimetric Analysis of Organoclays Intercalated with the Surfactant Octadecyltrimethylammonium Bromide,” J. Therm. Anal. Cal., vol. 81, pp. 91-97, 2005.

[75] M. T. Byrne, E. J. McCarthy, M. Bent and R. Blake, "Chemical Functionalisation of titania nanotubes and their utilisation for the fabrication of reinforced polystyrene composites," Journal of Materials Chemistry, no. 17, pp. 2351-2358, 2007.

[76] A. A. P. Ferreira e H. Yamanaka, "Microscopia de força atômica aplicada em imunoensaios," Quim. Nova.

[77] T. Gao, H. Fjellvag e P. Norby, "Protonic Titanate derived from CsxTi2$\mathrm{x} / 2 \mathrm{Mgx} / 2 \mathrm{O} 4$ ( $\mathrm{x}=0.7$ ) with Lepidocrocite-type Layered Structure," J. Mater Chem , vol. 19, pp. 787-794, 2009.

[78] T. Gao, H. Fjellvag e P. Norby, "Defect Chemistry of a ZincDoped Lepidocrocite Titanate CsxTi2-x/2Znx/2O4 (x=0.7) and its Protonic Form,” Chem Mater, vol. 21, pp. 3503-3513, 2009.

[79] E. Kontou, M. Niaounakis e P. Georgiopoulos, "Comparative Study of PLA nanocomposites reinforced with clay and silica nanofillers and their mixtures,” Journal of Applied Polymer Science, vol. 122, n. 3, pp. 15191529, 2011.

[80] J. R. Potts, D. R. Dreyer, C. W. Bielawski e R. S. Ruoff, "Graphene-based polymer nanocomposites,” Polymer, vol. 52, pp. 5-25, 2011.

[81] Y. Rao e T. N. Blanton, "Polymer Nanocomposites with a Low Thermal Expansion Coefficient,” Macromolecules, vol. 41, pp. 935-941, 2008.

[82] A. R. Soares, P. I. Pontón, L. Mancic, J. R. M. D'Almeida, C. P. Romao, M. A. White e B. A. Marinkovic, "Al2Mo3O12/polyethylene composites with reduced coefficient of thermal expansion,” J. Mater. Sci., vol. 49, pp. 78707882, 2014. 
[83] M. Sabzi, S. M. Mirabedini, J. Z. -Mehr e M. Atai, "Surface modification of TiO2 nano-particles with silane coupling agent and investigation of its effect on the properties of polyurethane composite coating," Progress in Organic Coatings, vol. 65, pp. 222-228, 2000. 